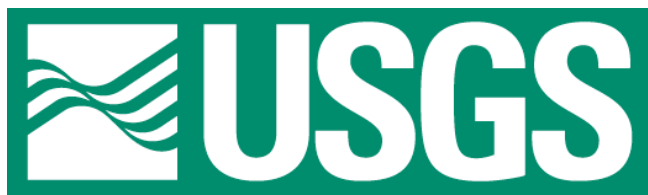

science for a changing world

The Role of Aeolian Sediment in the Preservation of Archaeological Sites in the Colorado River Corridor, Grand Canyon, Arizona: Final Report on Research Activities, 2003-2006

U.S. Department of the Interior

U.S. Geological Survey

Open-File Report 2007-1001

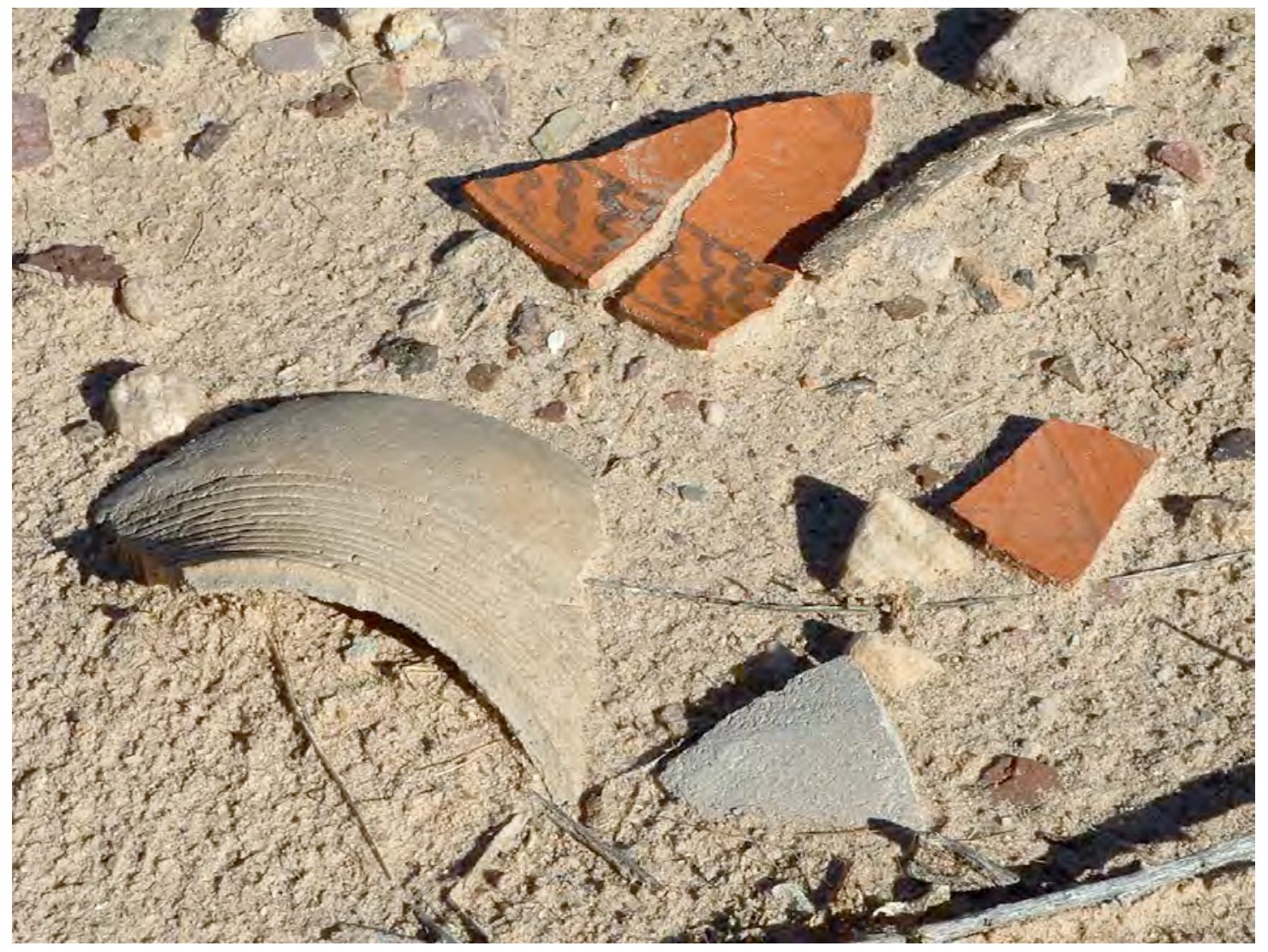




\section{The Role of Aeolian Sediment in the Preservation of Archaeological Sites in the Colorado River Corridor, Grand Canyon, Arizona: Final Report on Research Activities, 2003-2006}

Amy E. Draut and David M. Rubin

U.S. Geological Survey, Pacific Science Center, Santa Cruz, CA

U.S. GEOLOGICAL SURVEY

Open-File Report 2007-1001

Any use of trade, firm, or product names is for descriptive purposes only and does not imply endorsement by the U.S. Government. 


\section{U.S. Department of the Interior Dirk Kempthorne, Secretary}

\section{U.S. Geological Survey \\ Mark Myers, Director}

U.S. Geological Survey, Reston, Virginia 2007

Revised and reprinted: 2007

To download a copy of this report from the

World Wide Web: http://pubs.usgs.gov/of/2007/1001/

For more information on the USGS - the Federal source for science about the Earth, its natural and living resources, natural hazards, and the environment:

World Wide Web: http://www.usgs.gov

Telephone: 1-888-ASK-USGS

To contact the authors:

Amy Draut, USGS Pacific Sciences Center, Santa Cruz CA 95060

831-427-4733; adraut@usgs.gov

David Rubin, USGS Pacific Sciences Center, Santa Cruz CA 95060

831-427-4736; drubin@usgs.gov

For more information on USGS science in Grand Canyon, Arizona through the Grand Canyon Monitoring and Research Center: http://www.gcmrc.gov

Although this report is in the public domain, permission must be secured from the individual copyright owners to reproduce any copyrighted material contained within this report. 


\section{CONTENTS}

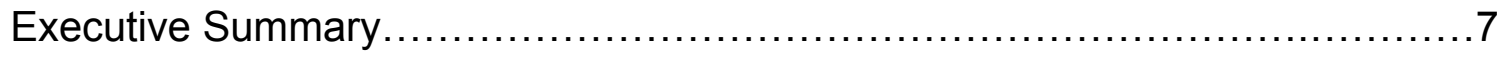

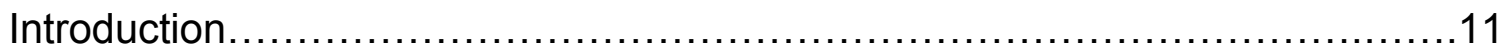

Overview of wind, precipitation, and aeolian sediment-transport monitoring ......14

Overview of sedimentary and geomorphic investigations ......................20

Identifying fluvial and aeolian deposits using sediment grain size .........28

Two types of aeolian deposits defined for the Colorado River corridor....31

Sedimentary environments_implications for restoration of archaeological sites.

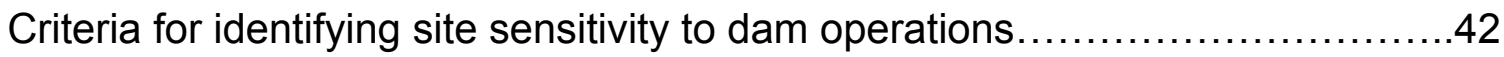

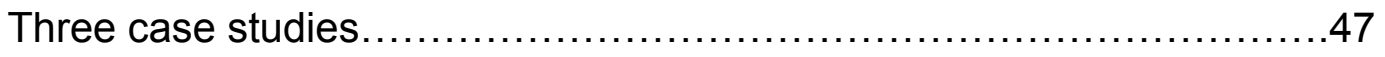

Effects of the November 2004 high-flow experiment on aeolian sediment

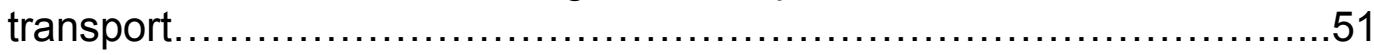

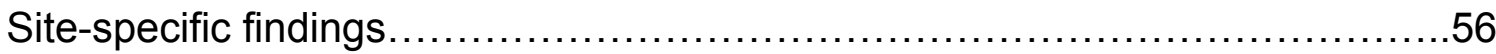

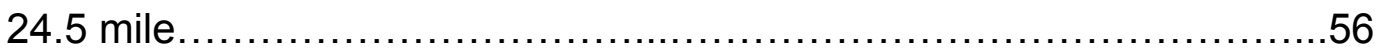

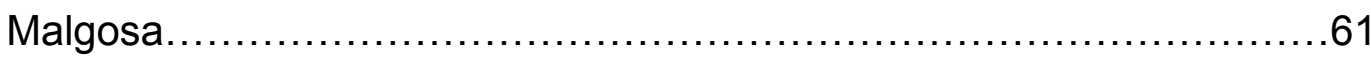

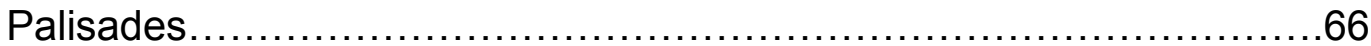

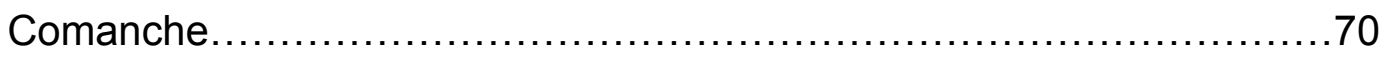

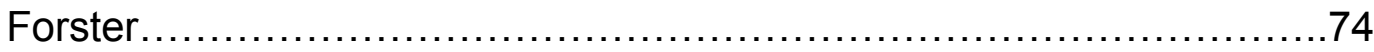

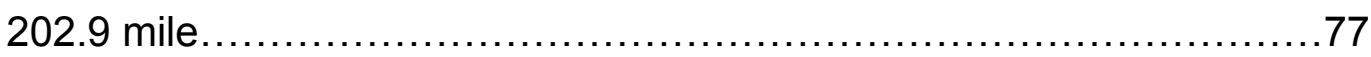

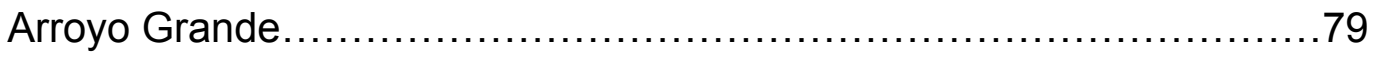

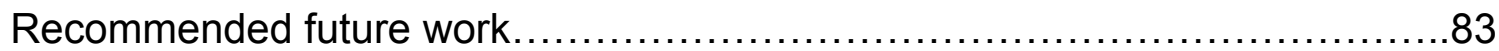

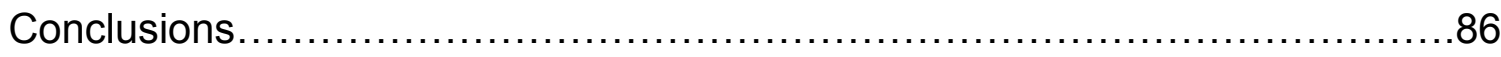

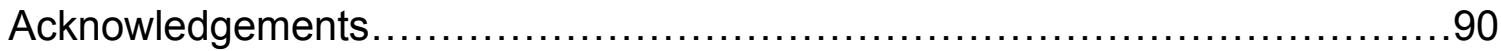


Appendix 1: Evaluation of aeolian sediment-transport models: can supply limitation be discerned?

Appendix 2: Estimation of historical changes in aeolian sand sources using a GIS database developed at Utah State University..........................115

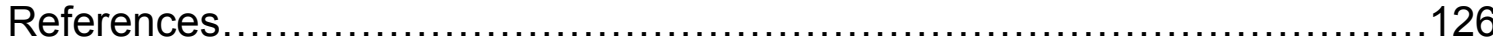

\section{LIST OF TABLES}

1. Summary of sedimentary processes affecting archaeological areas at Palisades.

2. Summary of sedimentary processes affecting archaeological areas at Lower Comanche.

3. Summary of sedimentary processes affecting archaeological areas at Arroyo Grande.

4. Aeolian sand-transport models tested using high-resolution wind data from Dumont Dunes (Death Valley, CA) and Malgosa (Grand Canyon).

5. Comparison of sand collected in sand traps during high-resolution experiments at Dumont Dunes and Malgosa.

6. Reaches of the Colorado River, and corresponding river miles, analyzed using a geomorphology GIS database developed by Utah State University.

7. Dates and river discharges of aerial photographs included in the USU GIS database, and the available mapped reaches in each.

\section{LIST OF FIGURES}

1. Location map showing the Colorado River through Grand Canyon, with study sites indicated.

2. Aerial photographs showing surficial geomorphology of the Palisades, Comanche, and Arroyo Grande areas.

3. Comparison of grain-size distributions in fluvial and aeolian deposits.

4. Photographs showing examples of two categories of aeolian deposits defined for the Colorado River corridor in Grand Canyon.

5. Strata mapped in detail at the (A) Palisades, (B) Lower Comanche, and (C) Arroyo Grande study sites.

6. Aerial photographs of 24.5 mile in 1965 and 2004.

7. Aerial photographs of 23.5 mile in 1965 and 2004.

8. Aerial photographs of Malgosa in 1965 and 2004.

9. Photographs of different zones within the Malgosa dune field.

10. Aerial photographs of the Palisades area in 1965 and 2004.

11. Aerial photographs of the Comanche area in 1965 and 2004. 
12. Aerial photographs of the area by the mouth of Forster Canyon in 1965 and 2004.

13. Aerial photographs of 202.9 mile in 1965 and 2004.

14. Aerial photographs of the Arroyo Grande area in 1965 and 2004.

15. Photograph showing the location of the experiment at Dumont Dunes.

16. Histograms of shear velocity $(u *)$ measured during high-resolution experiments at Dumont Dunes and Malgosa.

17. Sediment flux predicted for various shear velocities by eight aeolian sediment-transport models.

18. Total areas of various types of sediment deposits mapped from aerial photographs in the Glen Canyon (GL) reach.

19. Total areas of various types of sediment deposits mapped from aerial photographs in the Lees Ferry (LF) reach.

20. Total areas of various types of sediment deposits mapped from aerial photographs in the Redwall Gorge (RW) reach.

21. Total areas of various types of sediment deposits mapped from aerial photographs in the Point Hansbrough $(\mathrm{PH})$ reach.

22. Total areas of various types of sediment deposits mapped from aerial photographs in the Little Colorado River (LCR) reach.

\section{ADDITIONAL DIGITAL INFORMATION}

For an online PDF version of this report, please see:

http://pubs.usgs.gov/of/2007/1001/

Regarding additional Grand Canyon research:

Grand Canyon Monitoring and Research Center: http://www.gcmrc.gov

For more information on the U.S. Geological Survey Western Region's Coastal and Marine Geology Team, please see:

http://walrus.wr.usgs.gov/

\section{REPORT REFERENCE}

Draut, A.E., and Rubin, D.M., 2006, The Role of Aeolian Sediment in the Preservation of Archaeological Sites in the Colorado River Corridor, Grand Canyon, Arizona: Final Report on Research Activities, 2003-2006: U.S. Geological Survey Open-File Report 2007-1001, 141 p. 


\section{EXECUTIVE SUMMARY}

This report summarizes a three-year study of aeolian sedimentary processes in the Colorado River corridor, Grand Canyon, Arizona, and discusses the relevance of those processes to the preservation of archaeological sites. Findings are based upon detailed sedimentary and geomorphic investigations conducted in three areas of the river corridor, continuous measurements of wind, precipitation, and aeolian sediment transport at six locations for up to 26 months, short-term field study at 35 other sites, examination of historical aerial photographs, and review of data collected and analyzed by previous studies. Detailed results of this study, which involved collaboration with scientists at the Grand Canyon Monitoring and Research Center, National Park Service, Northern Arizona University, the Hopi Tribe, and GeoArch, Inc., have been published previously in topical USGS Open-File Reports (Draut and Rubin, 2005, 2006), a USGS Scientific Investigations Report (Draut and others, 2005), and will be discussed in two forthcoming journal articles. This report serves as an overview of the results and contains new conclusions regarding aeolian sedimentary processes in the Colorado River Ecosystem and their relevance to many archaeological sites.

At many of the locations studied, aeolian sediment serves as a substrate on which prehistoric cultural sites were formed (many sites are also formed on fluvial and slope-wash sediment) and, commonly, as a surficial deposit that helps to preserve cultural materials. Many cultural artifacts are exposed by wind deflation of the surrounding sediment, forming a lag deposit on the land surface. Cultural material is also vulnerable to erosion by gully incision. Incision of gullies and arroyos into sediment deposits during rainfall runoff is an erosive process counteracted by transport and deposition of aeolian sand, as gullies are natural traps for wind-blown sand. The ability of aeolian sand transport to inhibit gully formation and to heal small gullies ( $<1 \mathrm{~m}$ wide and deep) is a major factor controlling geomorphic evolution of Grand Canyon sediment deposits. Precipitation and aeolian sand-transport rates measured during this study 
showed that areas with heavy rainfall but abundant wind-blown sand may have no gullies (which form episodically but are quickly filled by aeolian sand) whereas areas of relatively low precipitation and little aeolian sand transport can be eroded substantially by gullies and arroyos, destabilizing archaeological sites.

Many aeolian dune fields in Grand Canyon show evidence of reduced sediment supply relative to some time in the past, with cryptogamic crust and vegetation covering relict dune forms. Soil crusts and vegetation indicate a lack of sediment deposition and decreased dune mobility compared to past times when supply and transport of aeolian sand were abundant enough to generate dune forms. Dunes with substantially reduced sediment supply (and with well developed vegetation and soil crust) have insufficient active aeolian sedimentation to counteract gully incision; large gullies and arroyos erode and degrade such dune fields and many of the archaeological sites within them.

The availability and transport of aeolian sand has important implications for management of Glen Canyon Dam operations, which regulate flow of the Colorado River through Grand Canyon. Because fluvial sandbars now provide the greatest source of aeolian sediment in the river corridor, the area of open (unvegetated) dry fluvial sandbars directly affects entrainment and transport of aeolian sand. Depending upon location and wind direction, fluvial-sandbar area therefore can also substantially affect the transport of aeolian sand to dune fields in which archaeological sites are covered by wind-blown sand. This relationship between fluvial sandbars and many of the canyon's aeolian deposits implies that the availability of aeolian sand is affected by dam operations that increase or decrease the area of open, dry fluvial sediment deposits. Dam operations can be used to increase aeolian sand transport toward specific dune fields and associated archaeological sites in locations with an appropriate dominant wind direction. This report discusses criteria for evaluating the sensitivity of archaeological sites to dam operations with regard to aeolian sedimentation.

We distinguish two types of aeolian deposits in the Grand Canyon river corridor: (1) MFS (Modern Fluvial Sourced) deposits-those that formed as the wind transported sand inland from a river-level sandbar, creating an aeolian dune 
field downwind, and (2) RFS (Relict Fluvial Sourced) deposits-those that formed as the wind eroded and redistributed sediment of extensive pre-dam flood deposits. MFS deposits tend to be smaller and to occur more commonly in Grand Canyon than RFS deposits. In RFS areas, the dominant wind direction may or may not be appropriate to carry sand from the river (non-flood-stage fluvial sandbars) toward local aeolian dune fields. Archaeological material is known to occur in aeolian deposits of both types.

Both MFS and RFS aeolian deposits are sensitive to dam operations, but for different reasons. MFS deposits, located directly downwind of fluvial sandbars, receive a quantity of wind-blown sand that is a function of wind velocity, the exposed dry fluvial sandbar area, and any barriers (such as vegetation) that exist between the fluvial deposit and its associated aeolian deposits. Fluvial sandbar area and riparian vegetation have both been shown, by numerous studies, to respond to dam operations. Therefore, changes in either fluvial sandbar area or riparian vegetation can affect the delivery of aeolian sand to dune fields downwind. RFS deposits include aeolian coppice dunes (vegetated sand mounds) that comprise the uppermost, wind-reworked part of pre-dam terraces that are largely alluvial in composition, containing sediment deposited by floods higher than any post-dam floods (up to and exceeding $5,660 \mathrm{~m}^{3} \mathrm{~s}^{-1}$ $\left.\left[200,000 \mathrm{ft}^{3} \mathrm{~s}^{-1}\right]\right)$. Because sediment-rich floods of that magnitude no longer occur in this regulated river, the fluvial deposits from which extensive RFS aeolian dune fields formed no longer constitute an active sediment source; no substantial new deposition is likely to occur on those dune fields as long as the lack of large sediment-rich floods continues. As vegetation and cryptogamic crust colonize RFS coppice-dune fields over time, active aeolian sand transport decreases within them such that these areas become increasingly unable to compensate for precipitation-induced gully erosion. Large gully and arroyo systems can develop in pre-dam terraces and associated RFS dune fields as a result.

Analysis of the effects of the November 2004 high-flow experiment on aeolian sediment transport indicate that sediment-rich controlled high flows are an effective means to restore sediment deposition in aeolian dune fields above 
the high-flow elevation. Sandbar-building flows on the order of $1,270 \mathrm{~m}^{3} \mathrm{~s}^{-1}$ $\left(45,000 \mathrm{ft}^{3} \mathrm{~s}^{-1}\right)$ have much more potential to enhance aeolian sedimentation on MFS deposits than on RFS deposits, because of the direct link between fluvial sandbars and MFS aeolian dunes downwind.

Our data suggest that restoration potential for cultural sites in aeolian deposits can be optimized by using dam operations (controlled floods and postflood flows) that maximize the open sand area on fluvial sandbars during the spring windy season (April through early June), when wind-borne sediment transport is greatest. To provide the most benefit to aeolian deposits and associated archaeological material, flows that follow sandbar-building high flows would need to be managed to retain and maximize high-elevation, open, dry sandbar area. In spring 2005, the first spring windy season that followed the November 2004 high flow, the one study site with both a clear MFS-type link between a fluvial sandbar and aeolian dunes and with substantial flood sediment remaining in spring 2005 (having not been entirely eroded by high fluctuating flows, as occurred at other study locations), wind-blown sand-transport rates were significantly higher than in the 2004 spring windy season. At the same site, gully erosion was effectively counteracted by deposition of aeolian sand derived from the 2004 high-flow deposit. There would be a greater opportunity for windblown sand to fill gullies and counteract erosion of aeolian deposits and associated archaeological sites if controlled high flows were followed by low fluctuating flows or steady low flows rather than the experimental high daily flow fluctuations that occurred in January-March 2005. Operating Glen Canyon Dam under low fluctuating flows (or steady low flow) between the end of a controlled high flow and the start of spring high winds is predicted to maintain the post-flood sandbar size better than in winter 2005 , leaving more sand available to be blown into higher-elevation dune fields during the subsequent spring windy season.

Sedimentation patterns documented during this study indicate that aeolian sediment deposits above the riparian zone can respond to dam operations, and that archaeological sites located within aeolian deposits can be affected consequently. "Sensitivity" of a MFS aeolian deposit and any associated cultural 
sites to dam operations should be considered to have both negative and positive connotations. If reduction of open, dry fluvial sandbar area causes reduced transport to and deposition on an aeolian dune field downwind, then transport to and deposition on that same dune field can be enhanced by managing river flows to enlarge the fluvial sandbar that serves as a sand source for the dune field. Increased aeolian transport in the dune field as a result of dam operations, as shown by this study, can counteract deflation and gully incision there, leading to greater preservation potential of associated cultural sites. Although preservation of artifacts in Grand Canyon on geologic time scales is unrealistic due to continual downcutting and backwasting of this bedrock canyon, cultural-site protection could likely be enhanced on decadal to century time scales by restoring fluvial and aeolian sedimentation to resemble more closely those processes that occurred before the river was regulated by upstream dams, including large, sediment-rich floods that left fluvial deposits from which sediment was remobilized by wind.

\section{INTRODUCTION}

Since the closure of Glen Canyon Dam in 1963, the natural hydrograph and sedimentary systems along the Colorado River in the reach through Grand Canyon have changed significantly (for example, Andrews, 1986; Johnson and Carothers, 1987; Webb and others, 1999a; Rubin and others, 2002; Topping and

others, 2003; Wright and others, 2005; Hazel and others, 2006a). The dam has reduced the fluvial sediment supply at the upstream boundary of Grand Canyon National Park by $\sim 95$ percent. Regulation of river discharge by dam operations has important implications for storage and redistribution of sediment in the river corridor. In the absence of floods, sediment is not deposited at elevations that received sediment regularly before dam closure. Riparian vegetation has colonized areas at lower elevation than in pre-dam time when annual floods 
removed young vegetation (Turner and Karpiscak, 1980). Together, these factors have caused a system-wide decrease in the size and number of subaerially exposed fluvial sand deposits over the past four decades, punctuated by episodic aggradation during exceptional high-flow intervals in 1983-1984, 1996, and 2004, and by sediment input from occasional tributary floods (Beus and others, 1985; Schmidt and Graf, 1987; Kearsley and others, 1994; Hazel and others, 1999; Schmidt and others, 2004; Wright and others, 2005).

When the Bureau of Reclamation sponsored the creation of the Glen Canyon Environmental Studies (GCES) research initiative in 1982, research objectives included physical and biological resources while effects on cultural resources were not addressed (Fairley and others, 1994; Fairley, 2003). At that time it was widely believed that, because few archaeological remains were preserved within the river's annual flood zone, cultural features would not be greatly affected by dam operations. However, recent studies indicate that alterations in the flow and sediment load of the Colorado River by Glen Canyon Dam may affect archaeological sites within the river corridor, even above the annual flood limit (Hereford and others, 1993, Yeatts, 1996, 1997; Thompson and Potochnik, 2000; Draut and others, 2005). (The annual flood zone is defined here by the mean annual pre-dam flood, 2,410 $\mathrm{m}^{3} \mathrm{~s}^{-1}$ [85,000 $\left.\mathrm{ft}^{3} \mathrm{~s}^{-1}\right]$; the 'pre-dam flood limit', the highest elevation at which fluvial deposits are locally present, was roughly equivalent to a rare, major event of $8,500 \mathrm{~m}^{3} \mathrm{~s}^{-1}\left[300,000 \mathrm{ft}^{3} \mathrm{~s}^{-1}\right.$; Topping and others, 2003]). Of the $\sim 500$ cultural sites documented between Glen Canyon Dam and Separation Canyon (255 river miles), more than 330 are considered to be within the Area of Potential Effect (APE) of dam operations designated by the National Park Service (NPS) to be below the $8,490 \mathrm{~m}^{3} \mathrm{~s}^{-1}\left(300,000 \mathrm{ft}^{3} \mathrm{~s}^{-1}\right)$ stage (Fairley and others, 1994; Neal and others, 2000; Fairley, 2005).

Archaeological research and monitoring in Grand Canyon National Park focus increasingly on the potential effects of Glen Canyon Dam operations on the landscape in which these cultural sites exist. Many cultural sites located in or on sediment deposits are now eroding due to aeolian deflation and incision by gullies (Leap and others, 2000; Neal and others, 2000; Fairley, 2003, 2005). 
Hereford and others (1993) first suggested that gully incision of sediment deposits, and the base level to which small drainage systems respond, were linked to dam operations; they hypothesized that pronounced arroyo incision, which occurs during rainfall runoff, was caused by lowering of the effective base level at the mouths of ephemeral drainages to meet the new, post-dam elevation of high-flow sediment deposition, $\sim 3-4 \mathrm{~m}$ below the lowest pre-dam alluvial terraces. Thompson and Potochnik (2000) modified that hypothesis to include restorative effects of fluvial deposition in the mouths of gullies and arroyos, presumed to raise effective base level at least temporarily, and new aeolian deposition on pre-dam alluvial deposits as wind reworks flood sand. Thompson and Potochnik (2000) concluded that sediment deprivation and lack of floods, caused by dam operations, reduce the potential for new deposition that could heal gullies formed by precipitation runoff. Neal and others (2000) suggested that aeolian deposition in incipient gullies is "one of the strongest restorative forces operating at archaeological sites." Repeated high-resolution mapping conducted after the 1996 controlled-flood experiment $\left(1,270 \mathrm{~m}^{3} \mathrm{~s}^{-1}\left[45,000 \mathrm{ft}^{3} \mathrm{~s}^{-1}\right]\right.$; see Webb and others, 1999b; Schmidt and others, 2001) confirmed that high flows can deposit sediment in arroyo mouths, and also suggested that those deposits can be a source for wind-blown sand that accumulates at higher elevation, causing sediment accretion above the flood-stage elevation (Yeatts, 1997; Hazel and others, 2000).

This study began in 2003 as a collaborative effort by the U.S. Geological Survey (USGS) and National Park Service (NPS), funded by the U.S. Bureau of Reclamation through the Grand Canyon Monitoring and Research Center (GCMRC), to investigate the role of aeolian sediment transport in the preservation of archaeological sites in the river corridor through Grand Canyon, and thereby to clarify the effects or potential effects of dam operations on aeolian deposits and any associated archaeological sites. Participants in this research included geologists and archaeologists from the USGS (including GCMRC), NPS, Northern Arizona University (NAU), GeoArch, Inc., the Hopi Tribe, the Hualapai Nation, and Western Area Power Administration (WAPA). 
Observations made by this research group during reconnaissance work in May 2003 formed the basis for more detailed sedimentary and geomorphic studies the following year and led to the selection of locations at which weather stations were deployed to measure wind, rainfall, and aeolian sand transport continuously between late 2003 and early 2006. This report summarizes the results of the aeolian-sediment study and provides a final analysis and conclusions drawn from the data. Detailed presentation, figures, and discussions of data are not included with this report but have been published previously in USGS Open-File Reports (Draut and Rubin, 2005, 2006), a USGS Scientific Investigations Report (Draut and others, 2005), are in press with the journal Geomorphology (Draut and others, submitted 6/05) and in review as a chapter in a volume to be published by the University of Arizona in fall 2007 (Draut and Rubin, submitted 12/05).

\section{OVERVIEW OF WIND, PRECIPITATION, AND AEOLIAN SEDIMENT-TRANSPORT MONITORING}

Wind, precipitation, and aeolian sand-transport data collected during this study at six locations constitute the only continuous weather record available from the river corridor between November 2003 and January 2006 with the exception of temperature and rainfall measurements made at Phantom Ranch (near river-mile 88) by NPS (locations in the river corridor are commonly referred to by distance in miles downstream of Lees Ferry, Arizona [Fig. 1]; this report follows that convention while using metric units for other measurements. River miles are those provided by the internet map server operated by GCMRC; http://www.gcmrc.gov/products/ims/ims.htm).

This study provided the first measurements at this temporal and spatial resolution of seasonal and regional variability in wind intensity and direction, and resultant aeolian sediment transport, as well as precipitation patterns within the interior of Grand Canyon. High-resolution records from these instrument stations 
can be used to identify rainfall events that caused gully incision and to predict aeolian sediment redistribution, thus aiding other sedimentary and geomorphic studies of sediment deposits in the river corridor. Quantifying wind magnitude and direction was essential for identifying sediment-transport pathways in the vicinity of the study locations, information used subsequently to evaluate the potential sensitivity of certain sites to dam operations. Detailed discussions of the data collected at the weather stations, as well as electronic data files, were published by Draut and Rubin $(2005,2006)$.

Nine weather stations operated in the Colorado River corridor in Grand Canyon as part of the aeolian sediment-transport investigations. Locations of instrument stations are shown in Figure 1. Three sites located in eastern Grand Canyon, at 24.5 mile, Malgosa (river-mile 57.9), and Palisades (river-mile 66.1), were equipped with two weather stations between November 2003 and January 2006. One instrument station operated at each of three additional sites: Comanche (river-mile 68.0) in eastern Grand Canyon, and Forster (river-mile 123.0), and 202.9 mile in western Grand Canyon, between April 2004 and January 2006. The weather stations were deployed in areas known to contain cultural artifacts but located such that the presence and operation of equipment would not disturb the sites. Analysis of aerial photographs indicated that all six study sites had experienced a reduction in open sand area after Glen Canyon Dam was constructed, and that all sites experienced new deposition as a result of the 1996 high-flow experiment (Webb and others, 1999b). These criteria were intended to allow monitoring of the effects of similar high-flow experiments in the event that any occurred during the two-year operation of the weather-stations; the effects of the November 2004 high-flow experiment were studied as part of this project. Digital wind and rainfall data were recorded at 4-minute intervals at all stations; aeolian sand-transport measurements were made based on collection of sand in sand traps emptied during maintenance visits every 4-8 weeks (Draut and Rubin, 2005, 2006).

At all study locations, the most common incidence of high wind velocities, and greatest potential for sediment transport (as well as actual measured sand- 


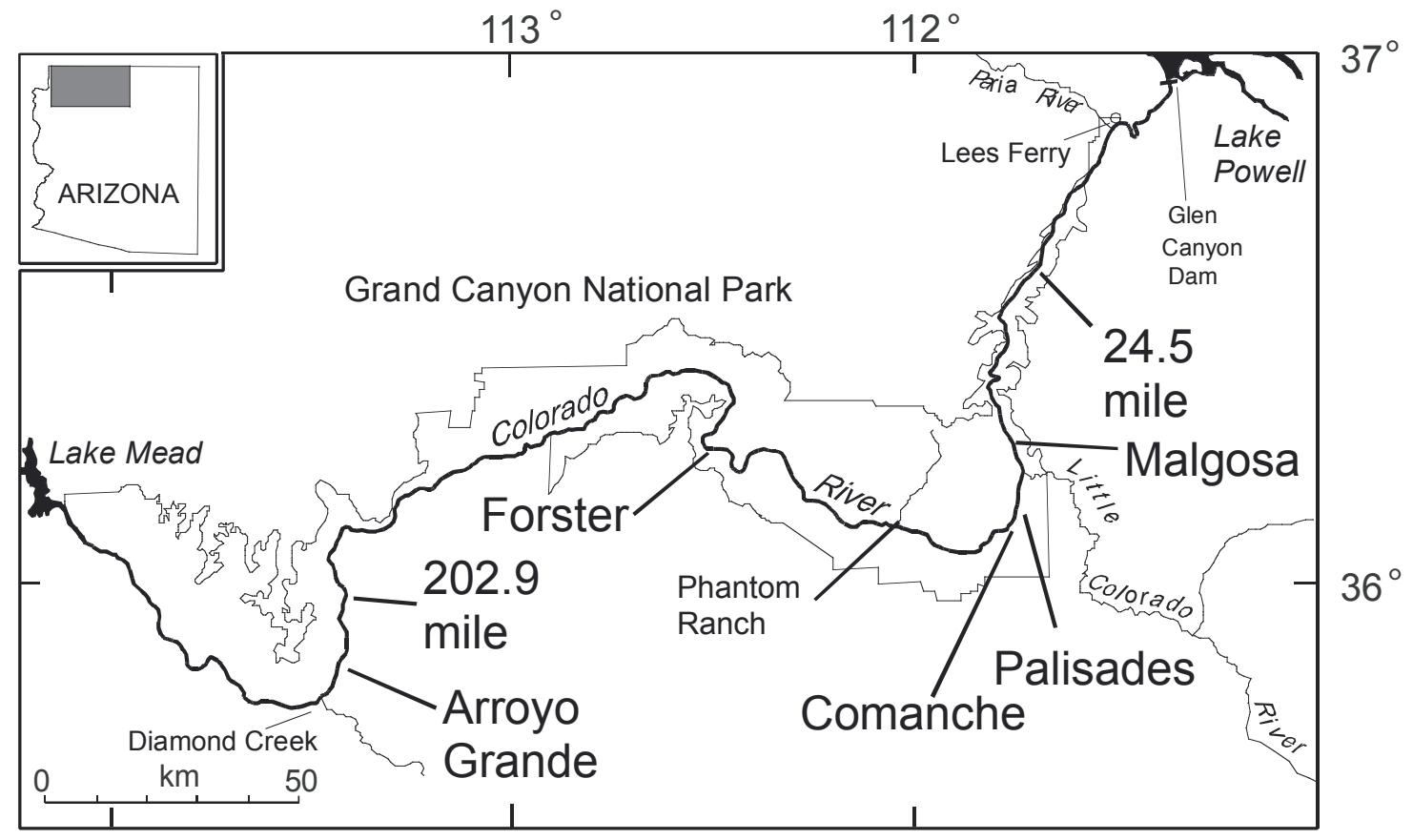

FIGURE 1. Location map showing the Colorado River through Grand Canyon, with study sites indicated. Weather stations collected data at 24.5 mile, Malgosa, Palisades, Comanche, Forster, and 202.9 mile. Sedimentary profiles were studied at Palisades, Comanche, and Arroyo Grande. Lees Ferry, Phantom Ranch, and Diamond Creek are shown for reference. The reach of the canyon between Lees Ferry and the Little Colorado River is known as Marble Canyon. 
transport rates), occurred during the spring windy season. In 2004, seasonal sediment transport peaked in April and May; the peak in 2005 was somewhat later, in May and early June. During the spring windy seasons of 2004 and 2005, maximum winds were locally as high as $\sim 25 \mathrm{~m} \mathrm{~s}^{-1}$, and sand-transport rates locally exceeded $100 \mathrm{~g} \mathrm{~cm}^{-1}$ day $^{-1}$. At all stations, rates of sand transport during the spring windy season were generally 5-15 times higher than at other times of year.

Wind direction was observed often to change radically over very short time intervals; wind velocities and dominant directions commonly varied on a diurnal cycle, with velocities typically highest in the afternoon. At 24.5 mile, Malgosa, and Palisades, where two weather stations operated at each site, wind velocities and aeolian sand-transport rates were consistently higher at the higher-elevation station than at river level. This is attributed in part to vegetation near the river, which reduces wind velocity and therefore aeolian sediment entrainment; sand transport has been shown in many cases to decrease approximately exponentially as vegetation cover increases (Olson, 1958; Bressolier and Thomas, 1977; Ash and Wasson, 1983; Wasson and Nanninga, 1986; Buckley, 1987; Bauer and others, 1996; King and others, 2005). Wind can also attain higher velocity at higher elevation given the reduced interaction of air flow with the canyon walls, although local topography can cause significant local variations in wind speed and direction.

Variations in sand-transport rates between study sites are related not only to variable wind strength but also to other local factors that affect the potential for sand entrainment. Sand transport is likely reduced near the river because moisture in the sediment that comprises fluvial sandbars limits entrainment of sediment there by wind because (sand becomes cohesive when damp; see Svasek and Terwindt, 1974; Sarre, 1988, 1989; McKenna Neuman and Nickling, 1989; Namikas and Sherman, 1995; Selah and Fryrear, 1995; Wiggs and others, 2004). In Grand Canyon, sandbars inundated by daily fluctuating flows often do not dry thoroughly before they are inundated again the following day. Although the sand traps used in this study did not allow resolution of sand transport on the 
daily scales of river flow fluctuations (no automated sand traps are available commercially that record sand transport at that resolution), this study documented a local increase in aeolian sand transport adjacent to a new dry (subaerial) sandbar deposited during the 2004 high-flow experiment (Draut and Rubin, 2006).

The highest rates of sediment transport were measured in "active" dune fields. Where active aeolian sediment transport is common, dune crests and sand shadows are well defined, while vegetation and cryptogamic (cryptobiotic) crust are rare. At active dune fields, particularly the Malgosa and Forster study sites, sand transport occurred by saltation and suspension at rates commonly on the order of $10 \mathrm{~g} \mathrm{~cm}^{-1}$ day ${ }^{-1}$ but reached $100-1000 \mathrm{~g} \mathrm{~cm}^{-1}$ day-1 during the spring windy season. In contrast, less-active aeolian dune fields (those with substantial vegetation cover and cryptogamic crust, such as Palisades and Comanche) had sediment-transport rates at least an order of magnitude lower $\left(0.1-1 \mathrm{~g} \mathrm{~cm}^{-1} \mathrm{day}^{-1}\right.$ during the non-windy season and $1-10 \mathrm{~g} \mathrm{~cm}^{-1}$ day $^{-1}$ during the windy season). Those measured differences are consistent with the findings of previous studies that have demonstrated lower transport rates on sparsely vegetated dunes and over surfaces with cryptogamic crust (Leys and Eldridge, 1998; Belnap, 2003; Goossens, 2004). The dune field at 24.5 mile, which has both active and relatively inactive areas, had transport rates more similar to those of Palisades and Comanche (order $1 \mathrm{~g} \mathrm{~cm}^{-1} \mathrm{day}^{-1}$ ) than to the very active Malgosa and Forster sites. With the lowest transport rates of any sites, the weather station near the river at Palisades (the station named Pal L; see Draut and Rubin, 2005, 2006 for locations), located on a relict fluvial cobble-boulder bar, typically recorded sediment-transport rates on the order of $0.01 \mathrm{~g} \mathrm{~cm}^{-1} \mathrm{day}^{-1}$. Such low transport rates at that location are apparently a function of a low supply of available sand, and cannot be accounted for only by lower wind speeds at Station Pal $L$ as compared to those within the Palisades dune field (Station Pal U; Draut and Rubin, 2006).

Precipitation data collected throughout the 26-month study interval showed considerable spatial and seasonal variation. Daily rainfall at the upper 
and lower rain gauges at a single location commonly differed by several tenths of millimeters, and daily rainfall totals by up to several $\mathrm{mm}$. Rain gauges recorded strong, spatially isolated storms, particularly during the summer and early fall monsoon season. Total annual rainfall varied by more than a factor of two over distances of $\sim 10 \mathrm{~km}$ in 2005 (Draut and Rubin, 2006), with Malgosa and Palisades receiving the highest and lowest precipitation measured during this study, respectively, a difference attributed to local topographic influence on the movement of weather systems. During the unusually wet winter of 2005 , western Grand Canyon received approximately twice as much rain as the average of the eastern Grand and Marble Canyon study sites. The degree of measured spatial variation in precipitation indicates that future sedimentary and geomorphic studies in the canyon would benefit substantially from continued or expanded data collection at multiple locations along the river corridor, because rainfall records collected by NPS at Phantom Ranch (near river-mile 88 ) are evidently not valid for other areas of the canyon. 


\section{OVERVIEW OF SEDIMENTARY AND GEOMORPHIC INVESTIGATIONS}

In May 2003, reconnaissance work was performed by personnel from the USGS, Hopi and Hualapai Tribes, GeoArch Inc., and the Western Area Power Administration (WAPA), led by NPS archaeologists J. R. Balsom, J. L. Dierker, and L. M. Leap. This group of scientists visited 38 archaeological sites at which aeolian sediment was believed to be important either as the material underlying the site or forming a protective cover. Depositional environments of sediment around these archaeological sites were determined where possible through identification of sedimentary textures that are characteristic of waterlain (fluvial or tributary flow) or aeolian deposition (e.g., Walker, 1963; Hunter, 1977; Rubin and Hunter, 1982, 1987; Gladfelter, 1985; Rubin, 1987; Rubin and others, 1990; Schmidt, 1990; Southard and Boguchwal, 1990). This initial 2003 survey, while noting that the selected sites were likely not typical of all sites in the river corridor, determined (through digging shallow pits into sediment to expose threedimensional sedimentary structures) that much of the sediment beneath or above these particular archaeological sites had been transported by wind from fluvial deposits at the river margins (Draut and others, 2005). Several of the sites were built on or buried by sediment deposited directly by large floods of the Colorado River. Observations made during the reconnaissance work in May 2003 formed the basis for more detailed sedimentary and geomorphic studies at a selected sub-set of the 38 sites the following year, and provided the basis for the establishment of the weather stations discussed above.

During the May 2003 field work, the research group observed that aeolian sand transport to archaeological sites is apparently limited largely by sediment supply and vegetation rather than by wind. Reduction in the open sand area on sandbars, and submergence of sandbars by daily flow fluctuations, can be expected to reduce aeolian sand transport to nearby dune fields that contain archaeological sites (cf. Ash and Wasson, 1983; Buckley, 1987; Namikas and Sherman, 1995; Wiggs and others, 2004). Reduced aeolian transport, in turn, can be expected to facilitate the growth of existing arroyos and establishment of 
new ones, as discussed by Thompson and Potochnik (2000). At many of the sites visited in May 2003, erosion of archaeological sites by arroyo incision was apparent; repeat photography at those sites by NPS over the past decade supports this observation (for example, Leap and others, 2000). Some archaeological sites are affected by small drainages that might be repaired by modest increases in aeolian sand deposition; in some locations, filling of small gullies ( $<1 \mathrm{~m}$ wide) by aeolian sand would aid preservation of archaeological features that have already been stabilized by construction of check-dams. Other sites are compromised by very large drainages that could not reasonably be expected to fill with aeolian sediment given the current local geomorphology and observable sand supply.

Sedimentary and geomorphic work conducted in May 2004 focused on the Palisades, Lower Comanche, and Arroyo Grande areas of Grand Canyon (Fig. 2). These reaches of the river corridor are characterized by alluvial terraces that represent multiple episodes of floodplain aggradation within the pool-and-drop bedrock canyon of the Colorado River. The highest alluvial terraces at each site contain deposits left by pre-dam flood events of over $5,660 \mathrm{~m}^{3} \mathrm{~s}^{-1}\left(200,000 \mathrm{ft}^{3} \mathrm{~s}^{-1}\right.$; Hereford and others, 1993; Topping and others, 2003). The terraces at all three sites contain arroyo networks (sensu Patton and Schumm, 1981; Waters and Haynes, 2001; Webb and Hereford, 2001) up to several meters deep and wide resulting from incision by local precipitation runoff. Coppice dunes partially cover the terrace surfaces at all three sites. Talus piles are commonly present at the base of bedrock walls, and debris fans occur at the mouths of side-canyon tributaries. The work conducted by this research group in 2004 complemented several previous studies, particularly at Palisades. Geomorphic mapping by Hereford $(1993,1996)$ and by Hereford and others $(1993,1996)$ at Palisades generated detailed interpretations of the surficial geology and radiocarbon dates; the same location was one area used by Hereford and others (1993) and Thompson and Potochnik (2000) to formulate the base-level hypotheses discussed above. Grams and Schmidt (1999) used historical photographs to document reduction in the extent of surficial sand deposits at Palisades since 

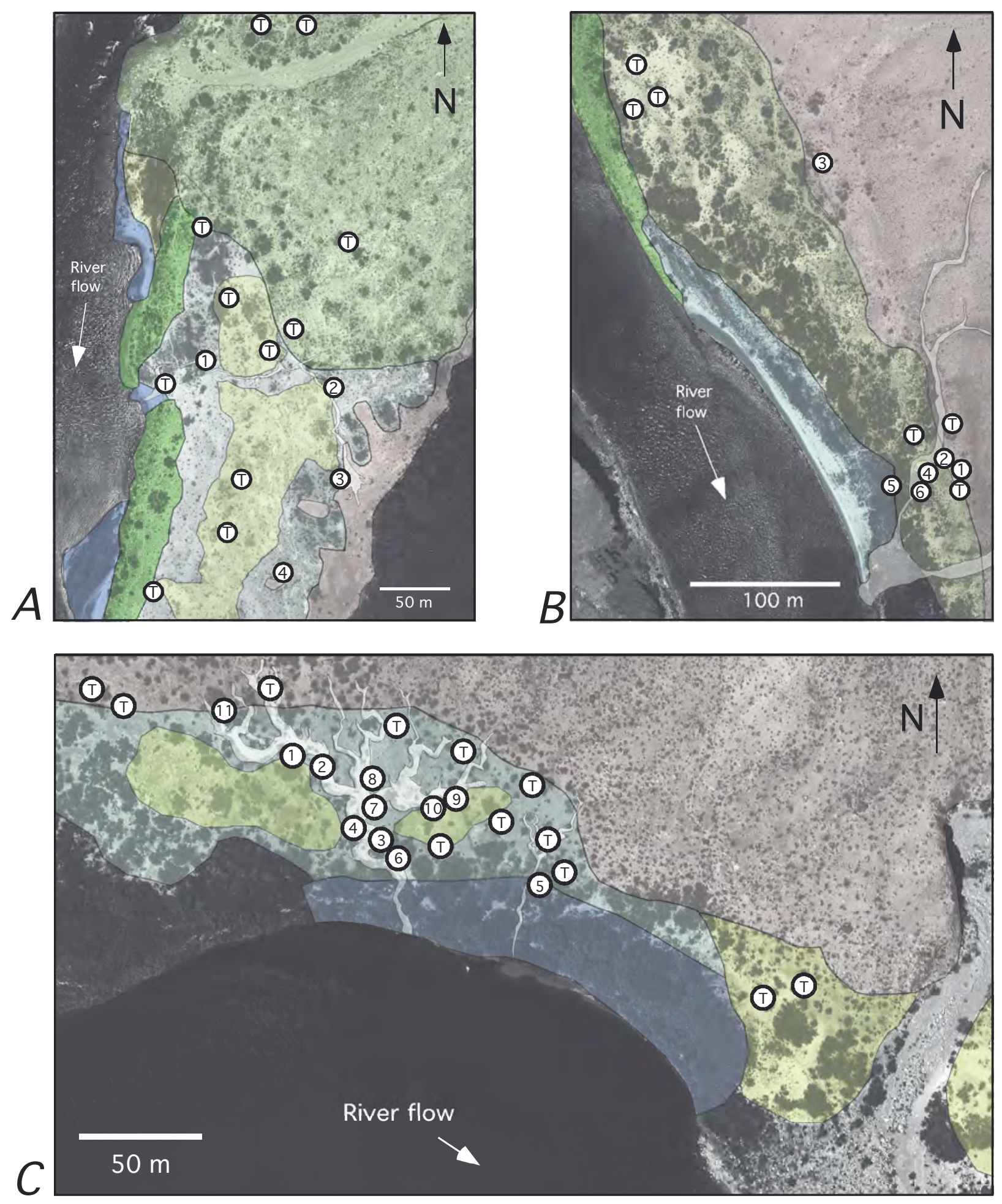
FIGURE 2. Aerial photographs showing surficial geomorphology of the Palisades, Comanche, and Arroyo Grande areas. General geomorphology is shown in colored overlays and the locations of studied sedimentary exposures are indicated with white circles. Circles with numbers are sedimentary profiles that were measured in detail and described by Draut and others (2005); circles labeled with a ' $T$ ' are test pits at which sedimentary properties were studied but in less detail and to shallower depth than at the numbered exposures. A. The Palisades area, with geomorphology based both on this study and mapping by Hereford (1993). The area outlined in pale green in the northern part of this image is a debris fan on which Hereford (1993) documented evidence of multiple debris flows. The darker green strip along the shoreline is a bar containing well rounded, well sorted boulders and cobbles that likely represents relict fluvial reworking of a debris-flow deposit. The broad area shown in light blue is a terrace surface mapped by Hereford (1993) as a relict (pre-dam) alluvial feature. The areas in darker blue are modern fluvial sandbars at an elevation within the river's usual dam-controlled fluctuations (below a discharge of $566 \mathrm{~m}^{3} \mathrm{~s}^{-1}[20,000$ $\left.\mathrm{ft}^{3} \mathrm{~s}^{-1}\right]$; in all three photographs in this figure, the flow is $226 \mathrm{~m}^{3} \mathrm{~s}^{-1}\left[8,000 \mathrm{ft}^{3} \mathrm{~s}^{-1}\right]$ ). Areas in yellow are coppice-dune fields. The area in orange is a playa-like surface where water forms small ponds after recent rain; slope-wash and colluvial sediment accumulates there. An arroyo drainage, which trends roughly perpendicular to the river, is outlined in white. B. The Lower Comanche area, with the same general color scheme as in A. The green area is a boulder bar probably reworked from a debris fan several hundred meters upstream of the area shown. The blue overlay shows the outline of fluvial deposits that form a narrow terrace, although the landward border is approximate because vegetation obscures the exposure. The large yellow area contains coppice dunes at the modern land surface. The orange area is a talus and colluvial slope drained by an ephemeral stream and arroyo network outlined in white. C. The Arroyo Grande area. Two alluvial terrace surfaces are apparent, one at higher elevation (shown in light blue) and one at lower elevation (darker blue). The boundary between these terraces is approximated here because vegetation obscures some of the exposure. Aeolian coppice dunes, shown in yellow, are present locally on the surface of the upper terrace and to its east. The area in orange is talus and colluvium with some bedrock exposed. The dendritic arroyo after which this site is named is outlined in white. 
1890. High-resolution mapping by Yeatts (1996) and Hazel and others (2000) indicated aggradation of fluvial sand deposits at Palisades as a result of the 1996 controlled flood released from Glen Canyon Dam, and inferred aeolian migration of sediment to higher elevation over the following year.

After viewing natural sediment exposures, the May 2004 research group chose to focus on those that were most complete vertically and that offered good spatial coverage throughout variable terrain. Data were obtained through detailed examination of sedimentary profiles and numerous shallow test pits in alluvial terraces, coppice-dune fields, and, at Palisades, near the distal margin of a debris fan from a tributary canyon (Fig. 2). Sediment exposures studied during this work were located in the general area of archaeological features but no cultural artifacts were exposed or collected. The presence of arroyos facilitated the exposure of vertical faces; at Palisades and Lower Comanche, three of the sections studied in detail were exposed by digging pits into areas without cultural artifacts. Thicknesses of sedimentary units were measured and sedimentary structures, clast lithology, and color of the sediment were described. At selected locations, sediment samples were collected for grain-size analysis using a Coulter laser particle-size analyzer at the GCMRC laboratory in Flagstaff, Arizona. Sedimentary structures were used to identify the number and thickness of fluvial deposits, aeolian reworking of fluvial sediment, and interaction of those processes with local runoff sedimentation. Geomorphic and sedimentary processes that affect each studied archaeological site are summarized for Palisades, Lower Comanche, and Arroyo Grande in Tables 1, 2, and 3, respectively; detailed discussions of each site have been published by Draut and others (2005). 
TABLE 1. Summary of sedimentary processes affecting archaeological areas at Palisades. Archaeological-site numbers are those assigned by the National Park Service (NPS). Detailed discussions of processes in these areas may be found in Draut and others (2005). Prehistoric sites have been dated by radiocarbon methods and artifact identification to the Pueblo I and Pueblo II (PI and PII) periods (Fairley and others, 1994; Hereford, 1996) although there is some evidence for Preformative occupation (Dierker and Downum, 2004). The historic site is associated with mining activity and was occupied from A.D. 1890-1910.

\begin{tabular}{|c|c|c|c|c|}
\hline $\begin{array}{l}\text { Site } \\
\text { Number }\end{array}$ & $\begin{array}{l}\text { Age and } \\
\text { Affiliation } \\
\text { of Site }\end{array}$ & $\begin{array}{c}\text { Sediment on which } \\
\text { site was originally } \\
\text { built }\end{array}$ & $\begin{array}{l}\text { Sediment } \\
\text { overlying } \\
\text { site }\end{array}$ & $\begin{array}{l}\text { Sedimentary and } \\
\text { geomorphic } \\
\text { characteristics }\end{array}$ \\
\hline C:13:033 & $\begin{array}{l}\text { Uncertain; } \\
\text { probable } \\
\text { Pueblo I-III }\end{array}$ & $\begin{array}{l}\text { Debris-fan cobbles, } \\
\text { gravel }\end{array}$ & $\begin{array}{l}\text { Aeolian } \\
\text { (minor) }\end{array}$ & $\begin{array}{l}\text { Dominated by debris-flow } \\
\text { deposition }\end{array}$ \\
\hline C:13:098 & Historic & $\begin{array}{l}\text { Debris-fan cobbles, } \\
\text { gravel }\end{array}$ & None & $\begin{array}{l}\text { Remains of } 19^{\text {th }} \text { century cabin } \\
\text { built on debris-fan sediment }\end{array}$ \\
\hline C:13:099 & Pueblo I-II & $\begin{array}{l}\text { Fluvial; slope-wash } \\
\text { sand and gravel }\end{array}$ & $\begin{array}{l}\text { Aeolian; distal } \\
\text { debris-flow } \\
\text { material }\end{array}$ & $\begin{array}{l}\text { Interbedding of fluvial, aeolian, } \\
\text { debris-flow and slope-wash } \\
\text { sediment }\end{array}$ \\
\hline C:13:100 & Pueblo I-II & Fluvial & Fluvial/aeolian & $\begin{array}{l}\text { Fluvial sediment modified by } \\
\text { wind }\end{array}$ \\
\hline $\mathrm{C}: 13: 101$ & Pueblo I-II & $\begin{array}{l}\text { Rounded cobbles, likely } \\
\text { fluvial }\end{array}$ & $\begin{array}{l}\text { Aeolian } \\
\text { (minor) }\end{array}$ & $\begin{array}{l}\text { Coppice dunes overlying } \\
\text { rounded cobbles }\end{array}$ \\
\hline C:13:272 & Pueblo I-II & $\begin{array}{l}\text { Debris-fan cobbles, } \\
\text { gravel }\end{array}$ & $\begin{array}{l}\text { Fluvial and } \\
\text { aeolian }\end{array}$ & $\begin{array}{l}\text { Fluvial sediment modified by } \\
\text { wind into coppice dunes; } \\
\text { bioturbated }\end{array}$ \\
\hline C:13:334 & Pueblo I-II & $\begin{array}{l}\text { Fluvial; ponded slope- } \\
\text { wash }\end{array}$ & Fluvial & $\begin{array}{l}\text { Eroding out of apparent fluvial } \\
\text { deposit }\end{array}$ \\
\hline $\mathrm{C}: 13: 336$ & Pueblo I-II & $\begin{array}{l}\text { Likely fluvial (artifacts } \\
\text { not in original position) }\end{array}$ & Fluvial/aeolian & $\begin{array}{l}\text { Fluvial sediment reworked by } \\
\text { wind into coppice dunes }\end{array}$ \\
\hline $\mathrm{C}: 13: 355$ & Pueblo II & $\begin{array}{l}\text { Fluvial; distal debris- } \\
\text { flow }\end{array}$ & $\begin{array}{l}\text { Fluvial and } \\
\text { aeolian }\end{array}$ & $\begin{array}{l}\text { Area dominated by debris fan, } \\
\text { smaller volumes of fluvial and } \\
\text { aeolian sediment }\end{array}$ \\
\hline
\end{tabular}


TABLE 2. Summary of sedimentary processes affecting archaeological areas at Lower Comanche. Site numbers have been assigned by NPS. Most cultural features in this area date to the Late PI - Early Pll Formative period (A.D. 200-1000; Fairley and others, 1994; NPS, 2004). At least one site contains artifacts related to late prehistoric and early historic use by the Hopi Tribe (Fairley and others, 1994). The Early Formative age given for Site C:13:273 is based on radiocarbon ages obtained from a hearth feature by Yeatts (1998).

\begin{tabular}{|c|l|l|l|l|}
\hline $\begin{array}{c}\text { Site } \\
\text { Number }\end{array}$ & $\begin{array}{c}\text { Age and } \\
\text { Affiliation of Site }\end{array}$ & $\begin{array}{c}\text { Sediment on } \\
\text { which site was } \\
\text { originally built }\end{array}$ & $\begin{array}{c}\text { Sediment } \\
\text { overlying } \\
\text { site }\end{array}$ & $\begin{array}{c}\text { Sedimentary and } \\
\text { geomorphic } \\
\text { characteristics }\end{array}$ \\
\hline C:13:273 & $\begin{array}{c}\text { Early Formative } \\
\text { (Basketmaker III) }\end{array}$ & $\begin{array}{l}\text { Fluvial, aeolian; } \\
\text { colluvial }\end{array}$ & $\begin{array}{l}\text { Aeolian } \\
\text { (minor) }\end{array}$ & $\begin{array}{l}\text { Fluvial and aeolian } \\
\text { deposits interbedded with } \\
\text { slope-wash colluvium }\end{array}$ \\
\hline C:13:274 & Pueblo I-II & Aeolian & None & $\begin{array}{l}\text { Aeolian substrate overlies } \\
\text { distal debris-fan sediment }\end{array}$ \\
\hline C:13:333 & Pueblo I-II & Aeolian & $\begin{array}{l}\text { Aeolian } \\
\text { (minor) }\end{array}$ & $\begin{array}{l}\text { Site destabilized by aeolian } \\
\text { deflation and dune } \\
\text { migration }\end{array}$ \\
\hline C:13:335 & Pueblo I-II & Aeolian & $\begin{array}{l}\text { Exposed by aeolian } \\
\text { deflation }\end{array}$ \\
\hline C:13:337 & Pueblo I-II & Aeolian & $\begin{array}{l}\text { Aeolian dunes; site in } \\
\text { interdune area }\end{array}$ \\
\hline C:13:373 & $\begin{array}{l}\text { Prehistoric to Early } \\
\text { Historic Hopi }\end{array}$ & Aeolian & $\begin{array}{l}\text { Seone } \\
\text { deflation and dune } \\
\text { migration }\end{array}$ \\
\hline
\end{tabular}


TABLE 3. Summary of sedimentary processes affecting archaeological areas at Arroyo Grande. Site G:03:064 includes 15 separate features. In general these are associated with the protohistoric and early historic-era Pai culture related to the Paiute and Hualapai Tribes. Many features were built on aeolian sediment directly, but this relatively thin aeolian substrate is underlain by volumetrically more substantial flood deposits.

\begin{tabular}{|c|c|c|c|c|}
\hline $\begin{array}{c}\text { Site } \\
\text { number }\end{array}$ & $\begin{array}{l}\text { Site age and } \\
\text { affiliation }\end{array}$ & $\begin{array}{l}\text { Sediment on } \\
\text { which site was } \\
\text { originally built }\end{array}$ & $\begin{array}{l}\text { Sediment } \\
\text { overlying } \\
\text { site }\end{array}$ & $\begin{array}{c}\text { Sedimentary and } \\
\text { geomorphic characteristics }\end{array}$ \\
\hline $\begin{array}{l}\text { G:03:064, } \\
\text { F1 }\end{array}$ & $\begin{array}{l}\text { Protohistoric to } \\
\text { Early Historic Pai }\end{array}$ & Aeolian & Aeolian (minor) & $\begin{array}{l}\text { Coppice dunes on upper terrace } \\
\text { surface }\end{array}$ \\
\hline $\begin{array}{l}\text { G:03:064, } \\
\text { F2 }\end{array}$ & $\begin{array}{l}\text { Protohistoric to } \\
\text { Early Historic Pai }\end{array}$ & Aeolian & Aeolian (minor) & $\begin{array}{l}\text { Coppice dunes on upper-terrace } \\
\text { surface }\end{array}$ \\
\hline $\begin{array}{l}\text { G:03:064, } \\
\text { F3 }\end{array}$ & $\begin{array}{l}\text { Protohistoric to } \\
\text { Early Historic Pai }\end{array}$ & Aeolian & Aeolian (minor) & $\begin{array}{l}\text { Coppice dunes on upper-terrace } \\
\text { surface }\end{array}$ \\
\hline $\begin{array}{c}\text { G:03:064. } \\
\text { F4 }\end{array}$ & $\begin{array}{l}\text { Protohistoric to } \\
\text { Early Historic Pai }\end{array}$ & Aeolian & Aeolian (minor) & $\begin{array}{l}\text { Interdune area in coppice-dune } \\
\text { field; arroyo incision affects } \\
\text { feature stability }\end{array}$ \\
\hline $\begin{array}{l}\mathrm{G}: 03: 064 . \\
\quad \mathrm{F} 5\end{array}$ & $\begin{array}{l}\text { Protohistoric to } \\
\text { Early Historic Pai }\end{array}$ & Aeolian & Aeolian (minor) & $\begin{array}{l}\text { Interdune area in coppice-dune } \\
\text { field; affected by aeolian } \\
\text { deflation }\end{array}$ \\
\hline $\begin{array}{c}\text { G:03:064. } \\
\text { F6 }\end{array}$ & $\begin{array}{l}\text { Protohistoric to } \\
\text { Early Historic Pai }\end{array}$ & $\begin{array}{l}\text { Terrace surface } \\
\text { (dominantly fluvial) }\end{array}$ & None & $\begin{array}{l}\text { Arroyo incision affects terrace } \\
\text { surface in the vicinity of this } \\
\text { feature. }\end{array}$ \\
\hline $\begin{array}{l}\text { G:03:064, } \\
\text { F7 }\end{array}$ & $\begin{array}{l}\text { Protohistoric to } \\
\text { Early Historic Pai }\end{array}$ & $\begin{array}{l}\text { Terrace surface } \\
\text { (dominantly fluvial) }\end{array}$ & None & Surface of upper terrace \\
\hline $\begin{array}{l}\text { G:03:064, } \\
\text { F8 }\end{array}$ & $\begin{array}{l}\text { Protohistoric to } \\
\text { Early Historic Pai }\end{array}$ & $\begin{array}{l}\text { Terrace surface } \\
\text { (dominantly fluvial) }\end{array}$ & None & Surface of upper terrace \\
\hline $\begin{array}{l}\text { G:03:064, } \\
\text { F9 }\end{array}$ & $\begin{array}{l}\text { Protohistoric to } \\
\text { Early Historic Pai }\end{array}$ & $\begin{array}{l}\text { Terrace surface } \\
\text { (dominantly fluvial) }\end{array}$ & None & Surface of upper terrace \\
\hline $\begin{array}{l}\text { G:03:064, } \\
\text { F10 }\end{array}$ & $\begin{array}{l}\text { Protohistoric to } \\
\text { Early Historic Pai }\end{array}$ & $\begin{array}{l}\text { Terrace surface } \\
\text { (dominantly fluvial) }\end{array}$ & None & Surface of upper terrace \\
\hline $\begin{array}{l}\text { G:03:064, } \\
\text { F11 }\end{array}$ & $\begin{array}{l}\text { Protohistoric to } \\
\text { Early Historic Pai }\end{array}$ & $\begin{array}{l}\text { Terrace surface } \\
\text { (dominantly fluvial) }\end{array}$ & None & Surface of upper terrace \\
\hline $\begin{array}{l}\text { G:03:064, } \\
\text { F12 }\end{array}$ & $\begin{array}{l}\text { Protohistoric to } \\
\text { Early Historic Pai }\end{array}$ & Aeolian & $\begin{array}{l}\text { Aeolian } \\
\text { (partially } \\
\text { covers feature) }\end{array}$ & $\begin{array}{l}\text { Small coppice dunes on upper- } \\
\text { terrace surface. Feature affected } \\
\text { by arroyo incision. }\end{array}$ \\
\hline $\begin{array}{l}\text { G:03:064, } \\
\text { F13 }\end{array}$ & $\begin{array}{l}\text { Protohistoric to } \\
\text { Early Historic Pai }\end{array}$ & Aeolian & None & $\begin{array}{l}\text { Small coppice dunes on upper- } \\
\text { terrace surface. Feature affected } \\
\text { by arroyo incision. }\end{array}$ \\
\hline $\begin{array}{c}\text { G:03:064, } \\
\text { F14 }\end{array}$ & $\begin{array}{l}\text { Protohistoric to } \\
\text { Early Historic Pai }\end{array}$ & $\begin{array}{l}\text { Interbedded } \\
\text { fluvial/aeolian/collu } \\
\text { vial }\end{array}$ & Aeolian & $\begin{array}{l}\text { Exposed in small drainage within } \\
\text { upper terrace }\end{array}$ \\
\hline $\begin{array}{l}\text { G:03:064, } \\
\text { F15 }\end{array}$ & $\begin{array}{l}\text { Protohistoric to } \\
\text { Early Historic Pai }\end{array}$ & Colluvium & None & $\begin{array}{l}\text { Near landward edge of upper } \\
\text { terrace, in area dominated by } \\
\text { slope-wash sedimentation }\end{array}$ \\
\hline $\begin{array}{c}\text { Not } \\
\text { assigned }\end{array}$ & Unknown & $\begin{array}{l}\text { Slope-wash } \\
\text { colluvium and } \\
\text { aeolian }\end{array}$ & $\begin{array}{l}\text { Fluvial, } \\
\text { aeolian, and } \\
\text { colluvial }\end{array}$ & $\begin{array}{l}\text { Hearth feature exposed in arroyo } \\
\text { wall within upper terrace }\end{array}$ \\
\hline
\end{tabular}




\section{Identifying Fluvial and Aeolian Deposits Using Sediment Grain Size:}

In addition to describing depositional units using sedimentary structures, we investigated the use of grain-size analysis to distinguish fluvial from aeolian material. Previous studies have shown that grain size and moment statistics are of little use for identifying fluvial and aeolian deposits when comparing samples from multiple geographic regions (Ahlbrandt, 1979; Tucker and Vacher, 1980; Gladfelter, 1985) due to variations in clast composition and weathering conditions. We analyzed particle-size distributions of 100 sediment samples from pre-dam fluvial deposits, post-dam fluvial deposits, and aeolian deposits collected only within the Colorado River corridor of Grand Canyon (Fig. 3), to assess whether enough consistency is present within this sedimentary system to use grain size to classify samples of unknown origin also collected within this same river corridor. (We refer here only to fine-grained fluvial deposits at floodstage elevation that are relevant to archaeology; deeper in the river channel, fluvial deposits include sediment up to boulder sizes to which this discussion does not apply).

Although there is a range of grain sizes within Colorado River fluvial deposits (a function of sediment availability, flow velocity, and proximity to flooding tributaries), this study found essentially no overlap between textural characteristics of pre-dam fluvial (Fig. 3a) and mature aeolian deposits (Fig. 3c) in Grand Canyon, such that the finest aeolian deposits are coarser than the coarsest pre-dam fluvial units sampled (Fig. 3e; see also Burke and others, 2003). The lack of overlap indicates that although the mature aeolian deposits are assumed to have been derived largely from pre-dam fluvial deposits, enough of the finer fluvial sediment is removed by wind that the grain-size distribution of the remaining (winnowed) sand in mature aeolian dunes is characteristically coarser than the original fluvial deposit (see also Rubin and others, 2006). Grainsize distributions of aeolian samples do overlap, however, with those from postdam high-flow deposits (Fig. 3f). The post-dam fluvial samples shown (deposited by the November 2004 high flow) are coarser, as a population, than the pre-dam 

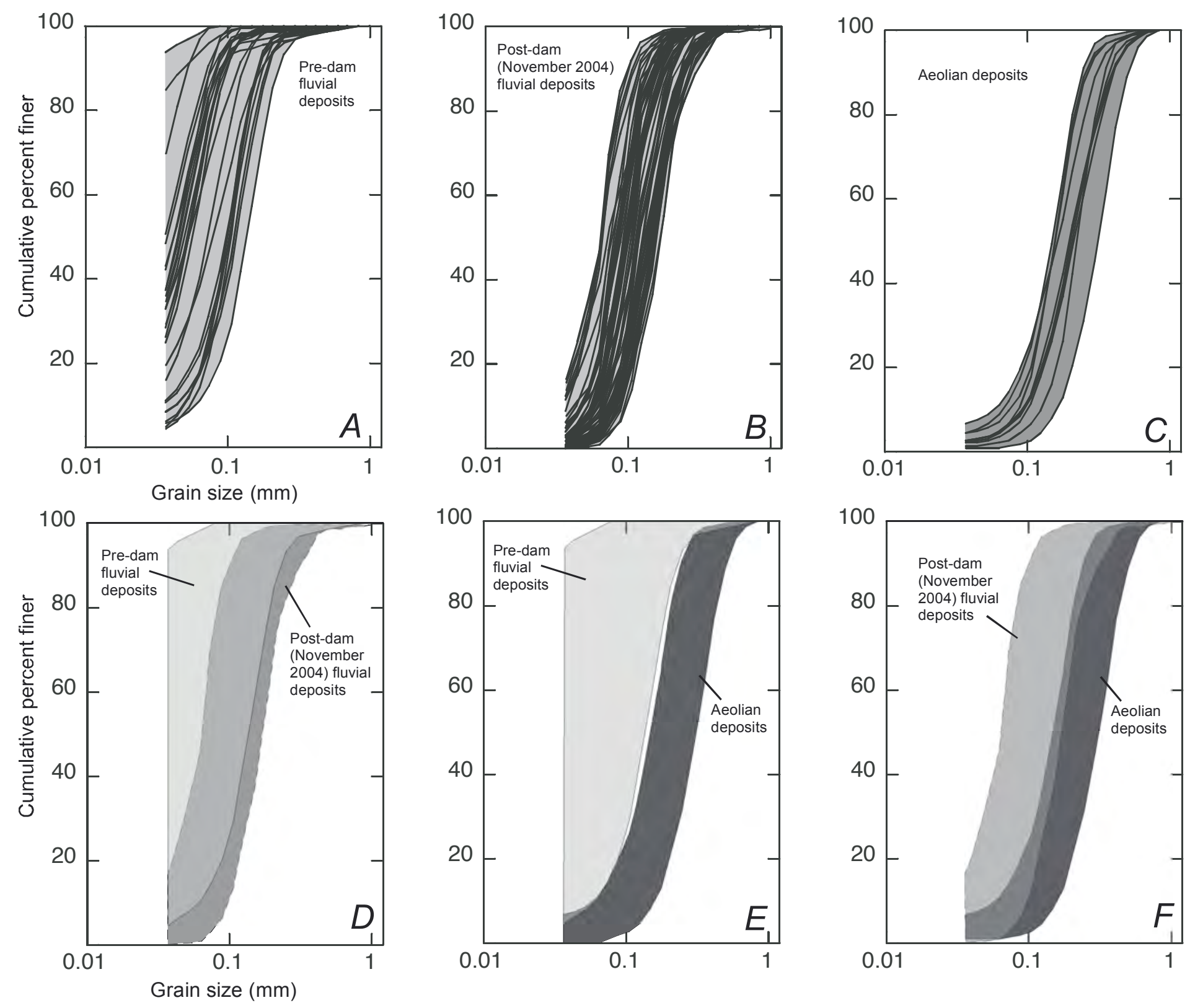
FIGURE 3. Comparison of grain-size distributions, obtained by laser particle-size analysis, in fluvial and aeolian deposits. In all plots, values on the vertical axis indicate the cumulative percent of the sediment sample that is finer than the corresponding grain diameter shown on the horizontal axis. Distributions are shown for a grain-size range of $0.037 \mathrm{~mm}$ (coarse silt) to $1.000 \mathrm{~mm}$ (the boundary between coarse sand and very coarse sand in the Wentworth classification). A. Grain-size distributions of 27 sediment samples collected from 10 different fluvial strata, all of which were deposited by Colorado River floods that pre-dated the closure of Glen Canyon Dam and associated changes in the downstream sediment load. These samples were collected in May 2004 from strata at Palisades, Lower Comanche, and Arroyo Grande identified as fluvial deposits by the presence of unequivocal sedimentary structures. Multiple samples were collected from some flood deposits because grain size commonly varies vertically within each deposit (Rubin and others, 1998). B. Grain-size distributions of 63 samples collected from 10 different deposits of the experimental flood conducted on the Colorado River through Grand Canyon in November 2004 (Topping and others, 2006). C. Grain-size distributions of samples collected at 10 aeolian deposits in Grand Canyon in 2003 and 2004. D. Comparison of the pre-dam fluvial deposits from A, shown with a light gray field outlined in a solid line, with the post-dam (November 2004) deposits of B, outlined with the darker gray field and dashed line. Deposits of the November 2004 flood are coarser, and show a tighter distribution, than the pre-dam deposits. This is consistent with previous findings (Rubin and others, 1998; Topping and others, 2000a, b) that the sediment transported and deposited by this river coarsened after closure of Glen Canyon Dam, in response to limitation of the upstream sediment supply and winnowing of the fine sediment already in the river channel. E. Comparison of the pre-dam fluvial deposits of $A$, the lightgray field, with the aeolian deposits of $C$, the dark gray field. A distinct grain-size separation is apparent, with the finest aeolian deposits being coarser than the coarsest pre-dam flood deposits. Minor overlap occurs in the two fields at the very coarsest and very finest grain sizes measured, but the fields are otherwise discrete. F. Comparison of the post-dam, November 2004 flood deposits of B, the medium-gray field with dashed border, with the aeolian deposits of $C$, the dark gray field. The November 2004 experimental-flood deposits show grain-size distributions that partially overlap with the aeolian field, the coarsest fluvial samples being coarser than the finest aeolian samples. 
flood deposits (Fig. 3d). This is consistent with previous analyses of other postdam flood deposits and reflects the fact that the sediment transported and deposited by this river coarsened after closure of Glen Canyon Dam, in response to limitation of the upstream sediment supply and winnowing of the fine sediment already in the river channel (Rubin and others, 1998; Topping and others, 2000a, b).

Grain size therefore apparently can be used to distinguish pre-dam flood deposits (which underlie and overlie archaeological sites in Grand Canyon, unlike the younger, lower-elevation post-dam deposits) from mature aeolian deposits within this river corridor if sedimentary structures are absent. Particle size as a diagnostic tool should still be used with caution even within one sedimentary system unless the range of grain sizes for known aeolian and fluvial deposits in that system is well defined. The difference in grain-size distribution between a fluvial deposit and its winnowed, aeolian counterpart depends on the initial composition of the flood sediment and on the wind conditions affecting the sediment. Colorado River fluvial sediment that has undergone some wind reworking might not yet plot within the mature aeolian field of Figure $3 \mathrm{c}$, limiting these diagnostic applications. The patterns in Figure 3 indicate that sand in the mature aeolian deposits sampled was derived almost entirely from extensive, pre-dam flood deposits with substantially less contribution from the smaller, lower-elevation deposits left by rare post-dam high flows.

\section{Two Types of Aeolian Deposits Defined for the Colorado River Corridor:}

Findings from the sedimentary and geomorphic investigations of 2004, combined with quantified seasonal wind directions and sediment-transport potential, indicate that aeolian deposits in the Grand Canyon river corridor fall into two categories referred to here as Modern Fluvial Sourced (MFS) and Relict Fluvial Sourced (RFS). The two categories are distinguished by the relative

locations and orientations of aeolian deposits, modern $\left(<1,270 \mathrm{~m}^{3} \mathrm{~s}^{-1}\left[45,000 \mathrm{ft}^{3}\right.\right.$ 
$\left.\mathrm{s}^{-1}\right]$ ) fluvial deposits, and dominant wind direction causing sediment transport in each setting.

MFS aeolian deposits are those located directly downwind from recent (post-dam) fluvial sediment deposits. These aeolian dune fields formed as the wind transported sand inland from a river-level sandbar, creating the dune field downwind. An example of a MFS aeolian deposit, at the mouth of Forster Canyon (river-mile 123.0), is shown in Figure 4a. At this location the wind direction (measured during this study) is consistently from the north-northeast, dune configuration indicates net sediment transport toward the south-southwest, and substantial wind velocities (>20 $\mathrm{m} \mathrm{s}^{-1}$ during the spring windy season) thus result in the transport of sediment away from a river-level sandbar to form a dune field downwind. Within this very active dune field, sand-transport rates on the order of $100 \mathrm{~g} \mathrm{~cm}^{-1}$ day $^{-1}$ were common in 2004 and 2005, and dune-surface elevations were observed to increase or decrease locally by tens of centimeters between equipment-maintenance visits made every six to eight weeks.

RFS aeolian deposits formed as the wind eroded and redeposited sediment that comprised extensive pre-dam flood deposits, generating aeolian dunes essentially 'in place' over parts of fluvial terraces. Whether or not RFS deposits are located downwind of modern fluvial sandbars, their most significant sediment source is not the modern, presently active sandbars (those containing fluvial sediment transported by river flows at or below $\sim 1,270 \mathrm{~m}^{3} \mathrm{~s}^{-1}\left[45,000 \mathrm{ft}^{3} \mathrm{~s}^{-}\right.$ ${ }^{1}$ ]) but larger pre-dam flood deposits. The coppice-dune field at Palisades, shown in Figure 4b, is an example of a RFS deposit. This study and Hereford and others $(1993,1996)$ showed that the Palisades area is underlain by extensive pre-dam fluvial deposits; the aeolian dune area lies atop part of the fluvial terrace. The dominant wind direction measured at Palisades over more than two years comes from the south-southeast (Draut and Rubin, 2006). If that net direction is representative of long-term local weather conditions, then it is unlikely that significant quantities of sediment are transported by wind from river-level sandbars to the aeolian dune field at Palisades. The aeolian dunes apparently formed instead from wind erosion and redeposition of sediment that comprised 

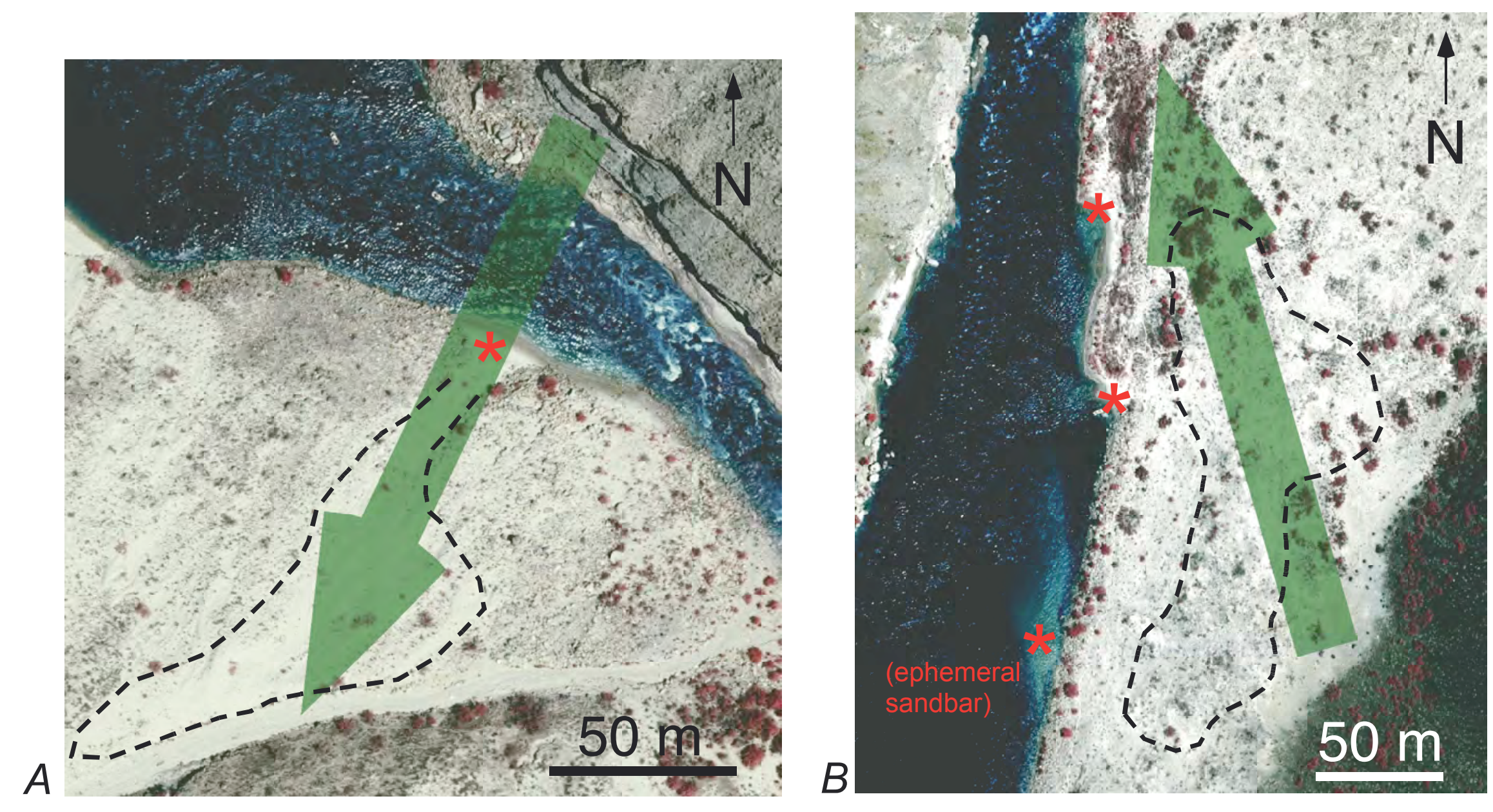

FIGURE 4. Photographs showing examples of two categories of aeolian deposits defined for the Colorado River corridor in Grand Canyon. Green arrows indicate the dominant local wind direction capable of transporting sand (obtained from vector sums of fourminute wind velocity measurements over many months; see Draut and Rubin, 2005, 2006). Aeolian dune fields are outlined with black dashed lines. Red asterisks indicate nearby fluvial sand deposits. A. Modern Fluvial Sourced (MFS) aeolian dune fields, such as this example at the mouth of Forster Canyon (river-mile 123.0) are located directly downwind from fluvial sand deposits. Here the wind direction is consistently from the north-northeast, transporting sand away from a river-level sandbar to form a dune field downwind. B. Relict Fluvial Sourced (RFS) aeolian deposits, such as this example from Palisades (river-mile 66) formed as the wind reworked sediment deposited by large pre-dam floods, generating aeolian dunes essentially 'in place' over parts of fluvial terraces. The dominant wind direction at Palisades is from the south-southeast. Modern fluvial sand deposits (shown by red asterisks) at Palisades are not directly upwind of the aeolian dune field, and so little sediment from those fluvial sandbars reaches the dunes. 
the pre-dam fluvial deposits. Some migration of aeolian dunes is apparent today in the northern part of the Palisades dune field, but in general this dune field is relatively inactive with grasses, mesquite, and cryptogamic crust well established. Although some new sediment is probably transported into the dune field on occasion from river-level sandbars (Yeatts, 1996) given appropriate short-term wind conditions, the net wind direction measured at Palisades by this study indicates that wind likely causes a net loss of sediment from this dune field toward the northwest (where it can be lost into the river) at rates on the order of $\sim 1 \mathrm{~g} \mathrm{~cm}^{-1}$ day $^{-1}$. Continued erosion of both aeolian and fluvial deposits by gullies causes substantial additional loss of sediment at Palisades. Because the mechanism of formation of this RFS aeolian deposit was linked inextricably with deposition of fluvial sediment during large, sediment-rich pre-dam floods, it is unlikely that substantial new sediment will be supplied to the Palisades dune field without similar large, sediment-rich floods in the future.

MFS aeolian deposits tend to be smaller and to occur more commonly in Grand Canyon than RFS deposits. Aeolian deposits of both types are known to contain archaeological material. Both MFS and RFS dune fields should be considered sensitive to Glen Canyon Dam operations, but for different reasons. MFS deposits, located directly downwind of fluvial sandbars, receive an amount of wind-blown sand that is a function of wind velocity, exposed dry fluvial sandbar area, and sediment-trapping vegetation that exist between the fluvial deposit and its associated aeolian deposits. Fluvial sandbar area and riparian vegetation have both been shown, by numerous studies, to respond to dam operations. Therefore, changes to either have the potential to affect the delivery of aeolian sand to MFS dune fields downwind.

The length and width of fluvial sandbars relative to the local wind direction control the supply of wind-blown sediment inland that forms MFS aeolian deposits and potentially covers local archaeological sites. For example, a narrow ( $2 \mathrm{~m}$ wide) sandbar extending $50 \mathrm{~m}$ along the river bank will be able to supply more wind-blown sand inland, and to a longer strip of shoreline, downwind than will a sandbar $10 \mathrm{~m}$ wide and $10 \mathrm{~m}$ long assuming equilibrium sand transport is 
attained during wind events for each. Sensitivity of MFS aeolian deposits to dam operations is therefore a function not only of post-dam changes in the area of open, dry sand on fluvial sandbars but also of the dimensions of the remaining open, dry sandbar and its location relative to aeolian deposits (and any archaeological sites) away from the river's edge.

RFS deposits include aeolian coppice dunes that comprise the uppermost, wind-reworked part of pre-dam terraces that are largely alluvial in composition, containing sediment deposited by floods higher than any post-dam floods have been (up to and exceeding $5,660 \mathrm{~m}^{3} \mathrm{~s}^{-1}\left[200,000 \mathrm{ft}^{3} \mathrm{~s}^{-1}\right]$ ). Sediment-rich floods of that magnitude no longer occur in this regulated river and the relict fluvial deposits no longer constitute an active sediment source. Therefore, no substantial new deposition is likely to occur on RFS dune fields as long as the lack of large sediment-rich floods continues. As vegetation and cryptogamic crust grow on RFS coppice-dune fields over time, active aeolian sand transport decreases within them such that these areas become increasingly unable to compensate for precipitation-induced gully erosion. Large gully and arroyo systems can develop in pre-dam terraces and associated RFS dune fields as a result (Figs. 2a, 2c).

\section{Sedimentary Environments-Implications for Restoration of Archaeological Sites:}

Fluvial deposits are the most common substrate underlying archaeological sites at Palisades and Arroyo Grande. Fluvial deposition was found generally to decrease with increased elevation and distance from the river as locally derived slope-wash and colluvial sediment became more prominent (Fig. 5). The proportion of fluvial sediment does not decrease regularly away from the river, however, in part because aeolian modification can occur across much of an alluvial terrace almost irrespective of distance from the river (although wind velocities are lowest at the river margin, especially in the post-dam era, where vegetation is commonly thick). In the Colorado River corridor through Grand 


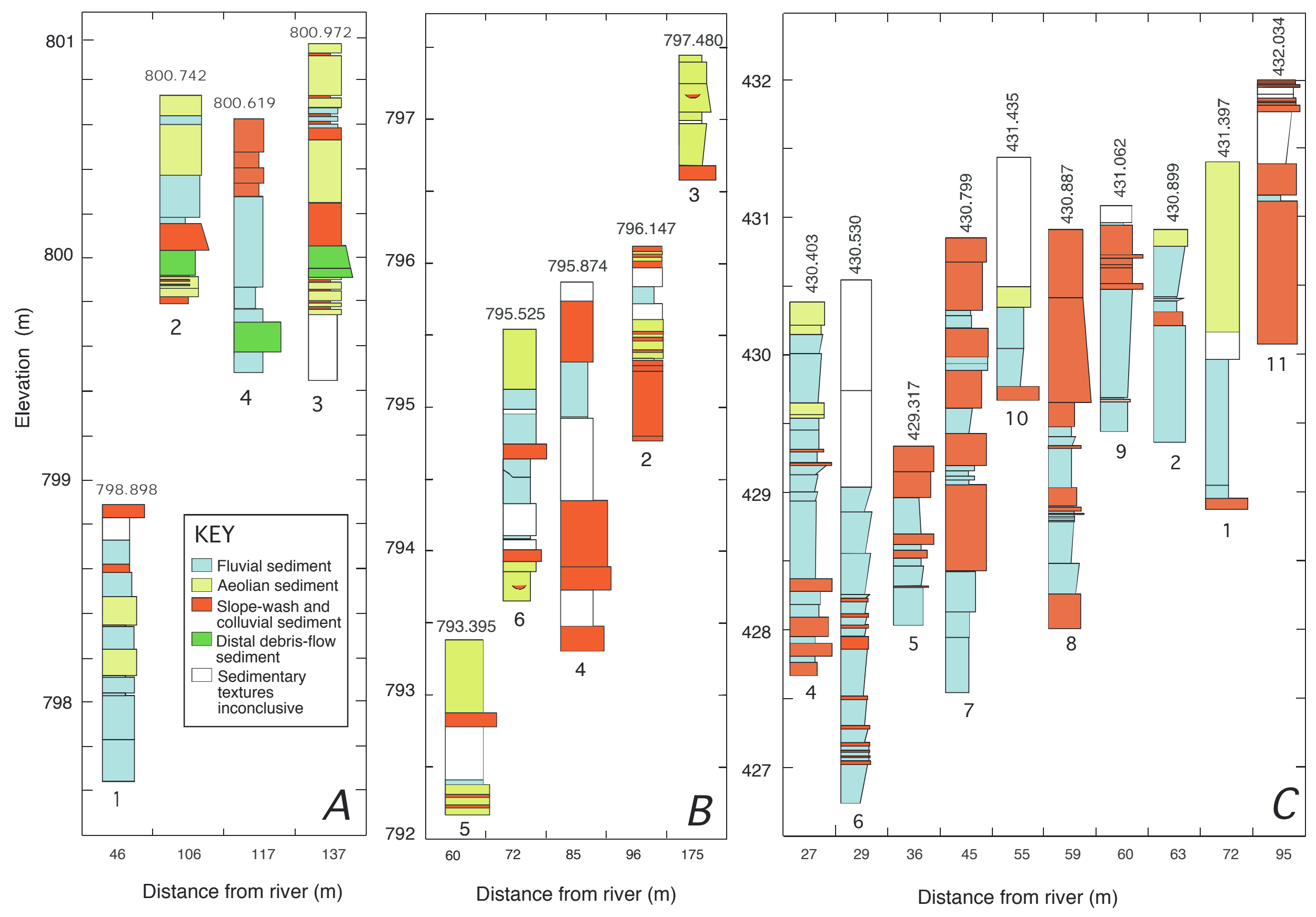


FIGURE 5. Strata mapped in detail at the (A) Palisades, (B) Lower Comanche, and (C) Arroyo Grande study sites. Horizontal axes indicate cross-shore distance from the river. The vertical axes indicate elevation $(m)$ referenced to the NAD83(1999) datum for the profiles; numbers above each profile are the elevation of the land surface, in meters. The 1,270 $\mathrm{m}^{3} \mathrm{~s}^{-1}\left(45,000 \mathrm{ft}^{3} \mathrm{~s}^{-1}\right)$ stage is equivalent to an elevation of $\sim 796 \mathrm{~m}$ at Palisades, $\sim 789 \mathrm{~m}$ at Comanche, and $\sim 425 \mathrm{~m}$ at Arroyo Grande (stage-discharge relationships for Palisades and Comanche are given in Draut and others [2005] and Hazel and others [2006b]; values for Arroyo Grande are an estimate only). Numbers beneath each profile are the stratigraphic section numbers by which these profiles are identified in a detailed unit-by-unit discussion in Draut and others (2005). Individual sedimentary units within each measured profile are shown; colors of strata correspond to inferred depositional environment (assigned on the basis of sedimentary structures, clast composition, and, in the case of approximately 10 individual strata, grain-size distribution). The color key shown in A applies to parts $A, B$, and $C$ : blue units are fluvial deposits, yellow are aeolian, orange are slope-wash and colluvial sediments derived from local bedrock and talus, green are distal debris-flow deposits, and blank (white) units are those for which a depositional setting was not assigned, either because sedimentary textures were inconclusive or because those parts of the sedimentary profiles were not accessible. Width of each sedimentary unit shown in the figure is a schematic representation of its grain size (the wider the unit, the coarser the sediment); some units coarsen upward or fine upward. Grain-size properties were determined primarily by visual inspection and use of grain-size-comparator charts. Selected strata were also sub-sampled for laser particle-size analysis, accounting for around $10 \%$ of the total number of strata described. In general, at the three study sites, the proportion of fluvial sediment decreases with distance from the river, as aeolian sediment and material derived from slope-wash and colluvial processes become more volumetrically significant away from the river and with increasing elevation. This trend is to be expected because areas farther from the river and at higher elevation would be inundated by only the largest floods, and to a shallower depth than low-elevation sites near the main channel. The decrease in recognizable fluvial deposits away from the river is not a uniform progression, however, because local topography affects all relevant depositional processes to some extent and because aeolian reworking of subaerially exposed flood sand can occur at virtually any elevation or distance from the river. Modification of fluvial deposits into aeolian deposits thus gradually reduces the proportion of recognizable "fluvial" sediment after a flood recedes. 
Canyon, wind speed (and aeolian modification of fluvial sediment) is typically greatest during the spring windy season, as discussed above. Although aeolian dunes are present on terrace surfaces at Palisades and Arroyo Grande, aeolian sediment was found to be more important as a protective cover of sites at these locations than as the substrate on which cultural features were formed. At Lower Comanche, in contrast, five of the six archaeological sites were formed on and are partially buried by aeolian sediment; however, the largest and most extensive site at Lower Comanche is not in the aeolian dune field but is on a lowerelevation terrace constructed of fluvial, aeolian, and slope-wash deposits. In all three study areas, geomorphic processes that affect the condition of cultural sites today include arroyo incision, wind action, and episodic local deposition of slopewash and debris-flow sediment. Arroyo incision and aeolian deflation contribute to exposure and erosion of artifacts in all three areas. Aeolian deflation exposes artifacts that may then be washed away by rainfall runoff, and dune migration (particularly at Lower Comanche) causes down-slope movement of artifacts as the sand surface shifts under them. Episodic deposition of flood sediment at Palisades and Arroyo Grande no longer occurs at elevations high enough to affect archaeological sites under the current dam-controlled flow regime of the Colorado River.

Many archaeological sites, including most of those at Palisades, Lower Comanche, and Arroyo Grande, were formed on terraces that consist largely of Colorado River alluvium. Many of those sites are preserved today by having been buried by flood deposits and aeolian dunes. From prehistoric times until the closure of Glen Canyon Dam in 1963, the greatest fluvial deposition in this river occurred during spring snowmelt floods that regularly exceeded even the highest post-dam discharge; the highest post-dam flow of 2,750 $\mathrm{m}^{3} \mathrm{~s}^{-1}\left(97,000 \mathrm{ft}^{3} \mathrm{~s}^{-1}\right)$ occurred in 1983, while the pre-dam eight-year flood level was $3,540 \mathrm{~m}^{3} \mathrm{~s}^{-1}$ $\left(125,000 \mathrm{ft}^{3} \mathrm{~s}^{-1}\right.$; Topping and others, 2003). Annual sediment-rich floods occurred concurrently with or receded during the spring windy season, when wind would have remobilized sand from recent flood deposits to form aeolian dune fields. The modern absence of sediment-rich floods eliminates the mechanism for 
depositing sediment at the elevations of prehistoric alluvium and also eliminates the source of new sediment to aeolian deposits. Dam operations have thus substantially altered both the fluvial and aeolian processes that acted on the prehistoric, inhabited landscape. This alteration potentially hinders the preservation of tens to hundreds of cultural sites, including most of those in this study, by limiting the fluvial and aeolian sediment available to bury and cover those sites (NPS lists several hundred sites as potentially affected by dam operations but we refer here only to those that were studied at this level of sedimentary detail for this project). Enhanced site protection could likely be achieved, therefore, by restoring fluvial and aeolian deposition processes to resemble more closely those that occurred before the river was dammed: large, sediment-rich floods that left fluvial sand deposits from which sand was remobilized by wind.

Fluvial deposits form the most extensive base on which archaeological sites at Palisades and Arroyo Grande are located, spanning hundreds of square meters in area (see also Hereford and others, 1996). Moderate-scale $\left(\sim 1,270 \mathrm{~m}^{3}\right.$ $\mathrm{s}^{-1} ; 45,000 \mathrm{ft}^{3} \mathrm{~s}^{-1}$ ) controlled Colorado River high flows, as were conducted in 1996 and 2004, can build sandbars that supply sand to aeolian deposits covering archaeological sites at higher elevation. However, to effect large-scale restoration of the fluvial terraces in these and other areas, a flow of $>4,810 \mathrm{~m}^{3} \mathrm{~s}^{-1}$ $\left(170,000 \mathrm{ft}^{3} \mathrm{~s}^{-1}\right)$ would likely be needed, based on stage-discharge relationships developed for Palisades from historical flood debris (Draut and others, 2005; Hazel and others, 2006b; we recognize that stage-discharge curves are somewhat variable due to episodic constriction of the river channel by debris flows). In order to cause deposition instead of erosion, flood waters would also require very high suspended-sediment concentrations (Hazel and others, 2006a; Topping and others, 2006). Suspended-sediment concentrations measured for pre-dam flows $>1,000 \mathrm{~m}^{3} \mathrm{~s}^{-1}\left(35,000 \mathrm{ft}^{3} \mathrm{~s}^{-1}\right)$ were within an order of magnitude of $0.1 \mathrm{~g} \mathrm{l}^{-1}$ (Topping and others, 2000a); although it is not known what the sediment concentration would be in a post-dam flood of $4,810 \mathrm{~m}^{3} \mathrm{~s}^{-1}\left(170,000 \mathrm{ft}^{3} \mathrm{~s}^{-1}\right)$. In general, the annual average post-dam sediment load is around five percent of 
average pre-dam values. An experimental flow of the magnitude needed to inundate pre-dam fluvial terraces at Palisades, $\sim 4,810 \mathrm{~m}^{3} \mathrm{~s}^{-1}\left(170,000 \mathrm{ft}^{3} \mathrm{~s}^{-1}\right)$, would be nearly four times greater than the highest experimental flows currently under consideration by the Glen Canyon Dam Adaptive Management Program. It is likely, also, that sediment concentrations would be too low in such a high flow to have a substantial restorative effect unless the flood were to follow an exceptionally large input of tributary sediment or unless sediment is added artificially downstream of Glen Canyon Dam. Were a sediment-rich, highdischarge dam release to occur, a large volume of new high-elevation fluvial deposits could then act as a source for aeolian sediment, which could be transported to Modern Fluvial Sourced (MFS) dune fields and reworked to form or replenish Relict Fluvial Sourced (RFS) dune fields. Increased transport of aeolian sand to dune fields is expected to inhibit erosion both by filling small gullies, which act as natural traps for wind-blown sand (documented in filled paleo-gullies by Thompson and Potochnik [2000] and observed during this study in several paleo-gully exposures and in modern dune fields; Draut and Rubin [2006]), and by providing additional protective cover to archaeological sites.

Generating a major new fluvial deposit as a source for aeolian sand is anticipated to produce a much greater benefit to aeolian deposits than creating smaller sources of aeolian sand by simpler, local methods (such as removing vegetation from selected channel-margin sand bars). Controlled dam releases of $\sim 1,270 \mathrm{~m}^{3} \mathrm{~s}^{-1}\left(45,000 \mathrm{ft}^{3} \mathrm{~s}^{-1}\right)$ in 1996 and 2004 deposited sand in arroyo mouths at Palisades and elsewhere (Yeatts, 1996; Hazel and others, unpublished data, 2004; Topping and others, 2006), which may have increased the preservation potential of some sites by temporarily raising the effective base level to which arroyos incise (Hereford and others, 1993). This effect is likely short-lived, however, as runoff from local rainstorms can quickly remove the new deposits in arroyo mouths and lower the effective base level once again. Relatively little data is available concerning the effects of sediment deposition during controlled floods, and its ability to control arroyo base level on various time scales, that would definitively support or refute the still-debated hypotheses of Hereford and 
others (1993) and Thompson and Potochnik (2000). Local climate, drainage area, substrate composition, and river-related sediment and base-level effects all contribute to arroyo incision and healing (Waters and Haynes, 2001; Webb and Hereford, 2001), although arroyo incision remains incompletely understood. Arroyo-incision processes in the Colorado River ecosystem could be clarified by repeated high-resolution mapping of gullies and affected archaeological sites to quantify local erosion and deposition rates, and by quantifying precipitation and other climate parameters that vary widely within the complex canyon topography. It is noteworthy that Palisades and Lower Comanche, where large arroyos erode multiple archaeological sites, were the two regions with the least rainfall out of the six monitored during this 26-month study (Draut and Rubin, 2006). If our data are representative of longer-term regional precipitation variability, then enhanced local precipitation might be eliminated as a possible cause of recent preferential arroyo development at those sites.

In general, deposition of slope-wash and debris-flow sediment has less potential to be affected by dam operations than are fluvial and aeolian deposits. However, deposits resulting from local runoff will vary in their extent and location from the pre-dam condition if the base level onto which local sediment is delivered is lowered. For example, if the configuration of aeolian dunes changes, or if a new gully breaches the dune field (as at Palisades), slope-wash events may cause additional gully incision that drains to the river instead of allowing slope-wash and colluvial sediment to accumulate in ponded areas. Loss of slopewash sediment would have the greatest effect farthest from the river, where the proportion of such sediment is highest. At our study sites, slope-wash and colluvial sediment was volumetrically less significant in site preservation than the protective cover provided by thicker fluvial and aeolian deposits. However, multiple exposures that we observed in other areas of the river corridor include interbedded aeolian and local sediment; a thin stratum of poorly sorted debrisflow sediment can form a resistant cap that protects the more erodible aeolian sediment beneath. Therefore, reduced accumulation of the cap-forming slope- 
wash sediment (caused by reconfiguration of local slope-wash drainage) could lead to increased erosion of aeolian sediment.

\section{CRITERIA FOR IDENTIFYING SITE SENSITIVITY TO DAM OPERATIONS}

This study combined analysis of prehistoric sedimentary and geomorphic environments with that of modern aeolian processes to assess the sensitivity of specific cultural sites to dam operations. Site-specific evaluation of cultural sites is very important because the relative importance of fluvial, aeolian, and other sedimentation processes, as well as local wind and precipitation patterns, differs widely among sites in the same region of the river corridor. We proposed a series of steps to determine the role of aeolian sediment in preserving any given archaeological site, and then to assess the effect of dam operations on aeolian sedimentation at that site (Draut and others, 2005); three case studies using those criteria were presented by Draut and Rubin (University of Arizona Press, in review). Here we summarize those site-evaluation criteria and case studies briefly. These guidelines were formulated specifically to apply to aeolian sedimentation, though our approach could be modified to address a wider range of processes and their interaction with archaeological features. We reiterate that, although the guidelines below refer only to aeolian sedimentation and specifically to MFS aeolian deposits, pre-dam fluvial terraces and associated cultural sites (as well as all RFS aeolian deposits, for reasons outlined above) should be considered sensitive to dam operations because the lack of sediment-rich floods on the order of $2,830 \mathrm{~m}^{3} \mathrm{~s}^{-1}\left(100,000 \mathrm{ft}^{3} \mathrm{~s}^{-1}\right)$ eliminates the mechanism by which those deposits formed and received significant quantities of new sediment.

An essential first step in evaluating factors that contribute to cultural-site preservation is to determine the depositional context of sediment on which the site was built and that which has buried (protected) the site. Depositional settings can be inferred by examining geomorphic features, sedimentary structures on the land surface, and sedimentary structures in the subsurface viewed in vertical 
section. Field investigations can be supplemented by laboratory analysis of sediment particle-size distribution, as discussed above, and by radiocarbon dating of materials that contain organic matter or charcoal (whether cultural or non-cultural). Radiocarbon dating not only provides information on the age of cultural occupation but can also be used to quantify recurrence intervals of floods and debris flows in the study area, events that may have affected occupation by prehistoric cultures (for example, Hereford and others, 1996, 2000).

If it has been determined, through field study of surface geomorphology and sedimentary horizons, that aeolian deposition has buried and thus protected a given cultural site, it is then necessary to establish whether aeolian sediment that previously covered the site has been lost. Recognizing whether aeolian-sand cover has been lost, by wind deflation or gully incision, is a step in assessing the risk of impending cultural-site degradation or the degree to which degradation has already occurred. If no loss of aeolian sediment is suspected at a particular site, that site may not be at immediate risk of artifact loss. Loss of aeolian sediment at a site could be documented most accurately using repeated highresolution mapping to quantify changes in the elevation of a deflating land surface or the depth and width of growing gullies. If quantitative survey methods are not available, loss of sediment can be qualitatively identified using repeated ground-based photography and geomorphic evidence of deflation. Evidence for deflation includes pedestal development (although erosion by rainfall may also leave small-scale pedestal features), winnowed lag deposits on the land surface, and exhumation of plant roots.

Deflation of aeolian deposits represents a net loss of sediment from an area that had formerly experienced net deposition. Such a situation would arise from a change in the balance between the sediment supply and the sedimenttransport capacity of local winds. If local wind conditions are assumed not to have changed significantly and a decrease in sediment supply is likely, the next step in this evaluation is to identify the source of aeolian sediment that buried the archaeological site. Source areas for aeolian sand are most readily identified by quantifying local wind conditions. The longer the time interval over which winds 
are measured, the more accurate the resulting sediment-transport predictions will be. In Grand Canyon, the most prominent sources of new sediment from which the wind can mobilize sand are fluvial sandbars. Records of wind speed and direction, such as those obtained during this study, can be used to generate vector sums that demonstrate the potential for aeolian transport of sediment over time (Draut and Rubin, 2005, 2006). If long-term weather monitoring is not feasible, recent local wind conditions can be inferred in the field from the orientation of ripple structures, sand shadows (which form in the lee of obstacles), and dune morphology (slip faces).

The presence of cryptogamic soil crusts also indicates that aeolian deposits now receive little or no active sand deposition. Cryptogamic crusts, dark-colored microbiotic soils that comprise up to 70 percent of desert soils in the southwestern United States, are dominated by cyanobacteria that live symbiotically with mosses and lichens. The crusts begin to establish in 6-24 months and require five or more years without disturbance to form a fully developed community. Although cryptogamic crust may survive after being subjected to very shallow burial, as the biota extend sheaths to the land surface to resume photosynthesis, deeper burial (> $0.5 \mathrm{~cm}$ in quartz sands) will kill the crust (Belnap and Eldridge, 2003; J. Belnap, written comm., 2006). Therefore, if an area with aeolian dune-forms on the land surface also contains well developed cryptogamic crust, this implies that although sediment accumulated there in the past (forming the dunes) it has been years since any substantial quantity of wind-blown sand was last deposited on that surface. Similarly, abundant vegetation on the surfaces of aeolian dunes implies that the dune forms are now relatively immobile and not undergoing rapid deposition or dune migration. Note that vegetation and cryptogamic crust on dunes are not themselves direct indicators of deflation (loss of aeolian sediment), only of an absence or near absence of deposition in an area that had formerly experienced it. In an aeolian dune field where sediment supply becomes limited, the land surface can first deflate (as wind transports more sand out of the dune field than into it), then after several years of limited sediment input and deposition, 
cryptogamic crust and grasses will colonize the deflated land surface and act to reduce additional deflation by armoring the relict dune forms (Leys, 1990; Leys and Eldridge, 1998; Belnap, 2003).

In such a dune field where dunes become less mobile over time (and where vegetation and cryptogamic crust have grown), dune "stability" should not be confused with "stability" of archaeological sites. An archaeological site located in a deflated, vegetated dune field is at risk of erosion via gully incision, as is commonly observed in Grand Canyon dune fields (such as those at Palisades, Comanche, Tanner/Cardenas [RM 70], Arroyo Grande, 202.9 mile), and in such dune fields where dunes are relatively immobile and not migrating, gully incision proceeds with little or no counteraction by aeolian sediment deposition, thereby ultimately destabilizing dunes and associated cultural sites.

After local wind conditions have been used to identify a sand source, it must be asked whether, and to what degree, the area of that sand source has decreased. Aerial photography and repeated high-resolution mapping can and have been used to document historical changes in sandbar area and structure throughout the Colorado River corridor in Grand Canyon (for example, Schmidt and others, 2004). Oblique, ground-based photography can effectively document other changes in source-area characteristics that might affect the ability of that sandbar to serve as a source for aeolian sediment. Important changes in sediment-source quality might include a decrease in area caused by sandbar erosion, growth of vegetation, increased moisture content of the exposed sand area (more frequent inundation by flow fluctuations than in the past), greater surface exposure of rocks, driftwood, or other obstacles that inhibit wind, or the development of cryptogamic soil crust on the land surface.

If the aeolian supply of sediment to a particular site in a MFS dune field appears to have declined, it is necessary to judge whether renewed deposition of aeolian sand could be expected to have a substantial restorative effect on protection of the archaeological site in question. Sites at which increased aeolian deposition would substantially aid the preservation of cultural features are those at which the greatest degradation occurs via deflation of sediment cover by wind, 
or from incision by gullies small enough to be healed by wind-blown sand $(<1 \mathrm{~m}$ wide and deep, judging by occasional exposures of filled gullies observed during this study and by Thompson and Potochnik, 2000). Aeolian sedimentation is unlikely to prevent the loss of archaeological features that are threatened more immediately by incision of a major arroyo or side-canyon channel than by deflation.

These steps thus provide a method for evaluating the sensitivity of a particular MFS aeolian deposit (and any associated archaeological sites) to dam operations by assessing how closely the condition of the aeolian deposit is linked to the condition of nearby fluvial sandbars, which in turn are greatly affected by the dam-controlled flow and sediment content of the river (for example, Wiele and others, 1996; Webb and others, 1999a; Schmidt and others, 2004; Topping and others, 2006). In the case of cultural sites that could be better preserved with the increased cover and gully-filling ability of additional aeolian sand, there are several ways to accomplish this. At some sites, erosion control by checkdams can keep gullies small enough to be partially or fully healed by windblown sand. Localized mitigation efforts by NPS and the tribes with whom NPS collaborates may substantially restore site conditions in such cases (Leap and Coder, 1995; Balsom and others, 2005). In many areas, however, and especially if a largerscale solution is desired, restoration of cultural sites that rely on aeolian sediment cover can be achieved only by restoration of the source areas from which the aeolian sediment is derived. Because Colorado River sand deposits constitute the largest source of new sediment mobilized by wind, increasing open, dry sandbar area is the most effective way to enhance the potential for transport to and deposition on MFS aeolian dune fields and associated archaeological sites. Sandbar restoration using controlled high flows under sediment-enriched conditions therefore holds the most promise as a means to restore aeolian deposits and cultural sites above the high-flow stage (Yeatts, 1997; Fairley, 2005; Draut and Rubin, 2006). 


\section{Three Case Studies:}

This study identified archaeological sites at which erosion is apparently linked to dam operations, sites at which erosion can be shown not to be linked to dam operations, and some sites where the connection between dam operations and site degradation remains unclear. Case studies of each situation are presented in this section. Locations of the sensitive archaeological sites cannot be disclosed, for obvious reasons; they are referred to here as Sites 1-3.

Site 1 constitutes an example of an archaeological site that displays considerable sensitivity to dam operations. Based on geomorphic observations and a shallow test pit dug into sediment near this site in May 2003, it was determined that aeolian sediment forms both the substrate on which the site was built and the cover that has kept the roasting feature and artifact scatter intact. This site, located near the landward, upper-elevation end of an aeolian dune field, has experienced loss of aeolian sediment manifested by downslope movement of artifacts as the land surface has deflated (based on years of monitoring by NPS). Although the dune field shows evidence of active sand transport in the vicinity of Site 1 , a large area of the dune field $\sim 10 \mathrm{~m}$ away has undergone pronounced deflation and cryptogamic-crust growth, indicating little or no active sand deposition at the present time. The source of the aeolian sediment that partially covers Site 1 is a fluvial sandbar $\sim 80 \mathrm{~m}$ directly upwind of the site. This source was identified based on wind conditions measured at an instrument station that operated nearby for more than a year. Comparison of oblique historical photographs demonstrates a major decrease in the area and volume of that same river-level sandbar from pre-dam (1920s) to post-dam (1970s) time (Turner and Karpiscak, 1980), a trend confirmed by comparison of aerial photographs of this location taken in the 1960s and 1990s. This suggests that the loss of the fluvial sandbar since dam closure is very probably related to the deflation and limited sand transport in the dune field $\sim 80 \mathrm{~m}$ downwind (identified therefore as a MFS dune field). Site 1 is presently intact enough that it could be better preserved given additional aeolian sediment cover-the site and 
its surroundings are not affected by gully incision, visitor trails, or any other processes of degradation.

The apparent sensitivity of Site 1 to dam operations implies that restoration of the fluvial sandbar by a sediment-rich controlled high flow could enhance wind-blown sediment delivery to the dune field, helping to cover artifacts. This sandbar received substantial new sediment during the 1996 flood experiment (based on pre- and post-flood aerial photographs) and again during the November 2004 high-flow experiment (based on pre- and post-flood site visits). Aeolian sand-transport rates measured in this area before and after the 2004 flood showed greater sand flux during the spring 2005 windy season compared to those of the previous spring. This provides an example, therefore, of dam operations rebuilding a sandbar from which sand transport to an archaeologically significant aeolian deposit was then enhanced.

Site 2 shares many characteristics with Site 1 in that it contains cultural features built on and buried by aeolian sediment. A natural cross-section exposure reveals debris-flow sediment underlying the aeolian dune field in the area of Site 2. Advanced deflation and well developed cryptogamic crust are apparent throughout the upper dune field. Although no quantitative measurements of wind conditions are available from this immediate area, orientation of dunes and sand shadows in the lower, more active part of the dune field, which was photographed during four visits over multiple seasons, indicate that the source of the aeolian sediment is a fluvial sandbar situated $\sim 70 \mathrm{~m}$ upwind of Site 2. Aerial photographs show a pronounced decrease in the open sand area of that sandbar between the 1960s and 1990s, and increased vegetation cover on the aeolian dune field. Thus far, evidence suggests that deflation and reduced sand mobility on the dune field are linked to post-dam shrinkage of the river-level sandbar that serves as the sediment source for that MFS dune field. However, although it is likely that the general condition of the dune field responds to dam operations, the rapid degradation of archaeological features in Site 2 cannot be linked to Glen Canyon Dam because other factors unrelated to wind-blown sand affect the site on shorter time scales. A large 
tributary channel known to have experienced major floods and debris flows in historic time has incised into aeolian sediment at the edge of the dune field. Cultural features of Site 2 erode more substantially from episodic tributary activity than from processes that could be reduced or reversed with more wind-blown sand (aeolian deflation or formation of small gullies).

In contrast to Sites 1 and 2, where cultural-site sensitivity to dam operations can be either confirmed or refuted, respectively, Site 3 presents a situation in which the effect of dam operations remains unclear even after detailed study. Similar to the first two examples, Site 3 was built on and buried by aeolian sediment; this site is located in a large, sparsely vegetated dune field. Individual features show evidence for some loss of aeolian sediment that previously covered them, including deflation, slumping, and down-slope movement of artifacts associated with dune migration. Minor cryptogamic crust is present in some areas, but most of the dune field appears to undergo active sediment transport. The dominant local wind direction, measured near Site 3 for more than a year, indicates that the most likely source of sediment for this dune field is a large, pre-dam fluvial terrace upwind. The modern morphology of that terrace suggests substantial loss of sediment from this source area: the terrace is incised by an arroyo network meters deep and meters wide, and its surface has been colonized by abundant vegetation and cryptogamic crust. These observations are consistent with the fact that no post-dam floods have deposited sediment on or near this terrace.

Although conditions in the aeolian dunes may be related to the post-dam reduction of sediment from the fluvial terrace upwind, it is not clear whether Site 3 would be better preserved if deposition from a very large, sediment-rich flood were to enhance sand transport from the terrace to the dune field. Aeolian processes are responsible for the disturbance of artifacts at Site 3, but the dune migration that affects them is a natural process endemic to active dune fields. In a natural system, continued dune migration would be expected eventually to cover Site 3. Over time scales of years to decades, migrating dunes in a natural, unaltered system would expose and cover any given part of the dune field 
repeatedly, and down-slope movement of artifacts would be expected as the sand shifts under them. Dunes near this site would need to be surveyed repeatedly over decades to determine whether dune migration will continue as it would in a natural system with plentiful sediment, or whether the dune field will show signs of exacerbated sediment-supply limitation in the future (increase in vegetation, cryptogamic crust, or winnowed lag deposits; decreased mobility of dune forms). The latter situation might indicate that deprivation of sediment caused by dam operations had prolonged the exposure of these artifacts, thereby increasing the risk of their exposure, damage, and loss.

In the manner outlined above, it can be determined through careful, sitespecific field study whether and to what degree any given location is sensitive to the effects of Glen Canyon Dam operations. Although preservation of cultural artifacts in situ on geologic time scales is unrealistic due to continual downcutting and backwasting of this bedrock canyon, cultural-site protection could likely be enhanced on decadal to century time scales by restoring fluvial and aeolian sedimentation to resemble more closely those processes that occurred before the river was regulated by upstream dams, including large, sediment-rich floods that left fluvial deposits from which sediment was remobilized by wind. 


\section{EFFECTS OF THE NOVEMBER 2004 HIGH-FLOW EXPERIMENT ON AEOLIAN SEDIMENT TRANSPORT}

Archaeological sites that depend on a supply of wind-blown sediment from fluvial sandbars for their continued preservation could benefit from restoration of sandbars by high-flow releases from Glen Canyon Dam. Sandbar restoration was the primary goal of the high-flow experiment conducted on the Colorado River in November 2004, the second experiment of its kind. To ensure a greater supply of sand in the upstream reach than was available in the first flood experiment (in March 1996; Webb and others, 1999b; Patten and others, 2001; Schmidt and others, 2001), the 2004 controlled high flow took place after substantial quantities of sand had recently been supplied to upper Marble Canyon by the Paria River and other tributaries, and after an interval of lower dam releases designed to minimize sediment export. Conditions during the 2004 high flow therefore represented sediment enrichment in the river channel relative to conditions during the 1996 flood (Topping and others, 2006).

The design of the 2004 high-flow experiment included a 60 -hour steady flow of $1,160 \mathrm{~m}^{3} \mathrm{~s}^{-1}\left(41,000 \mathrm{ft}^{3} \mathrm{~s}^{-1}\right)$ released from Glen Canyon Dam on November 22 and 23. Post-flood surveys indicated that the area and volume of sandbars in Marble Canyon above river-mile $\sim 40$ were significantly greater than before this high flow, and that approximately half of the surveyed sand deposits were much larger than they had been immediately after the 1996 controlled flood (Hazel and others, 2005; Topping and others, 2006). Below river-mile $\sim 40$, localized deposition and erosion were documented and a consistent pattern of sandbar aggradation could not be demonstrated, implying that in future high-flow experiments more sand must be present in the river channel to achieve deposition on sandbars throughout the canyon (Topping and others, 2006).

In addition to the sandbar surveys that followed the 2004 high-flow experiment (Hazel and others, 2005), fluvial sand deposits at sites associated with this study were photographed immediately before and immediately after the high flow (November and December 2004, respectively), and again multiple 
times during 2005; pre- and post-flood photographs have been published previously by Draut and Rubin $(2005,2006)$. The duration of this study included one year of pre-flood data spanning each season, and slightly more than one year of post-flood data. The sites in this study were chosen in part because they had experienced new fluvial sand deposition during the 1996 high-flow experiment. Therefore, it was predicted that similar deposition would occur at these locations during the November 2004 high flow. Based on wind conditions measured in the year before the high-flow experiment (Draut and Rubin, 2005) the greatest potential for redistribution of new, flood-deposited sediment was predicted to occur during the spring windy season of 2005.

At all six weather-station sites (Fig. 1), major deposition of new fluvial sand occurred as a result of the November 2004 controlled flood (Draut and Rubin, 2005, 2006). The substantial deposition in those areas during a sedimentrich Colorado River high flow implies that such flows have excellent potential as a management tool for restoring the sandbars that comprise the source areas of sediment for MFS aeolian deposits. In addition to depositing a substantial quantity of new sand on many sandbars, the November 2004 high flow also facilitated aeolian sand entrainment because the new sediment covered vegetation, rocks, and driftwood, decreasing the roughness of the land surface and thereby inhibiting entrainment of sediment by wind (Lettau, 1969; Marshall, 1971; Raupach and others, 1993; Gillies and others, 2000; King and others, 2005).

However, if maximizing aeolian redistribution of sediment is one of the management goals of a controlled high flow, river flows that occur between the time of the high flow and the next windy season must be managed to maximize open, dry sandbar area during that windy season (April through early June). Much of the 2004 flood sand was removed by high daily flow fluctuations that ranged from 142 to $566 \mathrm{~m}^{3} \mathrm{~s}^{-1}$ (5,000 to $\left.20,000 \mathrm{ft}^{3} \mathrm{~s}^{-1}\right)$ from January to March 2005 , before the spring windy season began (Draut and Rubin, 2006). The most dramatic changes were observed at the Malgosa study site (river-mile 57.9), where a new sand deposit $1.5 \mathrm{~m}$ thick and more than $10 \mathrm{~m}$ wide formed during 
the high flow but was eroded almost entirely over the following four months. Sites a short distance downstream of the Little Colorado River (LCR), such as Palisades and Comanche, 7.4 and $10.4 \mathrm{~km}$ below the LCR confluence, respectively, showed less-pronounced loss of sand during the January-March 2005 flow fluctuations than that observed in Marble Canyon, presumably because flooding of the LCR in February $2005\left(\sim 70 \mathrm{~m}^{3} \mathrm{~s}^{-1}\left[2,500 \mathrm{ft}^{3} \mathrm{~s}^{-1}\right]\right)$ provided additional sand to these areas.

At sites where the high-flow deposits were entirely removed before the 2005 windy season began, windy-season aeolian sand-transport rates in 2005 were comparable to or lower than those in the 2004 windy season, given similar wind conditions. However, at $\mathbf{2 4 . 5}$ mile, where approximately half of the flooddeposited sand remained at the start of the windy season in spring 2005, sandtransport rates measured near the river during the spring 2005 windy season were approximately double those in spring 2004 (Draut and Rubin, 2006). This is interpreted as a result of the increased area of available sand upwind and decreased roughness of the land surface where the 2004 flood sediment was still present. No similar increase in sand flux relative to the previous year was measured at the upper-elevation station in the same dune field.

The dominant wind direction at 24.5 mile transports sand from westsouthwest toward east-northeast (from river level toward the upper dune field; Draut and Rubin, 2006). Sand-transport measurements there suggested that, although the influence of the new flood sediment was felt near river level (at the lower of the two weather stations) in spring 2005, its effects had not yet propagated to the upper part of the dune field. In many areas of the river corridor, new sand would need to reach the highest parts of aeolian dune fields in order to benefit archaeologically significant locations. Because the sand flux measured at our upper weather station at 24.5 mile exceeded that measured at the lower station even with the new flood sand present (Draut and Rubin, 2006), the net flux of sand into this dune field was still negative even after the high-flow experiment. It is possible that, had the sandbar near the lower station at 24.5 mile still been as large during the spring 2005 windy season as it was 
immediately after the November 2004 high flow, the sand flux into the dune field might have balanced or exceeded the flux out of the dune field, resulting in net sediment gain. At this same site, the restorative function of aeolian sand derived from the flood deposit was still apparent more than a year after the high-flow experiment. In January 2006, a new gully was photographed that had recently begun to incise into the aeolian dune field at 24.5 mile. The orientation of the gully and of wind ripples in the sand indicated that sediment filling the lower part of this gully had blown inland from the November 2004 high-flow deposit. This is consistent with the dominant wind direction recorded at 24.5 mile over the preceding 26 months (Draut and Rubin, 2006). The ability of gullies to act as natural traps for wind-blown sand in this manner could contribute to slowing or cessation of erosional processes that affect the stability and preservation of archaeological sites in aeolian deposits (for example, Thompson and Potochnik, 2000).

Effects of the November 2004 high-flow experiment on aeolian sediment transport therefore indicate that sediment-rich controlled high flows are an effective means to restore sediment deposition in aeolian dune fields above the flood-stage elevation. Sandbar-building floods have much more potential to enhance aeolian sedimentation on MFS-type deposits than on RFS deposits as defined above (Fig. 4), because of the direct link between active fluvial sandbars (at or below the $1,270 \mathrm{~m}^{3} \mathrm{~s}^{-1}\left[45,000 \mathrm{ft}^{3} \mathrm{~s}^{-1}\right]$ stage) and MFS aeolian dunes downwind. To promote substantial sediment restoration at RFS dune fields would require sediment-rich floods on the scale of pre-dam spring snowmelt floods, twice as high as those conducted experimentally thus far. It is therefore expected that any future controlled high flows on the scale of the 2004 experiment could cause substantial enhancement of aeolian deposition on MFS dune fields (provided that post-flood flows are managed to maintain the size and condition of new fluvial deposits through the next windy season) but that those same floods would have little effect on aeolian sediment flux into RFS dune fields.

The high daily flow-fluctuation schedule (142 to $566 \mathrm{~m}^{3} \mathrm{~s}^{-1}[5,000$ to $\left.20,000 \mathrm{ft}^{3} \mathrm{~s}^{-1}\right]$ ), which itself comprised experimental flows, was conducted from 
January-March of 2003, 2004, and 2005 to suppress non-native fish populations. Each of those high-fluctuating-flow intervals exported approximately twice as much fluvial sediment as under Modified Low Fluctuating Flow (MLFF) operations of Glen Canyon Dam for comparable volume months and comparable sediment influx (Wright, 2006). Therefore, substantially more fluvial sand would be retained and available for subsequent aeolian transport to dune fields if a sediment-rich high flow were followed by low fluctuating flows rather than by high daily flow fluctuations. Operating under low fluctuating flows (or steady low flow) between the end of a controlled flood and the start of spring high winds is predicted to maintain much more of the post-flood sandbar size until the wind can redistribute flood sediment into higher-elevation aeolian deposits during the subsequent spring windy season. 


\section{SITE-SPECIFIC FINDINGS}

\section{5 mile:}

An aeolian dune field on the downstream side of a debris fan at 24.5 mile was the site of two weather stations deployed during this project: one near river level (Station $24.5 \mathrm{~L}$ ) and one at the upper end of the dune field (Station $24.5 \mathrm{U}$ ). The region of the dune field between the two weather-station locations (Draut and Rubin, 2005, 2006) undergoes active aeolian sand transport and has little vegetation or cryptogamic crust, while an area of approximately equal size at the northern (upstream) end of the dune field is relatively inactive, with well developed cryptogamic crust and evidence of deflation of the land surface. Comparison of aerial photographs taken in 1965 with more recent images (Fig. 6) shows a marked decrease in the size of river-level sandbars and increased riparian vegetation at 24.5 mile in post-dam time. Notably, a river-level sandbar at the western end of the aeolian dune field is clearly visible in 1965 photographs (marked 'a' in Fig. 6) but is much smaller or absent in recent photographs (see also Fig. 39 of Turner and Karpiscak, 1980). This sandbar was temporarily enlarged by the 1996 flood experiment (based on examination of aerial photographs) and again by the November 2004 high-flow experiment (Draut and Rubin, 2006) after which it was partially eroded by daily flow fluctuations. A second fluvial sand deposit (labeled 'b' in Fig. 6) is now smaller than in 1965 and is partially covered by vegetation; Figure 6 shows that riparian vegetation is much more abundant today than in 1965.

Wind velocity and direction measured at the two weather stations at 24.5 mile between November 2003 and January 2006 reveal a very consistent pattern of wind blowing from the west-southwest. Calculated vector sums of wind data sampled continuously at four-minute intervals, excluding those intervals during which wind velocities were below the threshold of motion needed to transport sand, yielded a net potential sediment-transport direction of 244 degrees at both weather stations during calendar-year 2005; data from 2004 were very similar 


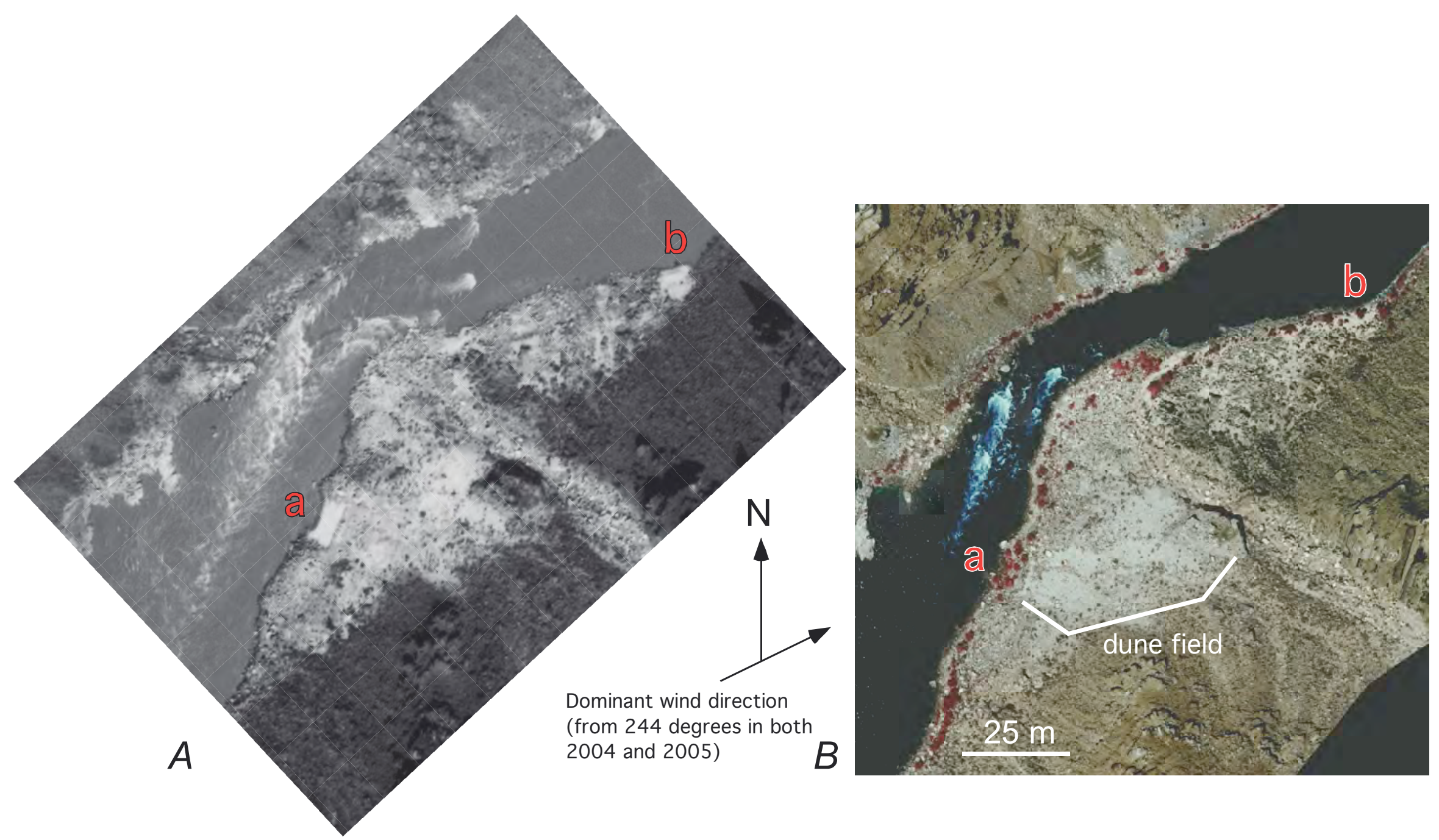

FIGURE 6. Aerial photographs of 24.5 mile in 1965 and 2004. River discharge in the May 1965 photograph (A) is between 680 and $792 \mathrm{~m}^{3} \mathrm{~s}^{-1}\left(24,000-28,000 \mathrm{ft}^{3} \mathrm{~s}^{-1}\right)$. Discharge in the May 2004 photograph (B) is $226 \mathrm{~m}^{3} \mathrm{~s}^{-1}(8,000$ $\left.\mathrm{ft}^{3} \mathrm{~s}^{-1}\right)$. Locations 'a' and ' $b$ ' mark fluvial sand deposits. The modern extent of the aeolian dune field is indicated in B. Dominant wind direction (the direction of net sediment transport) is from the west-southwest at 24.5 mile (see Draut and Rubin, 2005, 2006 for details on calculation of net sand-transport direction). Note increased riparian vegetation and decreased open fluvial sandbar area since 1965. 
(see Draut and Rubin, 2005, 2006 for all data and additional discussion of method and results) ${ }^{1}$. The aeolian dune field at 24.5 mile is therefore located directly downwind of the river-level sandbar marked ' $a$ ' in Figure 6 and is an example of a MFS aeolian deposit as defined above.

Rates of aeolian sediment transport were typically on the order of $1 \mathrm{~g} \mathrm{~cm}^{-1}$ day $^{-1}$ in this dune field; transport rates at the upper end of the dune field were consistently higher than those measured near river level by a factor of two to four, consistent with higher wind velocities measured at Station 24.5 U (Draut and Rubin, 2006). Given the projected strong link between sediment comprising the fluvial deposit ' $a$ ' and the aeolian dune field, it was not surprising that replenishing sediment on the sandbar 'a' during the 2004 high flow was followed by a measured increase in aeolian sediment transport near river level (recorded at Station $24.5 \mathrm{~L}$ ) in the spring windy season of 2005, compared to the spring windy season of 2004. As discussed above, however, no similar increase in sand flux relative to the previous year was measured at the upper-elevation station. Because the sand flux measured at the upper station at 24.5 mile exceeded that at the lower station even with the new flood deposit present, the net flux of sand into this dune field was still negative, indicating deflation of its land surface. Assuming wind conditions similar to those measured in 2005, the sediment flux at the lower station would need to be $\sim 50$ percent higher than that measured in 2005 to equal the sand flux at the upper station; such a situation would indicate that the dune field experienced no net gain or loss of sediment. We speculate

\footnotetext{
${ }^{1}$ Dominant wind directions given in this report were calculated using vector sums of the 4-minute wind measurements at each weather station. Complete documentation of all data and methods used in these and other net wind directions mentioned were published by Draut and Rubin (2005, 2006). Vector sums (magnitude and direction of wind, using only data points in which wind velocity exceeded the critical threshold of motion needed to transport sand of the grain size found at each site) for each month of data at each weather station were reported by Draut and Rubin $(2005,2006)$. Error in each wind measurement is estimated to be no more than 10 degrees for the wind's direction ( 5 degrees is the manufacturer's stated accuracy for the anemometers, and allowing another 5 degrees for operational error). For the magnitude component of wind velocity, analyses include error of $0.5 \mathrm{~m} \mathrm{~s}^{-1}$ for velocities $<17 \mathrm{~m} \mathrm{~s}^{-1}$ and $\pm 3 \%$ for velocities between 17 and $30 \mathrm{~m} \mathrm{~s}^{-1}$ (manufacturer's stated accuracy). Draut and Rubin $(2005,2006)$ published both the magnitudes and directions of net (dominant) wind and potential sediment transport for each month of data at each station. Measurement errors are expected not to affect net (dominant) wind calculations significantly except in cases where wind blew often from opposing directions, such as at 202.9 mile. For all other sites, wind direction was consistent enough that measurement errors would not significantly affect the reported dominant wind and sediment-transport direction.
} 
that, if the sandbar near the lower station at 24.5 mile had still been as large during the spring 2005 windy season as it was immediately after the November 2004 flood (having been reduced to half its post-flood size by high daily flow fluctuations between January and March 2005), the wind-blown sand flux into the dune field might have balanced or exceeded that measured at the upper station, resulting in net sediment gain in the dune field.

Archaeological sites are known to occur in the vicinity of 24.5 mile that are built on and buried by aeolian sediment. Because this is a MFS aeolian system in which an aeolian deposit receives sediment from a fluvial sandbar located directly upwind, changes in the amount of sediment available on the fluvial sandbar that serves as a sand source can be expected to affect the stability and preservation potential of archaeological material in the aeolian deposit to which this fluvial sediment is linked. It is very probable that the relatively 'inactive' northern area of the 24.5-mile dune field has experienced deflation as a result of the decreased sand source upwind (the fluvial sandbar marked 'a' in Fig. 6) since the 1960s. The growth of the same fluvial sand deposit during the 2004 high-flow experiment, consequent increased aeolian sand flux into the dune field, and the filling of a small gully by wind-blown sand derived from the 2004 high-flow deposit (Draut and Rubin, 2006) clearly indicate that sediment-rich floods of the magnitude conducted in $2004\left(1,160 \mathrm{~m}^{3} \mathrm{~s}^{-1}\left[41,000 \mathrm{ft}^{3} \mathrm{~s}^{-1}\right]\right)$ can significantly increase aeolian sediment transport to and deposition on MFS aeolian deposits and archaeological sites associated with them.

It may be possible to extrapolate the dominant west-southwest wind direction (and same projected net sediment-transport direction) measured at 24.5 mile for some short distance upstream and downstream. Because wind conditions are very variable with local topography, however, it is not recommended to extrapolate these results for great distances and any extrapolations that are made should be considered speculative. However, because the orientation of the canyon around 24.5 mile remains approximately constant (trending northeast and varying by no more than 10 degrees between river-miles 22.5 and 25.0), similar net aeolian sediment movement may be 


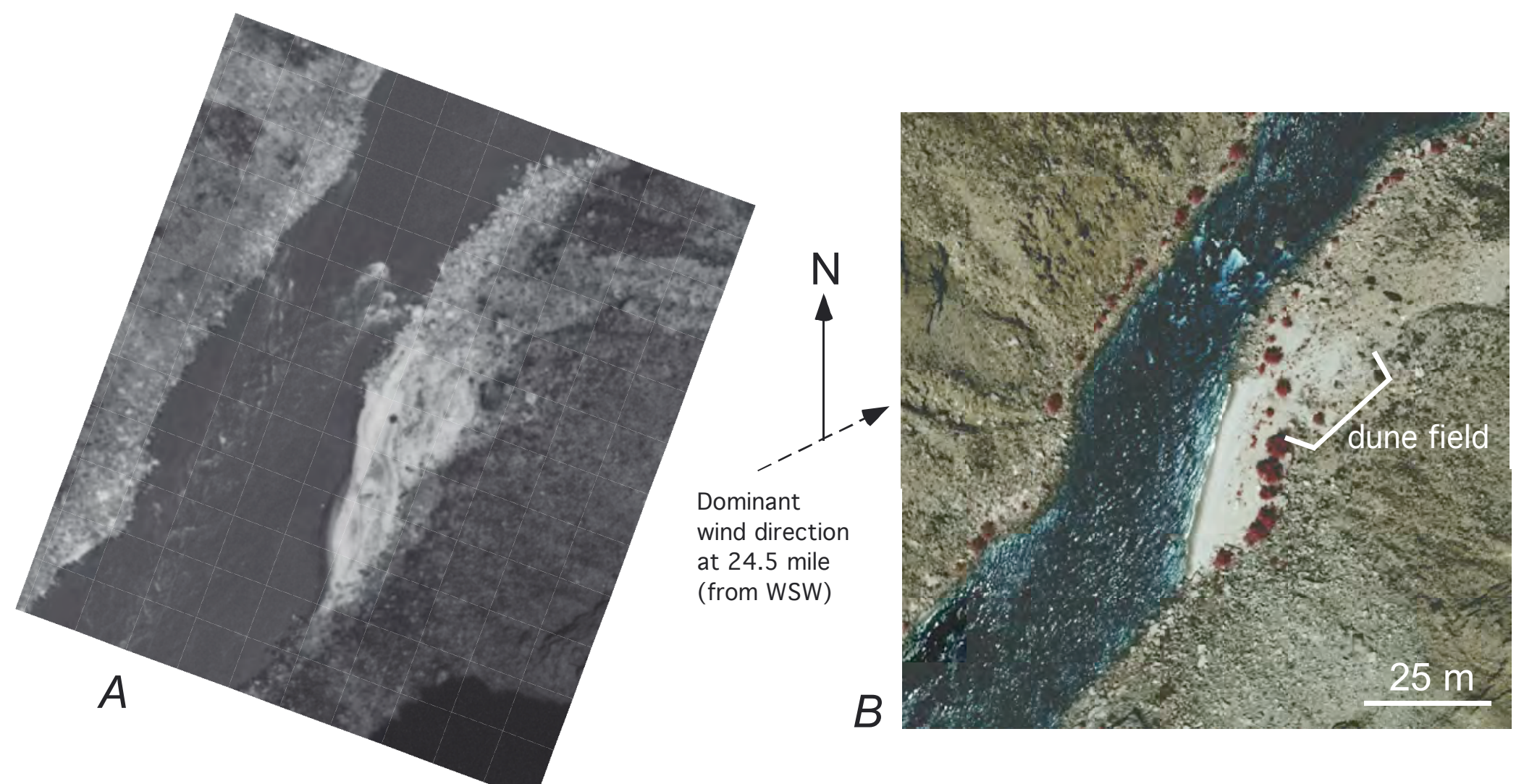

FIGURE 7. Aerial photographs of 23.5 mile in 1965 and 2004. River discharge in the May 1965 photograph $(A)$ is between 680 and $792 \mathrm{~m}^{3} \mathrm{~s}^{-1}\left(24,000-28,000 \mathrm{ft}^{3} \mathrm{~s}^{-1}\right)$. Discharge in the May 2004 photograph $(B)$ is $226 \mathrm{~m}^{3} \mathrm{~s}^{-1}\left(8,000 \mathrm{ft}^{3} \mathrm{~s}^{-1}\right)$. A small aeolian deposit is indicated in $B$. Note the decreased area of open sand, and increased vegetation, in the 2004 photograph relative to 1965. If the same dominant wind direction is assumed to occur at 23.5 mile as at 24.5 mile, the aeolian dune field is directly downwind of a fluvial sandbar. 
anticipated for other sediment deposits between river-miles 22.5 and 25.0. The largest fluvial sandbar that presently exists in that reach of the river is located at river-mile 23.5. Aerial photographs show that the 23.5-mile sandbar is now smaller and that the area contains more vegetation than in 1965 (Fig. 7), similar to changes apparent at 24.5 mile. If a dominant west-southwest wind direction is assumed for 23.5 mile, this implies that the small aeolian deposit immediately northeast of the fluvial sandbar there is likely also a MFS aeolian deposit in which sedimentation is linked to sand supply from the 23.5-mile fluvial sandbar. The aeolian dune field at 23.5 mile is approximately half the size of that at 24.5 mile and was not studied directly during this project.

\section{Malgosa:}

The aeolian dune field at the downstream, south side of the Malgosa Canyon debris fan (river-mile 57.9; Fig. 8) is one of the most active dune fields observed during this study. Wind gusts exceeding $20 \mathrm{~m} \mathrm{~s}^{-1}$ were not uncommon during 2004 and 2005 in the upper dune field; aeolian sand transport rates on the

order of $10-100 \mathrm{~g} \mathrm{~cm}^{-1}$ day $^{-1}$ were typical, and in May 2004 a two-day event was recorded during which transport rates exceeded $4000 \mathrm{~g} \mathrm{~cm}^{-1}$ day $^{-1}$. Wind direction in this dune field aligned with the orientation of the main canyon, blowing from either south-southeast or north-northwest. Wind records from Malgosa commonly show daily fluctuations in wind strength and direction, with wind at higher velocity and more consistently from the south-southeast in the afternoons (Draut and Rubin, 2005, 2006). Wind velocities high enough to transport sediment of the grain size found in the Malgosa dune field ( $>2 \mathrm{~m} \mathrm{~s}^{-1}$ ) come most often from the south-southeast at this site, such that net sediment transport is directed upstream with respect to the Colorado River. This is consistent with dune morphology on the southern side of the Malgosa debris fan, which includes north-facing slip faces that indicate northward dune migration. The primary sediment source for this dune field is therefore found to be the fluvial 
sandbar immediately upwind of the dune field, marked 'a' in Figure 8. A second sandbar located across the river and $\sim 200 \mathrm{~m}$ downstream, labeled ' $b$ ' in Figure 8, occasionally also provides a minor amount of sediment to the Malgosa dune field (in May 2004, sand was observed to blow from sandbar 'b' across the river and into the Malgosa dune field upstream of sandbar ' $a$ '). The orientation of the aeolian dunes with respect to fluvial sandbars, together with the dominant wind direction measured from November 2003 to January 2006, implies that the Malgosa dune field is a MFS aeolian deposit in which aeolian sedimentation is directly linked to sediment supply from a fluvial sandbar (or sandbars) upwind.

The higher river discharge in the 1965 aerial photos compared to those taken since the mid-1990s and the generally low elevation today of sandbars ' $a$ ' and ' $b$ ' make it difficult to compare fluvial-sandbar area between the two sets of photographs in Figure 8. Aerial photographs do however show greater vegetation cover along the riparian zone and in the Malgosa dune field itself in 2004 compared with 1965 (Fig. 8). Increasing vegetation in the Malgosa dune field since the 1960s suggests that the dunes have become less mobile over that time. Dunes on the north side of Malgosa Creek (a tributary of the Colorado River that is dry except after recent heavy rain) can be considered relatively 'inactive' compared with those on the south side of Malgosa Canyon and have well developed grass cover and cryptogamic crust. Photographs in Figure 9 demonstrate the difference in dune surfaces between the north and south sides of Malgosa Creek. These differences are attributed to the Malgosa Canyon channel trapping aeolian sand between the two parts of the dune field-the southern dunes migrate north but their sand is removed by episodic runoff in Malgosa Canyon before significant quantities of sand reach the northern dune field. Only sediment carried in suspension during high wind velocity can therefore be expected to reach the northern dune field; sand moving north by saltation or reptation will be trapped in the tributary drainage and unavailable to the northern dune field. Aeolian sediment-transport rates were not measured in the dunes to the north of Malgosa Canyon during this study. That substantial sand dunes exist at all on the northern part of the Malgosa debris fan, although they are now fairly 


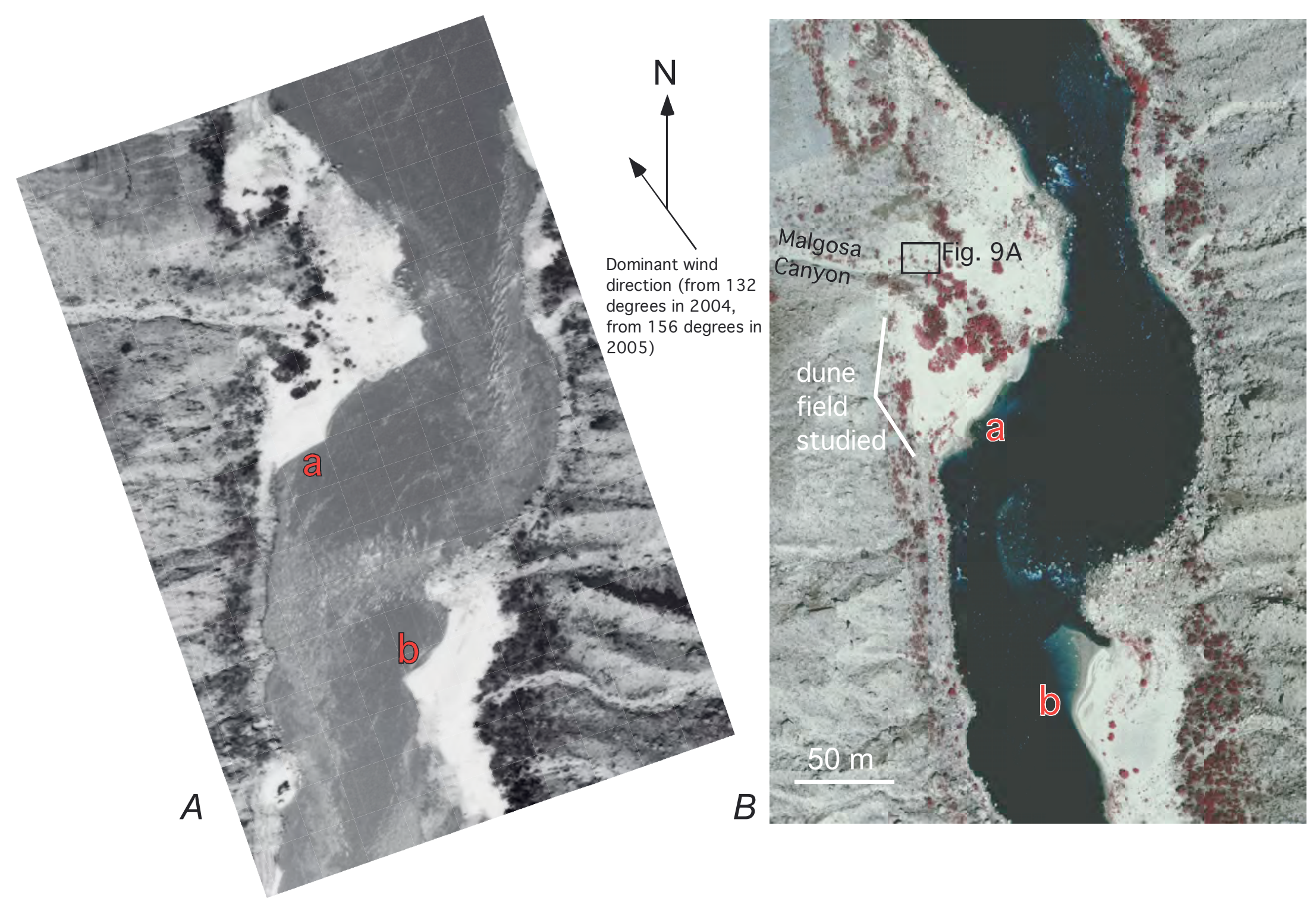

FIGURE 8. Aerial photographs of Malgosa in 1965 and 2004. River discharge in the May 1965 photograph (A) is between 680 and $792 \mathrm{~m}^{3} \mathrm{~s}^{-1}\left(24,000-28,000 \mathrm{ft}^{3} \mathrm{~s}^{-1}\right)$. Discharge in the May 2004 photograph (B) is $226 \mathrm{~m}^{3} \mathrm{~s}^{-1}\left(8,000 \mathrm{ft}^{3} \mathrm{~s}^{-1}\right)$. Locations ' $a$ ' and ' $b$ ' mark fluvial sand deposits. The most-active area of the aeolian dune field on the downstream side of the Malgosa Canyon debris fan is indicated in B. The box in B shows the area that appears in the photograph in Figure 9A. Dominant wind direction (the direction of net sediment transport) is from the south-southeast at Malgosa (see Draut and Rubin, 2005, 2006 for details on calculation of net sand-transport direction). Note increased riparian vegetation since 1965. 
inactive, suggests that in the past there was likely a greater supply of sediment to this northern dune area than occurs today.

Malgosa experienced not only the highest aeolian sand-transport rates measured at any site during this study but also the highest rainfall. Annual precipitation at Malgosa totaled nearly $270 \mathrm{~mm}$ in 2005, a factor of two greater than that measured at the next-nearest study site (Palisades, $\sim 12 \mathrm{~km}$ downstream). High rainfall at Malgosa compared to other sites was common on an event-by-event basis. The marked differences between rainfall at Malgosa and elsewhere are attributed to local topography, but this interpretation is not well constrained and only 26 months of rainfall data are available from this study, which may not accurately represent long-term climate at either site. The Malgosa Canyon tributary trends northeast and drains the eastern side of the Walhalla Plateau, located southeast of the main Kaibab Monocline. It is possible that the orientation of Malgosa Canyon and drainage-basin geometry affect movement of local weather systems, perhaps creating a funneling effect for eastward-moving storms that could account for the significantly higher rainfall recorded near river level at Malgosa compared to other sites (see Draut and Rubin, 2006).

It is noteworthy that although Malgosa experiences unusually high rainfall compared to other areas of Grand and Marble Canyons, the active dune field there is not incised by gullies. Small ephemeral gullies have been observed there on occasion that were soon filled by wind-blown sand and did not grow large enough to cause any significant erosion at this site. This relationship among precipitation, gully incision, and the restorative effects of aeolian sand contrasts with the conditions at the Palisades site, discussed below, where major gully incision occurs even in an area that received unusually low precipitation compared to other sites during this study, but where wind-blown sand transport was be at least an order of magnitude lower than at Malgosa and is apparently unable to keep pace with gully formation.

The November 2004 high-flow experiment resulted in deposition of a major new sandbar at Malgosa, at the location marked 'a' in Figure 8, that was up to $2 \mathrm{~m}$ thick and more than $10 \mathrm{~m}$ wide. High daily flow fluctuations for the first 


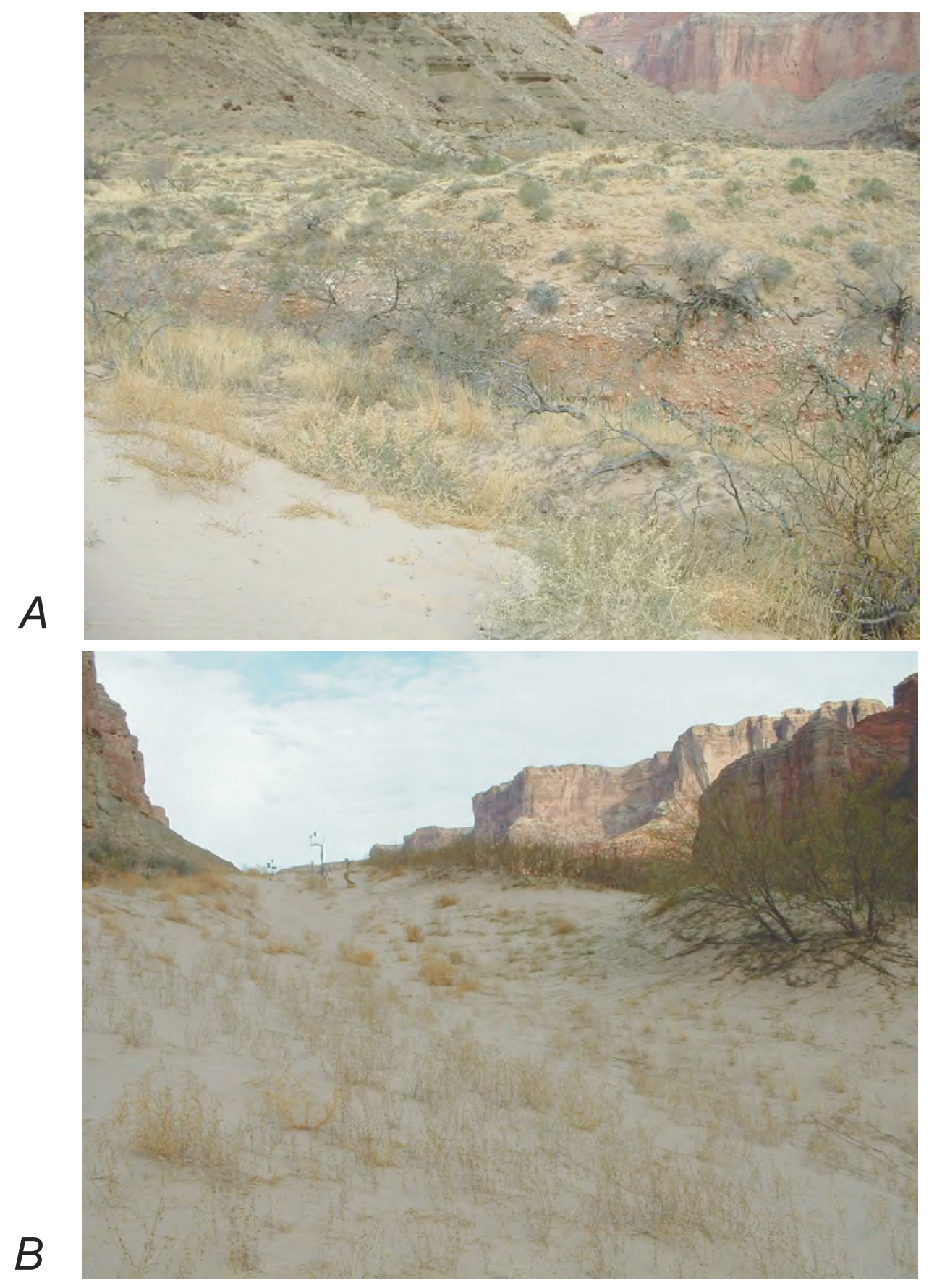

FIGURE 9. Photographs of different zones within the Malgosa dune field. The photo in A was taken facing north (upstream with respect to the Colorado River) from the top of a dune crest just south of the Malgosa Creek tributary (mid-ground of photograph). In the background are dune forms north of the tributary; these dunes are covered with abundant grass and other vegetation; cryptogamic crust also occurs there, indicating little active aeolian sand deposition there. In contrast, B shows the southern part of the Malgosa dune field (south of Malgosa Creek); there, vegetation is much more sparse and sand transport rates reach hundreds of $\mathrm{g} \mathrm{cm}^{-1}$ day $^{-1}$. 
three months of 2005 eroded this sand deposit almost entirely, however, and by May 2005 the location 'a' appeared almost identical to its pre-flood condition (photographs published by Draut and Rubin, 2006). Because this sandbar had eroded so significantly before the spring 2005 windy season began, it was not surprising that aeolian sand-transport rates measured at the Malgosa weather stations in spring 2005 were no higher than in spring 2004.

\section{Palisades:}

This research group studied sedimentary profiles in detail in the Palisades (Palisades of the Desert) area near river-mile 66, in addition to deploying two weather stations there that measured wind, precipitation, and aeolian sand transport from November 2003 to January 2006. Detailed discussions of the measured strata and surface morphology studied at Palisades (Figs. 2a, 4a) were published by Draut and others (2005).

The Palisades region forms the upstream part of the geomorphic reach of the canyon described by Schmidt and Graf (1987) as the Furnace Flats reach. As discussed in the Overview of Sedimentary and Geomorphic Investigations section above, alluvial terraces in this area represent multiple episodes of floodplain aggradation in pre-dam time, represented by distinct fluvial sedimentary structures in the studied profiles. The areal extent of fluvial deposits demonstrated that the entire terrace area in the Palisades region was submerged episodically during pre-dam high flows (cf. Hereford, 1996; Hereford and others, 1993, 1996). No post-dam flows (since 1963) have inundated the majority of this terrace. A stage-discharge relationship developed from driftwood deposits indicated that the terraced area was almost entirely inundated by a flow of $\sim 5,940$ $\mathrm{m}^{3} \mathrm{~s}^{-1}\left(210,000 \mathrm{ft}^{3} \mathrm{~s}^{-1}\right.$; Draut and others, 2005; Hazel and others, 2006b), a flood level reached most recently in 1884 . Reworking of fluvial sediment by wind was common in pre-dam time, evidenced by aeolian deposits between fluvial 
deposits; aeolian material was also found interbedded with 'ponded' sediment deposits where slope-wash runoff had formed small, isolated pools at the eastern side of the terrace. Aerial photographs show that the amount of vegetation on the terraced area has increased somewhat since 1965 while vegetation in the riparian zone has increased substantially (Fig. 10). The now-substantial arroyo at Palisades (Fig. 2a) has deepened since the 1960s and is believed to have increased after this local drainage breached pre-dam alluvium exposures and aeolian dunes in the late 1970s or early 1980s and commenced to drain directly to the Colorado River (Hereford and others, 1993; Thompson and Potochnik, 2000).

Six of the nine archaeological sites at Palisades were formed in or on fluvial sediment, some of which had been reworked by wind (Tab. 1; see also Draut and others, 2005). Five of the nine sites are preserved at least in part by a cover of aeolian sediment, with minor contributions from aeolian sedimentary cover at two additional sites. Erosion associated with arroyo incision affects two of the sites. Exposure of artifacts can be attributed at least in part to aeolian deflation at five archaeological sites.

The relative abundance of fluvial sediment compared to aeolian sediment in vertical profiles indicates that the aeolian coppice dunes on the terrace surface apparently formed by wind-reworking of the extensive pre-dam flood deposits that underlie the Palisades area, defining the Palisades dune field as a RFS aeolian deposit (Fig. 5b; Hereford, 1996). Wind tends to align with the northsouth orientation of the river in this area and may blow either from north or south, although the dominant wind direction at Palisades (at velocities strong enough to transport sediment) comes from the south-southeast (Draut and Rubin, 2005, 2006). Aeolian sediment-transport rates within the coppice dunes were on the order of $\sim 1 \mathrm{~g} \mathrm{~cm}^{-1}$ day ${ }^{-1}$ while on a cobble deposit at the river's edge, rates were an order of magnitude lower. Given the net wind direction from the southsoutheast, it is unlikely that significant quantities of sediment are transported by wind from river-level sandbars (the locations of which are indicated in Fig. 10) into the coppice dunes at Palisades. Some migration of aeolian dunes is 


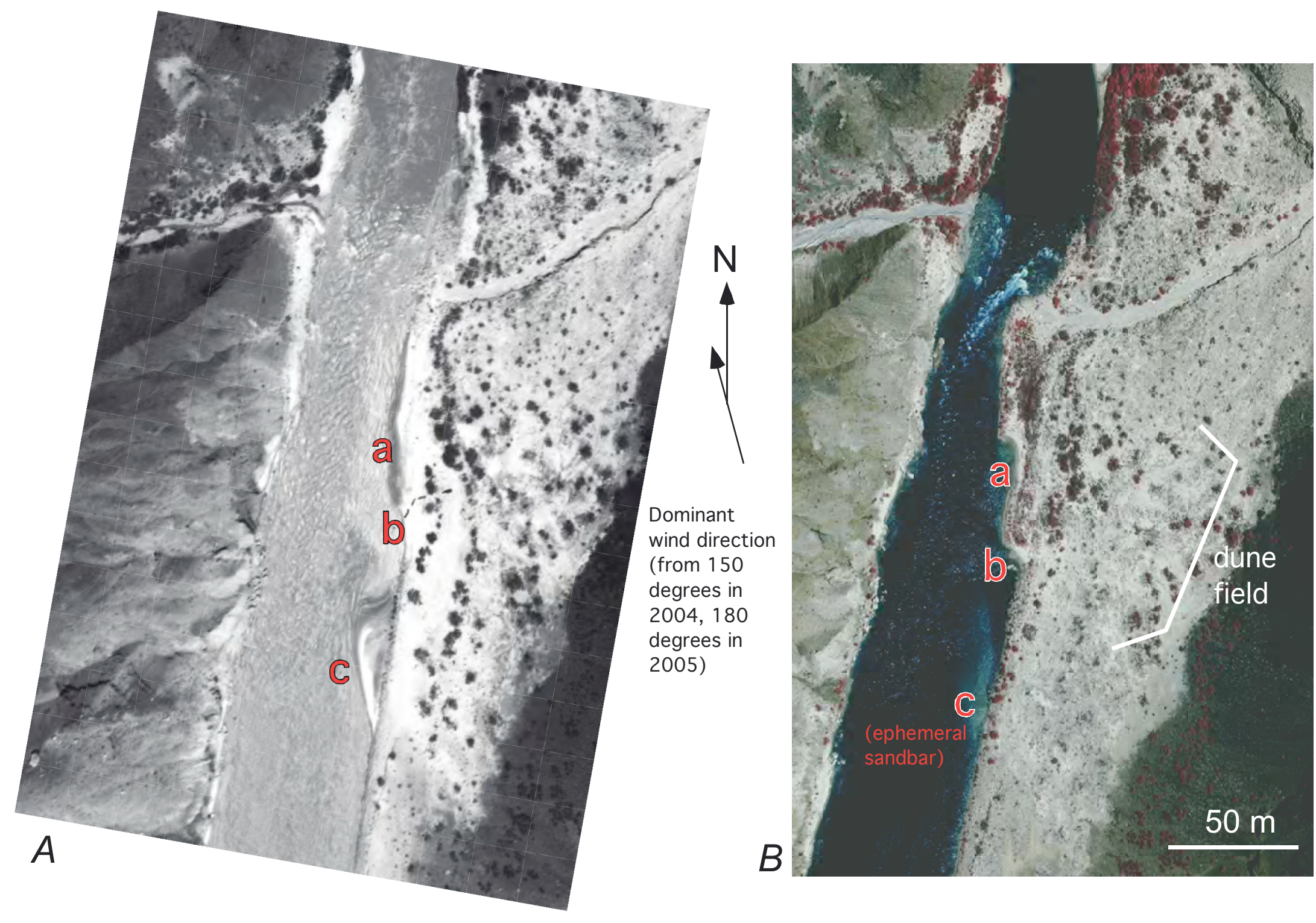

FIGURE 10. Aerial photographs of the Palisades area in 1965 and 2004. River discharge in the May 1965 photograph (A) is between 680 and $792 \mathrm{~m}^{3} \mathrm{~s}^{-1}\left(24,000-28,000 \mathrm{ft}^{3} \mathrm{~s}^{-1}\right)$. Discharge in the May 2004 photograph (B) is 226 $\mathrm{m}^{3} \mathrm{~s}^{-1}\left(8,000 \mathrm{ft}^{3} \mathrm{~s}^{-1}\right)$. Dominant wind direction (the direction of net sediment transport) is from the west-southwest at Palisades (see Draut and Rubin, 2005, 2006 for details on calculation of net sand-transport direction). Locations 'a', ' $b$ ', and 'c' mark fluvial sand deposits. The most-active area of the Palisades dune field is indicated in B. Note increased riparian vegetation and decreased open fluvial sandbar area since 1965. 
apparent today in the northern part of the dune field, but in general the dunes are relatively inactive with grasses, mesquite, and cryptogamic crust well established. Although some new sediment is probably transported into the dune field on occasion from river-level sandbars (Yeatts, 1996), the net wind direction measured during this study indicates that there is probably a net loss of sediment from this dune field toward the northwest (where it can be lost into the river). As discussed above, gully and arroyo incision causes episodic additional erosion of sediment at Palisades. Because the formation of this RFS aeolian deposit was linked to deposition of fluvial sediment during large, sediment-rich pre-dam floods, it is unlikely that substantial new sediment will be supplied to the Palisades dune field without similar large, sediment-rich floods in the future. Controlled Colorado River high flows on the order of $\sim 1,270 \mathrm{~m}^{3} \mathrm{~s}^{-1}\left(45,000 \mathrm{ft}^{3} \mathrm{~s}^{-1}\right)$ can enlarge the fluvial sand deposits labeled in Figure 10; substantial deposition there was documented after high flows in 1996 (Yeatts, 1996) and 2004 (Draut and Rubin, 2006). However, flows of that magnitude are unlikely to promote substantial aeolian sand transport into the Palisades dune field given the dominant wind direction measured during this study and the location of sandbars ' $a$ ', 'b', and 'c' relative to the location of the aeolian dunes.

As mentioned in the previous section, during this study the annual precipitation at Palisades was significantly lower than that measured $\sim 12 \mathrm{~km}$ upstream at Malgosa (in 2005, the $\sim 135 \mathrm{~mm}$ recorded at Palisades was less than half of the rainfall at Malgosa). Palisades in fact received the lowest total annual rainfall of any site studied during this project, though it was similar to that measured nearby at Comanche (river-mile 68, where $138 \mathrm{~mm}$ of rain fell in 2005). The much-studied arroyo at Palisades has therefore reached its advanced state of terrace incision despite being located in a region of the river corridor that experienced unusually low rainfall, at least during the 26-month duration of this study. Although many factors contribute to gully incision (including long-term climate, drainage-basin geometry, substrate composition, and effective base level), we infer that the arroyo incision would not have progressed as far as it has if aeolian sand movement within the Palisades terrace area were an order of 
magnitude greater than it is today. A short distance upstream, gullies are typically absent from the Malgosa dune field - a site with twice the rainfall, but ten times the aeolian sand-transport rates, of Palisades. Active aeolian sediment movement at Malgosa more than accommodates the episodic gully incision there, and gullies (which act as natural traps for wind-blown sand) are quickly healed, similar to the situation observed at 24.5 mile in January 2006 (Draut and Rubin, 2006).

\section{Comanche:}

As discussed above, sedimentary profiles were analyzed at Lower Comanche, near river-miles 68-69, in May 2004. One weather station measured wind, precipitation, and aeolian sand transport in the northern part of this study area between April 2004 and January 2006. Detailed discussions of the measured strata and surface morphology studied in the Comanche area were published by Draut and others (2005); see Figures 2b and 4b.

Stratigraphy of the southern, arroyo-incised part of the Comanche area indicated multiple episodes of fluvial sedimentation followed by reworking at the land surface by wind and local runoff that follows rainfall events. Aeolian climbing ripples were present in some of the deposits; much of the silt and fine sand did not contain preserved diagnostic sedimentary structures. Colluvium (recognized by sandstone and shale clasts derived from local bedrock) was present in all six profiles studied at Lower Comanche. Five of the six cultural sites in the vicinity are located within aeolian dunes (Tab. 2). Of those, four were originally situated on aeolian sediment, with the fifth built on an interdune, playa-like surface. Four sites were at least partially buried by aeolian sediment; two of those four have only minor sediment cover ( $<10 \mathrm{~cm}$ thick). Three of the five sites within the dune field are affected by active aeolian deflation and dune migration. The one cultural site not located in or among the large coppice dunes at Lower Comanche (Site 
C:13:273; Tab. 2) was constructed on a terrace that contained slope-wash sediment interbedded with lighter-colored, better-sorted fine sand and silt with poorly preserved sedimentary structures that appeared to grade laterally into both fluvial and aeolian deposits.

Based on field relationships between fluvial and aeolian deposits, the aeolian dunes in the Comanche area most likely originated by reworking of large, pre-dam flood deposits-some in place and some that occur to the immediate southeast (upwind) of the dune area-in a similar manner to processes described above for Palisades. The large aeolian dune field at Comanche is defined therefore as primarily a RFS deposit. The net wind direction (net potential sand-transport direction) identified for Comanche in 2004 and 2005 comes from the southeast, directed upstream. A substantial component of potential sediment transport does come from the south, however (Draut and Rubin, 2005, 2006), implying that some sediment from non-flood-stage fluvial deposits may reach the aeolian dunes. If sand does blow from river-margin sandbars (in the area labeled 'a' in Fig. 11) toward the aeolian dunes, it is probable that this supply of sediment has diminished since the 1960s because the area of open sand has decreased and the riparian vegetation increased between the sandbar and aeolian dunes over that time (Fig. 11). Decreased open sand area and increased vegetation are similarly apparent at area ' $b$ ' in Figure 11, several hundred meters downstream and to the south-southeast of ' $a$ '. The November 2004 high flow caused a substantial increase in the open sand area on sandbar ' $a$ '. The new flood sand was eroded rapidly by high daily flow fluctuations in early 2005 , such that six months after the flood the beach was essentially identical to its pre-flood state (photographs of the Comanche sandbar 'a' appear in Fig. 28 of Draut and Rubin, 2006). Post-flood aeolian sand-transport rates during the spring windy season in 2005 were higher, however, than in spring 2004, by up to a factor of two (transport rates in this dune field are typically on the order of $0.1 \mathrm{~g} \mathrm{~cm}^{-1} \mathrm{day}^{-1}$, reaching $>1 \mathrm{~g} \mathrm{~cm}^{-1}$ day $^{-1}$ during spring winds).

Given the proximity of the Palisades and Comanche sites ( $\sim 5 \mathrm{~km}$ apart), the consistent north-south orientation of the main canyon between them, and the 

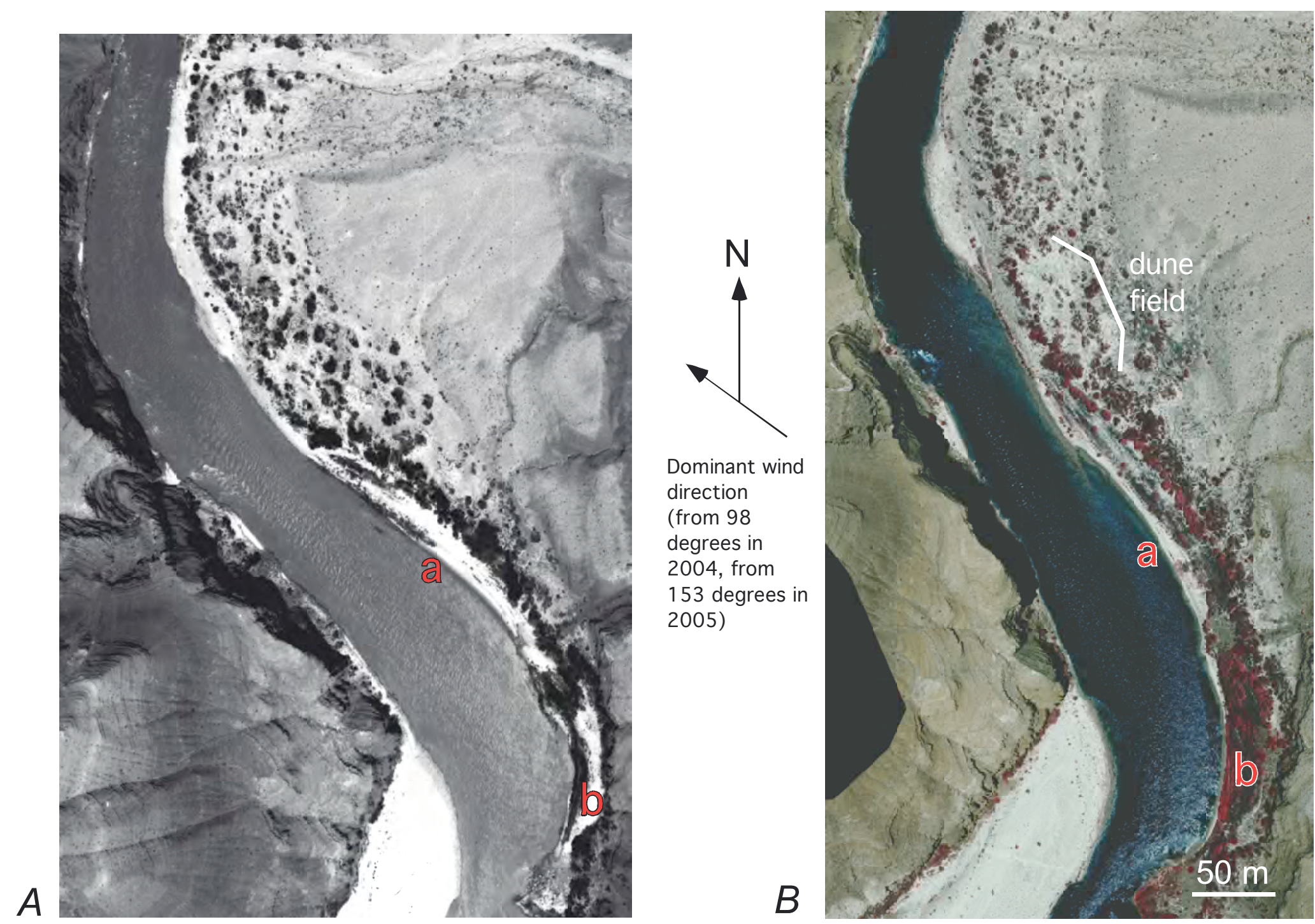

FIGURE 11. Aerial photographs of the Comanche area in 1965 and 2004. River discharge in the May 1965 photograph $(A)$ is between 680 and $792 \mathrm{~m}^{3} \mathrm{~s}^{-1}\left(24,000-28,000 \mathrm{ft}^{3} \mathrm{~s}^{-1}\right)$. Discharge in the May 2004 photograph $(B)$ is $226 \mathrm{~m}^{3} \mathrm{~s}^{-1}\left(8,000 \mathrm{ft}^{3} \mathrm{~s}^{-1}\right)$. Locations 'a' and 'b' mark fluvial sand deposits. The modern extent of the aeolian dune field is indicated in B. Dominant wind direction (the direction of net sediment transport) is from the southwest at Comanche (see Draut and Rubin, 2005, 2006 for details on calculation of net sand-transport direction). Note increased riparian vegetation and decreased open fluvial sandbar area since 1965. 
similar south-southeast dominant wind directions measured at each, we consider it reasonable to extrapolate similar net aeolian sand transport pathways for the reach of the river corridor between these two studied areas. There are few fluvial sandbars on river right (the west bank of the river) in that reach, with the exception of the small deposit at the Lava-Chuar camp site (river-mile 65.3). On river left, there is more open area with some fluvial deposits from which sand is likely remobilized and transported, predominantly, toward the north-northwest. The dominant transport direction calculated for both Palisades and Comanche is oriented such that new fluvial sand deposits left by flows on the order of $1,270 \mathrm{~m}^{3}$ $\mathrm{s}^{-1}\left(45,000 \mathrm{ft}^{3} \mathrm{~s}^{-1}\right)$ will probably not act as major sand sources for adjacent dune fields on river left; instead, at those sites and presumably along the $\sim 5 \mathrm{~km}$ of the river corridor between them, the net transport from fluvial sandbars on the east side of the river (river left) is directed upstream and toward the river, where windblown sand would become entrained in the water.

Immediately downstream of Comanche the canyon widens considerably and makes several tight bends in the Tanner area (river-miles 69-71). Given the significant topographic variations between Comanche and the Tanner area, we believe it is not reasonable to extrapolate a similar south-southeast dominant aeolian transport direction for this reach below Comanche; wind conditions there would need to be measured independently to identify transport pathways for that area.

Because many of the archaeological sites in the Comanche area are associated with aeolian sediment, and because the local aeolian sediment is apparently sourced from pre-dam and, to a lesser extent, post-dam fluvial deposits, the presence or absence of sediment-rich floods is linked to sedimentary processes in the dune field and can likely affect the preservation of cultural material there. As with several other large aeolian dune fields in Grand Canyon, however (see discussion of Site 3 in the Three Case Studies section above), it is uncertain whether archaeological sites at Comanche would be better preserved if new flood sediment were available to be blown into the dune field because many of the sites are exposed by dune migration, which occurs 
naturally as aeolian dunes migrate over time. If the Comanche dunes are significantly affected by sediment-supply limitation in the future (in other words, by the effects of dam operations), the dune field will experience an increase in vegetation cover and cryptogamic crust, both of which indicate decreased mobility of the aeolian sediment comprising the dune forms. Continued NPS monitoring and topographic surveys of dunes would indicate whether, and how rapidly, dune migration and sand transport occurs. As aeolian sediment transport becomes less and less active in a sediment-supply-limited dune field, and rates of dune migration correspondingly decrease, the risk of archaeological-site destabilization by dune migration diminishes. However, although artifacts will be less likely to be disturbed by dune migration in that case, the risk of site erosion by gully incision increases because with less aeolian sand transport, gullies that form during rain runoff will have less opportunity to be filled by aeolian sand.

\section{Forster:}

The study site at the mouth of Forster Canyon (river-mile 123.0) was an aeolian dune field located south-southwest of a small fluvial sand deposit opposite the tail waves of Forster rapid (Fig. 12; fluvial deposit labeled 'a'). Higher river discharge in the 1965 aerial photographs compared to those taken in the 1990s and 2000s makes it difficult to determine accurately changes in the size of sandbars 'a', 'b', and 'c' at Forster (Fig. 12); however those photographs clearly show an increase in riparian vegetation covering formerly open sandbar area.

A weather station in the Forster dune field from April 2004 to January 2006 suffered multiple equipment failures related to adverse conditions caused by high winds and abundant wind-blown sand. During its operation, the station recorded winds almost exclusively from the north and northeast (oriented up the axis of Forster Canyon, perpendicular to the trend of the Colorado River at this location), with a dominant wind direction very consistently from the north- 


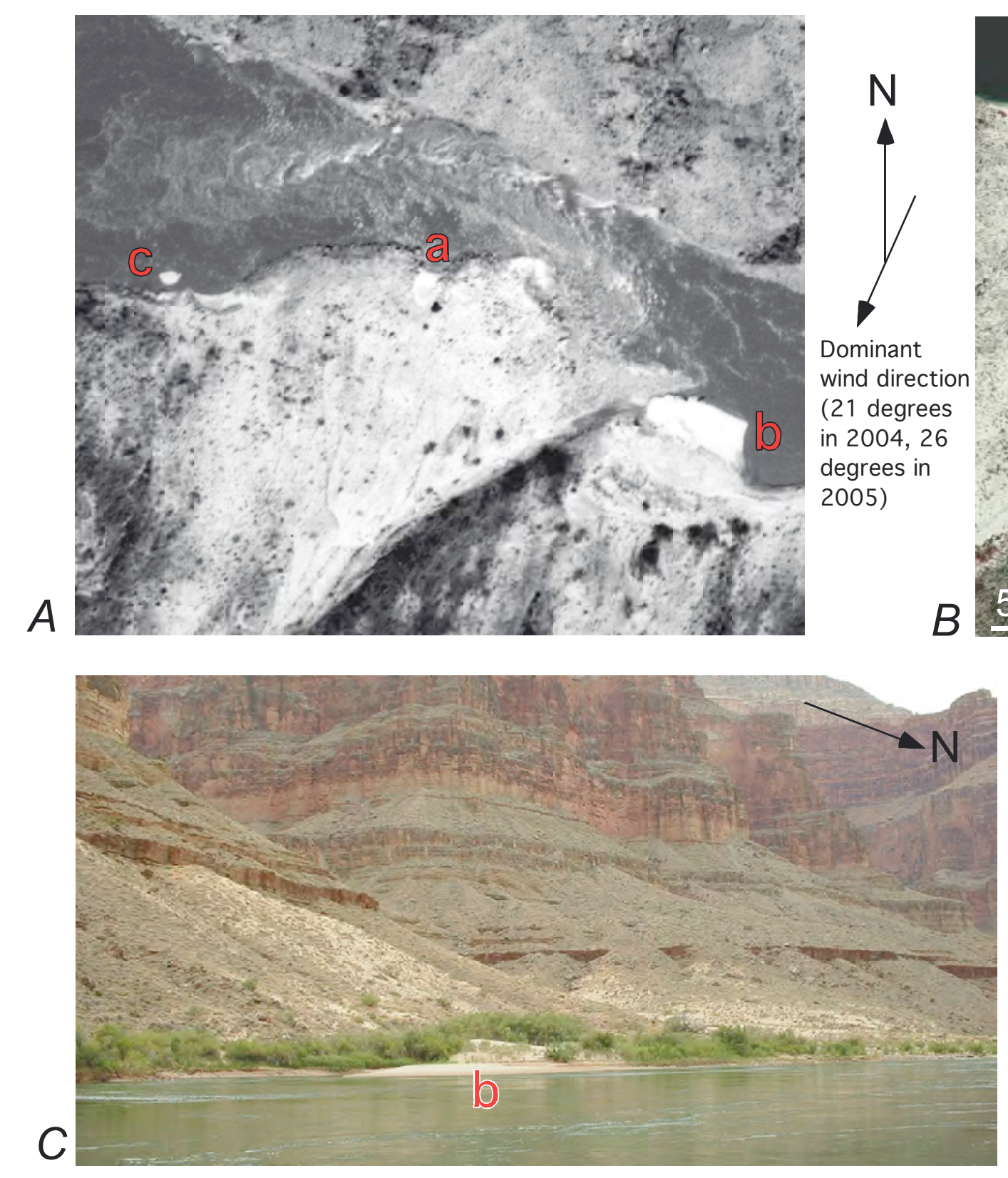

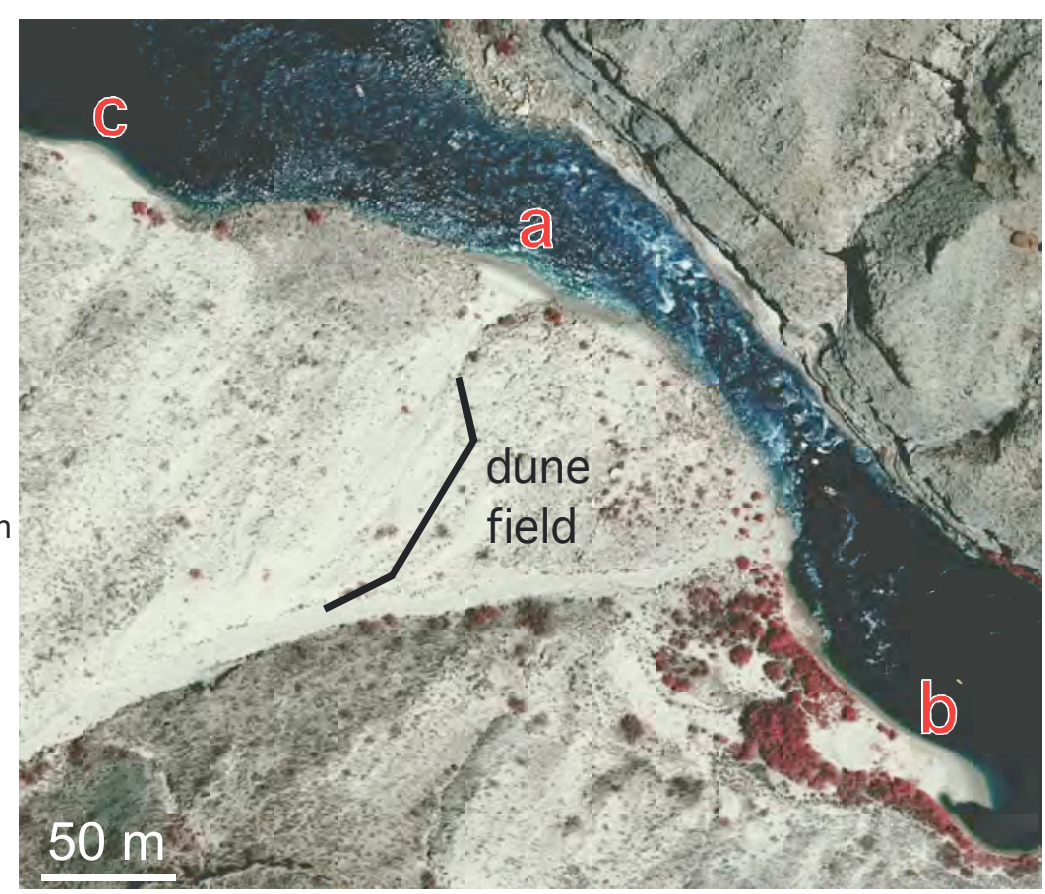

FIGURE 12. Aerial photographs of the area by the mouth of Forster Canyon in 1965 and 2004. River discharge in the May 1965 photograph (A) is between 680 and $792 \mathrm{~m}^{3} \mathrm{~s}^{-1}$ (24,000-28,000 $\left.\mathrm{ft}^{3} \mathrm{~s}^{-1}\right)$. Discharge in the May 2004 photograph (B) is $226 \mathrm{~m}^{3} \mathrm{~s}^{-1}\left(8,000 \mathrm{ft}^{3} \mathrm{~s}^{-1}\right)$. Locations ' $a$ ', 'b', and 'C' mark fluvial sand deposits ('C' is mostly obscured by high discharge in the 1965 photo). The modern extent of the aeolian dune field is indicated in B. C. Oblique view of the same area facing southwest toward river left near sandbar 'b'. Light-colored aeolian deposits are visible on the slopes above the river, downwind of the fluvial sand deposits. Photograph C was taken in April 2004. The dominant wind direction (the direction of net sediment transport) is very consistently from the north-northeast at Forster (see Draut and Rubin, 2005, 2006 for details on calculation of net sand-transport direction). Note increased riparian vegetation and decreased open fluvial sandbar area since 1965. 
northeast (net potential sediment transport came from 26 degrees during 2005; Draut and Rubin, 2006). The aeolian dune field at Forster (Figs. 5a, 12b) is thus located directly downwind of sandbar ' $a$ ', and is defined as a MFS aeolian deposit. Sand transport rates within this dune field were among the highest measured during this study (commonly $>100 \mathrm{~g} \mathrm{~cm}^{-1} \mathrm{day}^{-1}$ ), and the sand surface was observed to aggrade and deflate repeatedly at the site of the weather station by tens of centimeters on time scales of weeks. Forster was the site of the highest wind speed measured during this study, a gust in July 2004 of $29 \mathrm{~m} \mathrm{~s}^{-1}$. Aside from the main dune field at Forster aeolian sediment also occurs at elevations tens of meters above the river, where sediment is deposited on a steep, vegetated, sloping canyon wall on the south side of the river (left bank). These aeolian deposits on the slope, visible at the bottoms of aerial photographs in Figure 12a and b and shown in an oblique view in Figure 12c, are downwind of fluvial deposits ' $a$ ', ' $b$ ' and ' $c$ ' and are assumed to have been sourced from them. Controlled sediment-rich flows on the order of $1,270 \mathrm{~m}^{3} \mathrm{~s}^{-1}\left(45,000 \mathrm{ft}^{3} \mathrm{~s}^{-1}\right)$ are apparently capable of depositing significant new sediment in at least three locations on river left at Forster (sand deposits ' $a$ ', 'b', and 'c') and are therefore expected to replenish sediment in the dune field and on aeolian deposits of the adjacent canyon-wall slope.

Aerial photographs taken before and after the 1996 flood experiment showed an increase in the size of sandbar ' $a$ ' at the upstream end of the Forster dune field. Although the schedule of flood-related field work did not permit this beach to be photographed immediately before or immediately after the 2004 high flow, preliminary observations including a shallow sedimentary profile dug in early 2005 indicated that new sand was deposited there as a result of the 2004 high flow. High daily flow fluctuations from January to March 2005 caused partial erosion of the new flood deposit until tamarisk roots were exposed by March 2005 that had not been exposed prior to the November 2004 flood. Transport rates during the spring windy season of 2005 were significantly higher than those measured in spring 2004, but sand-trap malfunctions during spring 2004 and 
anemometer malfunctions in spring 2005 prevent confident comparison of preand post-flood spring wind conditions and sand transport at Forster.

Known archaeological sites in the Forster area include several that are built on and buried by aeolian sediment. Dune migration causes many of the artifacts to be exposed and covered repeatedly. Because this is a very active MFS aeolian system with frequent high winds that move significant quantities of sand, the supply of sediment to the Forster dunes is strongly linked to the amount of available sediment at fluvial sandbar 'a' (Fig. 12). Because the Forster study site is located in a section of Grand Canyon where the canyon orientation changes substantially within several $\mathrm{km}$ of this site, it is not recommended to assume that a north-northeast wind direction can be extrapolated for other areas upstream and downstream.

\section{9 mile:}

One weather station operated on the west side of the river (river right) at river-mile 202.9 from April 2004 to January 2006. This site includes an aeolian dune field near river level that is covered by trees and abundant other vegetation. The heavy vegetation cover has grown on the dune field and on a large riverlevel sand bar just downstream of the dune field since the 1960s (labeled 'a' in Fig. 13), and now covers a large area of previously open sand. Immediately upstream from the instrument site, an aeolian dune field shows evidence of erosion by deflation, some cryptogamic crust, and gully incision. The purpose of instrumenting this site was to identify the sand source for that eroding, higherelevation dune field by documenting the dominant wind direction that could cause sand transport. Knowing this could establish to what degree vegetation encroachment downstream of the site may have affected the condition of the upper dune field by limiting aeolian transport from its sand source.

Data collected between April and December 2004 at 202.9 mile indicated that the dominant sand transport would be directed north (from downstream; 

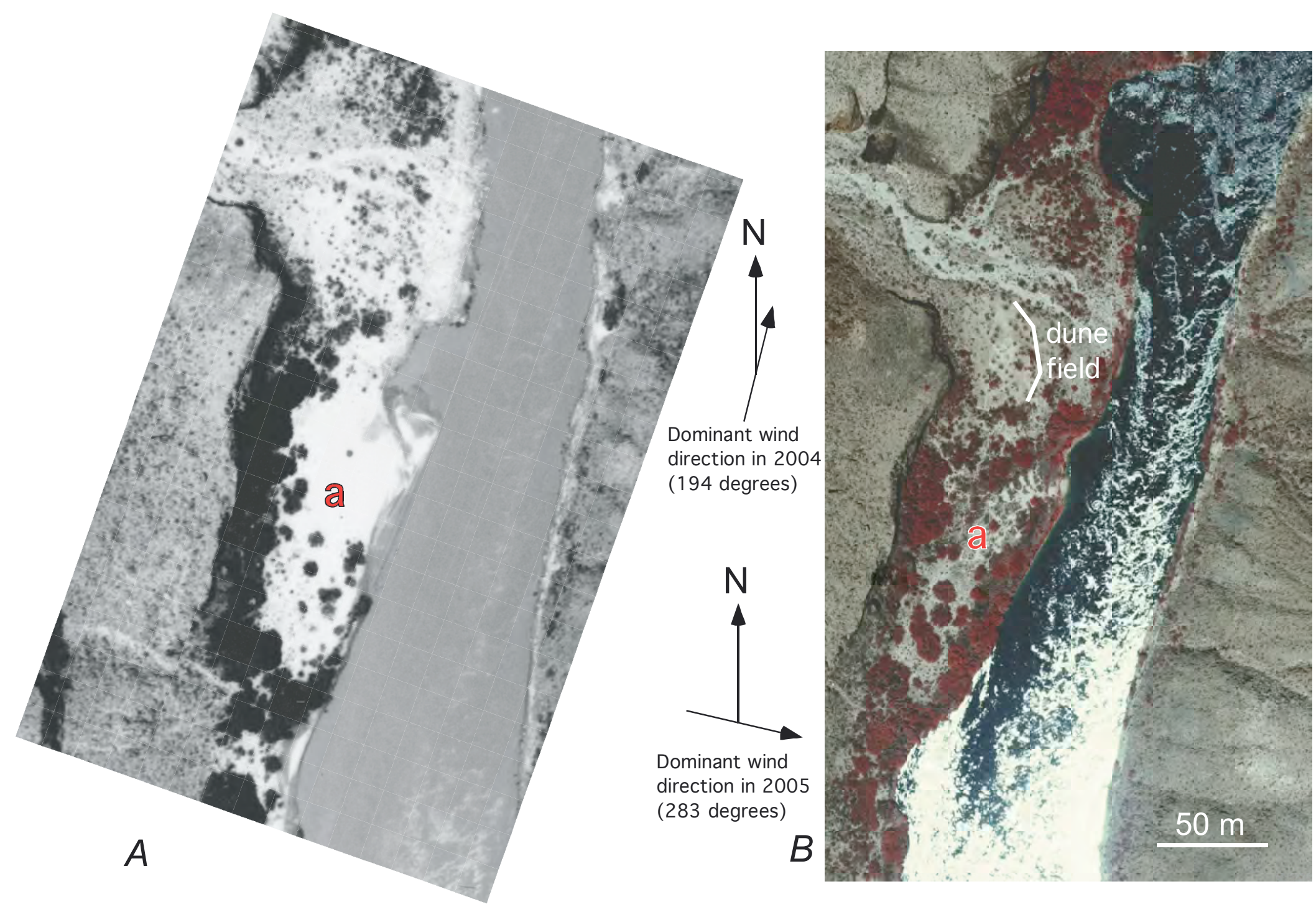

FIGURE 13. Aerial photographs of 202.9 mile in 1965 and 2004. River discharge in the May 1965 photograph (A) is between 680 and $792 \mathrm{~m}^{3} \mathrm{~s}^{-1}\left(24,000-28,000 \mathrm{ft}^{3} \mathrm{~s}^{-1}\right)$. Discharge in the May 2004 photograph (B) is $226 \mathrm{~m}^{3} \mathrm{~s}^{-1}$ (8,000 ft $\left.\mathrm{s}^{-1}\right)$. Location 'a' marks a large fluvial sand deposit. Note greatly increased riparian vegetation and decreased open fluvial sandbar area since 1965. The modern extent of the aeolian dune field, on the downstream (south) side of a small debris fan, is indicated in B. Dominant wind direction is highly variable at 202.9 mile, with calculations yielding net potential sediment transport from the south-southwest in 2004 and from the west in 2005 (see Draut and Rubin, 2005, 2006 for details on calculation of net sand-transport direction). 
Draut and Rubin, 2005). Those initial data supported the idea that the large sandbar ' $a$ ' formerly provided a sand source to the dune field on the debris fan (Fig. 13). This in turn implied that reduced sand-entrainment potential from the newly vegetated sandbar had affected or could affect the condition of the aeolian deposits downwind (upstream) of this sandbar. Wind conditions there in 2005, however, indicated a more complex situation. Although upstream and downstream winds nearly balanced each other at that site in 2005, a tertiary component from the northwest yielded a vector sum showing net sediment transport toward the river (Fig. 22 of Draut and Rubin, 2006). Thus the longerterm record now available from this site seems to suggest that although loss of the potential sand source (the now-vegetated sandbar) downstream of this site may affect the condition of that dune field, the availability of sand from other sources could also affect aeolian deposition and erosion processes there.

\section{Arroyo Grande:}

The Arroyo Grande site is located on land managed by both the Hualapai Nation and Grand Canyon National Park. The area studied there spanned $\sim 250$ $\mathrm{m}$ by $\sim 70 \mathrm{~m}$; the nearest side-canyon tributaries enter the Colorado River $>1 \mathrm{~km}$ upstream and $300 \mathrm{~m}$ downstream of the study area (Fig. 2c). A large eddy is present on river left in the Arroyo Grande area even at non-flood stage. An arroyo system up to $5 \mathrm{~m}$ deep has incised two levels of pre-dam alluvial terraces in this area (the arroyo is shown in Fig. 2c and is indicated by the white arrow in Fig. 14). Aeolian coppice dunes, most of which are now relatively inactive with cryptogamic crust and sparse vegetation, are present on the terraces. Terrace surfaces are deflated, indicated by development of pedestals holding pebbles and cultural artifacts at heights up to $5 \mathrm{~cm}$ above the surrounding land surface. Four archaeological-site complexes are present in alluvial-terrace and tributarydelta regions of the Arroyo Grande area. The largest of these, Site G:03:064, is 
affected by the arroyo. This site contains 15 documented cultural features on the land surface with several additional features exposed within arroyo walls.

Colorado River flood deposits dominate the stratigraphic record around the extensive archaeological site G:03:064 at Arroyo Grande. Profiles within the upper terrace (Fig. 2c) showed the proportion of fluvial sediment generally increasing toward the river. The record of flood deposition is best preserved in sedimentary profiles closest to the river, with 15 individual flood events evident in one profile (Draut and others, 2005). All profiles showed evidence of subaerial reworking and incorporation of colluvial and slope-wash sediment between floods. The repeated occurrence of fluvial deposits overlain by subaerial sediment led to the description of a 'flood couplet' facies consisting of a lower fluvial and upper subaerial member (Draut and others, 2005). Bioturbation and the presence of lithic clasts in the upper parts of flood couplets (derived from the local gneiss bedrock) indicated reworking of the flood sediment at the land surface. Similar to the Lower Comanche site, channel-fill deposits exposed at Arroyo Grande indicate multiple episodes of gully formation and filling during past subaerial exposure. Aeolian sediment constituted a relatively minor volume in the measured sections. The most likely sediment source for small, deflated coppice dunes visible on the land surface today is reworking of the extensive fluvial deposits that created the terrace morphology in this area. The aeolian dunes at Arroyo Grande, as at Palisades, can thus be considered to be relict features that formed by in situ aeolian reworking of large, pre-dam flood deposits, and so we define this dune field as a RFS aeolian deposit.

Abundant charcoal and ash material in many strata at Arroyo Grande is most probably attributable to grass fires during times of subaerial exposure. It is likely that these fires were deliberately set by the inhabitants of the area, although lightning strikes could also have caused occasional fires. The Hualapai and Southern Paiute Tribes, both with ancestral ties to the Arroyo Grande region, have cultural traditions that include the deliberate setting of grass fires to initiate seed germination and to prevent other, larger fires from starting (L. Jackson and I. Bullets, oral commun. with L. M. Leap, 2004). The setting of grass fires was 

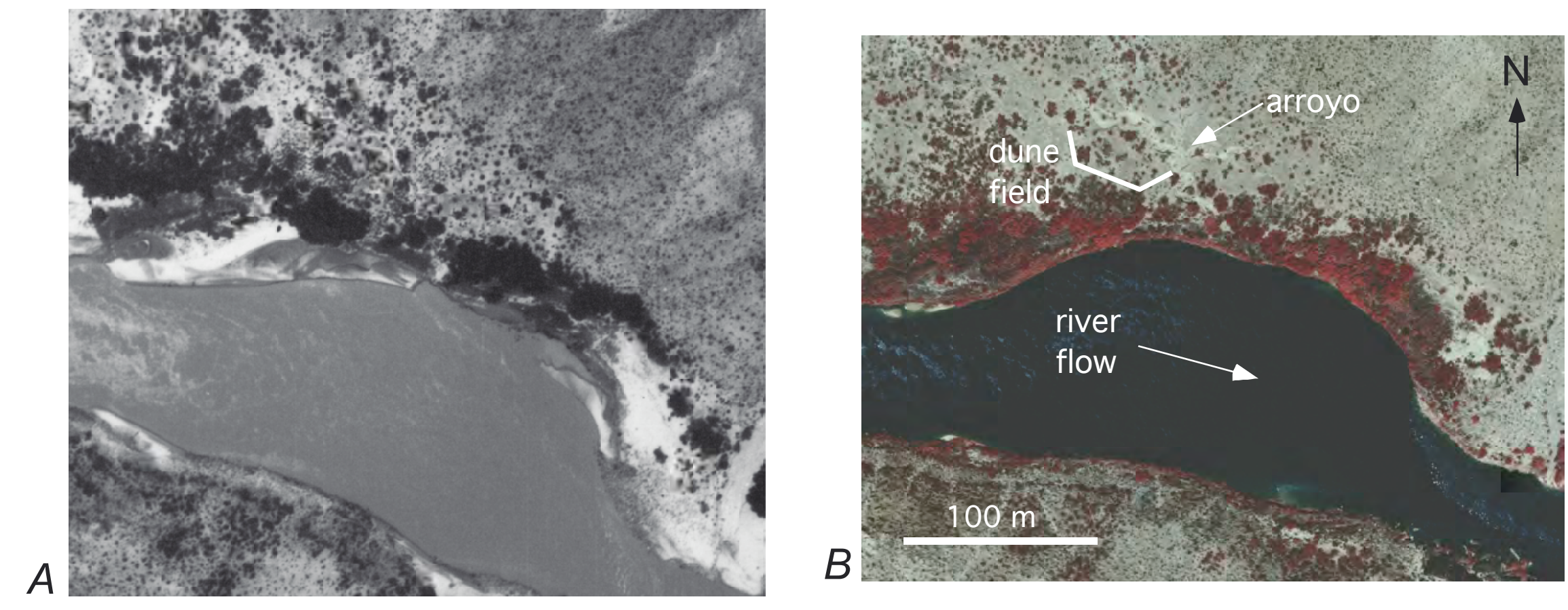

FIGURE 14. Aerial photographs of the Arroyo Grande area in 1965 and 2004. River discharge in the May 1965 photograph (A) is between 680 and $792 \mathrm{~m}^{3} \mathrm{~s}^{-1}\left(24,000-28,000 \mathrm{ft}^{3} \mathrm{~s}^{-1}\right)$. Discharge in the May 2004 photograph (B) is $226 \mathrm{~m}^{3}$ $\mathrm{s}^{-1}\left(8,000 \mathrm{ft}^{3} \mathrm{~s}^{-1}\right)$. Extensive fluvial sand deposits are visible in the riparian zone in the 1965 photographs that are no longer present as open sand areas in the 2004 photo despite the lower river discharge; note also the greatly increased riparian vegetation since 1965. The modern extent of the aeolian dune field, on the downstream (south) side of a small debris fan, is indicated in B. The location of the arroyo is shown (see also Fig. 2c). 
practiced at certain prescribed times of year, and continues today. Other possible reasons for deliberately set fires include hunting and warfare (Powell, 1878; Kelly and Fowler, 1986; Boyd, 1999).

Of the 16 cultural features we examined at Arroyo Grande, 15 are exposed at the land surface (Tab. 3). Fourteen were formed on the surface of the upper terrace, of which seven are located within coppice dunes on the terrace surface. Seven of the 14 features on the terrace surface are partially covered by aeolian sediment. Of the two features not on the upper terrace surface, one was built on colluvium near the landward edge of the terrace and the other, for which no site name or affiliation has been assigned, was exposed within an arroyo wall.

Comparison of aerial photographs taken in 1965 and 2004 shows a substantial decrease in open sandbar area along several hundred meters of the north side of the river channel (river left) in post-dam time, even though the 2004 photographs were taken at much lower flow (Fig. 14). Riparian vegetation has also increased substantially over the same time interval. A stage-discharge relationship was not developed for the Arroyo Grande area but we estimate that a flood of $\sim 5,660 \mathrm{~m}^{3} \mathrm{~s}^{-1}\left(200,000 \mathrm{ft}^{3} \mathrm{~s}^{-1}\right)$, a level last reached in 1884 , would probably inundate the upper terrace (recognizing that stage-discharge relations are episodically altered when debris flows constrict the river channel and cause water to pool upstream of the constriction). Because the Arroyo Grande aeolian dune field is defined as a RFS system based on sedimentary profiles through the dunes and underlying terrace, the post-dam lack of sediment supply to this terrace by floods has removed the major source of sediment to the aeolian dunes as well. Although we do not know the extent to which lower-elevation fluvial sandbars (those at or below the $1,270 \mathrm{~m}^{3} \mathrm{~s}^{-1}\left[45,000 \mathrm{ft}^{3} \mathrm{~s}^{-1}\right]$ stage) contributed wind-blown sand to the dune field in pre-dam time, it is unlikely that any aeolian sediment reaches the dune field from the small river-level sandbars that still exist in this area given the very thick vegetation now separating the sandbars from the dune field. It is therefore unlikely that a high-flow experiment of $1,270 \mathrm{~m}^{3} \mathrm{~s}^{-1}$ $\left(45,000 \mathrm{ft}^{3} \mathrm{~s}^{-1}\right)$ would deposit new sediment that would blow into the aeolian dune field. We believe this to be the case even though the dominant wind direction in 
the Arroyo Grande area was not quantified during this study, because such dense vegetation separates the dune field from the river in essentially any direction. Dominant wind capable of transporting sediment is likely from the east, directed upstream, based on the slip-face orientation of a large, active dune at the eastern edge of the study area (Draut and others, 2005).

\section{RECOMMENDED FUTURE WORK}

In order to evaluate the degree to which the presence and operation of Glen Canyon Dam may influence the stability of archaeological features in the Grand Canyon river corridor, site-specific stratigraphic and geomorphic knowledge is essential. Establishing the local importance of fluvial, aeolian, and other processes in pre-dam and post-dam time is an important prerequisite for accurate assessments of dam effects, and site sensitivity to dam operations must be evaluated on a site-by-site basis because the relative roles of various sedimentation processes differ widely between sites, even comparing sites within the same reach of the river. Future sedimentary and geomorphic studies could assess the sensitivity to dam operations of additional archaeological sites not included in this study. It would be highly informative to include field analysis of vertical sediment profiles such as those conducted here (identifying depositional environments using sedimentary structures) in any future excavation of cultural sites conducted in the river corridor.

The 26 months of wind, precipitation, and sand-transport data collected by this study span a variety of conditions and weather patterns but still are probably not representative of long-term climate in the Grand Canyon region. A quasipermanent weather-monitoring program would allow weather patterns and potential sand-transport measurements to be refined with greater accuracy. To represent weather conditions at high spatial resolution over the entire river corridor in Grand Canyon, many stations would be required. To represent spatial variability of weather in the canyon, a minimum of five (but preferably more) 
stations should be distributed between Lees Ferry and Diamond Creek (river-mile 226; Fig. 1). Although the stations used in this study monitored weather that was directly relevant to archaeological sites (that is, aeolian sand transport and precipitation), longer-term weather monitoring could utilize additional equipment to measure air temperature, relative humidity, barometric pressure, and other variables to generate a broader-scale record of climate in the Colorado River corridor useful for physical, biological, and cultural research. The measured broad spatial variation in rainfall documented during this study indicates that future sedimentary and geomorphic studies in the canyon would benefit substantially from continued or expanded weather monitoring at multiple locations along the river corridor, because rainfall records collected by NPS at Phantom Ranch cannot be considered valid for other areas of the canyon.

Recording climatic data in the river corridor is only one step, however, in resolving the complex geomorphic processes that affect the condition of aeolian deposits, and, by extension, many archaeological sites. The information gathered and presented in this and our other reports could form the basis for a wide array of detailed modeling studies in the future. It is becoming increasingly clear that aeolian transport and deposition of sediment can and do affect the condition of archaeological sites in the river corridor, and that the availability of sediment from open-sand areas on fluvial sandbars is an integral component in these processes. Although transport modeling formed a component of this study (Appendix 1), three further, related, research initiatives are suggested to address these issues in more detail:

1) A detailed aerodynamic modeling study of one or more locations that would involve numerical representation of air flow, including dynamic interactions with obstacles, slope, and irregular spatial boundaries.

2) Construction of a new sand-trap design, currently under development at the USGS in Santa Cruz, CA, that would allow unprecedented temporal resolution of sediment-transport response to specific, short-duration wind conditions. Future research in these two linked directions would 
undoubtedly lead to a better understanding of the aeolian-transport systems that affect natural and cultural resources in Grand Canyon.

3) Because there is an approximately exponential inverse relationship between aeolian sand transport and vegetation cover (Bressolier and Thomas, 1977; Buckley, 1987), studying the response of aeolian transport systems to localized removal of riparian vegetation would be worthwhile. Areas such as the sandbar downstream of the 202.9-mile study site, or along the east bank of the river near Comanche, are possible locations where vegetation removal could promote additional aeolian sand transport given that aeolian dune fields are located nearby and that vegetation cover is known to have increased locally in post-dam time (Figs. 11, 13). To promote wind-blown sand transport effectively, near-complete removal of vegetation would be necessary; wind velocities are negligible near the bed on surfaces with $\sim 40$ percent vegetation cover (Buckley, 1987), and in many riparian areas in Grand Canyon the vegetative cover is much denser than that. Nevertheless, it is recommended that if vegetation-removal projects are conducted in the future, wind and aeolian sand transport should be measured at the work sites for several months, ideally spanning a windy season, before and after vegetation removal to assess its effects. 


\section{CONCLUSIONS}

Aeolian sediment serves as a substrate on which many archaeological sites in the Colorado River corridor were formed (in many locations also associated with fluvial and slope-wash sediment) and, more commonly, as a surficial deposit covering cultural material. Without sufficient aeolian sand, artifacts are exposed by wind deflation of the surrounding sediment, forming a lag deposit on the land surface. Many aeolian dune fields in Grand Canyon show evidence of reduced sediment supply, in the form of cryptogamic crust and vegetation covering relict dune forms. The presence of well developed microbiotic soil crusts and colonization by grasses indicates a lack of sediment deposition and decreased dune mobility, respectively, compared to times in the past when supply and transport of aeolian sand were abundant enough to generate dunes. Dune fields in Grand Canyon with well developed cryptogamic crust and vegetation typically experience an order of magnitude lower aeolian sand-transport rates than those without. Although vegetation and cryptogamic crust limit mobility (migration) of dunes compared to their prior state of sediment abundance, this does not imply that dunes and associated archaeological sites are safe from erosion. Dunes with substantially reduced sediment supply (and with vegetation and soil crust) have insufficient sediment transport and deposition to counteract gully incision, and in these vegetated, cryptogamic-soil-rich dunes large gullies and arroyos cause major erosion and degradation of dunes and archaeological sites.

Reduction in the source areas that provide wind-blown sand to aeolian deposits is evident from comparison of aerial photographs taken in the 1960s with modern images; at the sites studied for this project, many fluvial sandbars are smaller, and riparian vegetation more abundant, now than in 1965. This is consistent with findings of previous studies in many other areas of the river corridor (Turner and Karpiscak, 1980; Beus and others, 1985; Schmidt and Graf, 1987; Kearsley and others, 1994; Leschin and Schmidt, 1995; Hazel and others, 1999; Schmidt and others, 2004). 
Exposure at the land surface leaves cultural material vulnerable to erosion by gully incision. We view the problem of archaeological-site preservation as essentially a competition between two processes: precipitation runoff, which creates gullies that erode into sediment deposits, and aeolian sand transport, which fills in small gullies inhibiting their growth (gullies act as natural traps for wind-blown sand). The ability of aeolian sand transport to counteract gully formation and to heal small gullies ( $<1 \mathrm{~m}$ wide and deep) is a major factor controlling geomorphic evolution of Grand Canyon sediment deposits. Areas that had heavy rainfall but high sand-transport rates during this study can be absent of gullies (which form episodically but are quickly filled by wind-blown sand) whereas areas that had low precipitation and little aeolian sand transport during this study have been eroded substantially by gullies and arroyos, destabilizing archaeological sites. Although many factors (long-term climatic fluctuations, drainage-basin geometry, substrate composition, and effective base level) contribute to gully formation, we infer that the arroyo incision would not have progressed as far as it has in some areas if aeolian sand-transport rates were significantly greater. For example, several kilometers upstream of the deeply incised Palisades terrace, gullies are typically absent from the Malgosa dune field - a site that, during this study, had twice the rainfall but ten times the aeolian sand-transport rates of Palisades.

Two types of aeolian deposits occur in the Grand Canyon river corridor, defined by relative locations of aeolian deposits, nearby fluvial sandbars, and the locally dominant sediment-transport direction. Modern Fluvial Sourced (MFS) deposits formed as the wind transported sand inland from a river-level sandbar, creating an aeolian dune field downwind; Relict Fluvial Sourced (RFS) deposits formed by in situ wind reworking of pre-dam flood deposits. Aeolian deposits of both types are known to contain archaeological material. Both MFS and RFS aeolian deposits are sensitive to dam operations, but for different reasons. Changes in open, dry fluvial sandbar area and dimensions (a function of dam operations) affect the transport of aeolian sand to MFS dune fields downwind; we have defined criteria that can be used to judge the sensitivity of particular 
archaeological sites within MFS deposits to dam operations. RFS deposits comprise the uppermost, wind-reworked part of pre-dam terraces that are largely alluvial in composition, containing sediment deposited by flows up to and exceeding $5,660 \mathrm{~m}^{3} \mathrm{~s}^{-1}\left(200,000 \mathrm{ft}^{3} \mathrm{~s}^{-1}\right)$. Because sediment-rich floods of that magnitude do not occur in this regulated river, fluvial deposits from which RFS aeolian dune fields formed no longer constitute an active sediment source; no substantial new deposition is likely to occur on RFS dune fields as long as the lack of large, sediment-rich floods continues.

Management of Glen Canyon Dam operations affects aeolian sand transport in the Colorado River corridor through Grand Canyon. The size and number of fluvial sandbars from which wind remobilizes sand can be increased using controlled, sediment-rich flows on the order of $1,270 \mathrm{~m}^{3} \mathrm{~s}^{-1}\left(45,000 \mathrm{ft}^{3} \mathrm{~s}^{-1}\right)$, with the result that wind-blown sand transport can significantly increase in the vicinity of new flood deposits and that new flood sand can be transported by wind to elevations above the flood stage, replenishing sediment in MFS aeolian deposits. All of those processes were documented during this study following the November $20041,160 \mathrm{~m}^{3} \mathrm{~s}^{-1}\left(41,000 \mathrm{ft}^{3} \mathrm{~s}^{-1}\right)$ high-flow experiment. It is important, however, that if enhancing wind-blown sand transport to aeolian dune fields (thereby increasing the protective cover on associated archaeological sites) is one of the management goals of controlled high flows, post-flood dam operations must be used to maximize the size and number of fluvial sandbars during the spring windy season, between April and early June, when aeolian sand-transport rates are $\sim 5-15$ times greater than in other seasons. Following the November 2004 high flow, newly deposited sandbars were eroded substantially by daily flow fluctuations of 142-566 $\mathrm{m}^{3} \mathrm{~s}^{-1}\left(5,000-20,000 \mathrm{ft}^{3} \mathrm{~s}^{-1}\right)$ between January and March 2005 , before the spring windy season began. Sandbar erosion by high daily flow fluctuations thus removed much of the sand that was potentially available for aeolian redistribution, limiting the benefits of the 2004 flood for archaeological resources. Because high fluctuating flows export approximately twice as much fluvial sand as under Modified Low Fluctuating Flow (MLFF) operations of Glen Canyon Dam, more aeolian sand would be available to be blown inland (to MFS 
dune fields and the archaeological sites within them) if sediment-rich high flows were followed by low fluctuating flows rather than by high daily fluctuations. Operating under low fluctuating flows or steady low flow between the end of a controlled high flow and the start of spring high winds is predicted to retain much more of the post-flood sandbar area until the next spring windy season when wind can transport sand into aeolian deposits above the flood-stage elevation.

Although preservation of artifacts in the Colorado River corridor on geologic time scales is unrealistic due to continual downcutting and backwasting of this bedrock canyon, tens to hundreds of archaeological sites in Grand Canyon could be better preserved on decadal to century time scales by restoring fluvial and aeolian sedimentation to resemble more closely those processes that occurred before the river was regulated by upstream dams, including sedimentrich floods that left fluvial deposits from which sediment was remobilized by wind. 


\section{ACKNOWLEDGEMENTS}

This study has been supported by funding from the U.S. Bureau of Reclamation, through the Grand Canyon Monitoring and Research Center (GCMRC) and is a cooperative effort with the National Park Service (NPS). The following people are thanked for their collaboration at many stages of this project: J. Balsom, M. Barger, K. Burnett, S. Davis, B. Dierker, J. Dierker, J. Draut, H. Fairley, C. Fritzinger, A. Fuller, S. Goeking, guides and students from Grand Canyon Youth, R. Griffiths, J. Grissom, D. Harris, G. Hatcher, J. Hazel, S. Hueftle, R. Hunter, L. Jackson, S. Jones, M. Kaplinski, K. Killoy, J. Logan, T. Melis, F. Nials, M. Piller, S. Reeder, M. Rubin, J. Running, T. Sabol, E. Todd, D. Topping, R. Tusso, N. Voichick, S. Wright, S. Wyse Mietz, M. Yeatts. D. Sherman (Texas A\&M University) provided shear-velocity values for two of the aeolian transport models listed in Appendix 1. J. Johnson and R. McDonald are thanked for their valuable reviews of this manuscript. R. Hereford and R. Hunter are also thanked for their comments and discussion of this report. 


\section{APPENDIX 1: Evaluation of Aeolian Sediment-Transport Models: Can Supply Limitation be Discerned?}

An outstanding question remains regarding the evolution of aeolian sediment deposits in the Colorado River corridor of Grand Canyon: to what extent has the sediment supply to individual sand deposits been limited by Glen Canyon Dam operations? Aeolian sand supply has always been somewhat restricted by confinement within this bedrock canyon-dune fields can become only so large before they encounter canyon walls, the river, substantial accumulations of talus, and other spatial limitations. It is apparent from this study, however, that aeolian sediment supply is now more limited than in pre-dam time because wind-blown sediment transport to at least some aeolian deposits (particularly of the MFS variety) increases or decreases in response to changes in fluvial sandbar area upwind, and dam operations are known to have reduced the size and number of fluvial sandbars overall.

We wanted to investigate whether it is possible to use aeolian sedimenttransport models (established empirically through field and wind-tunnel experiments) to discern sediment-supply limitation from field measurements of wind and sand transport. If the modeled transport under given wind conditions closely matches measured transport during those conditions in a field setting where sediment supply is not limited by sand availability, soil crusts, vegetation, or bed roughness, it may be possible to infer sediment-supply limitation in other

field settings where the same models consistently over-predict measured sand transport. In that case, the inferred sediment-supply limitation could be caused by 
one or more factors (lack of sand availability, soil crusts, vegetation, or bed roughness) and further work would be necessary to back out which of the possible causes were relevant. The experiments discussed in this Appendix were conducted as part of the Grand Canyon aeolian sedimentation study but involved field work in the Dumont Dunes, southern Death Valley, California, as well as in Grand Canyon.

Eight models of aeolian sediment transport were tested through a field experiment in a desert environment in the absence of factors such as vegetation, limited sand area, and soil moisture, which may affect comparable studies conducted in coastal sand dunes. Comparison of measured sand flux with transport predicted by the tested models indicates that although models may perform better in this field setting where sources of uncertainty have been minimized, in general the models did not yield results accurate enough to suggest their potential use in determination of sediment-supply limitation. We believe this to be in part a function of the limited range of wind velocities that occurred during the field experiment. Subsequent high-resolution tests on the Malgosa dune field (river-mile 57.9, Grand Canyon) provided a greater range of wind velocities, but there the physically more complex setting (canyon walls, vegetation, steeply sloping dune face) were such that the results cannot be considered to have been obtained under simple, supply-unlimited conditions, as was the case at the Dumont Dunes site. This remains a topic that could benefit from further study; multiple avenues of environmental management could benefit from deterministic transport models through which the effect of a limited sediment supply could be quantified.

\section{INTRODUCTION}

Quantification and prediction of sediment transport by wind is a primary focus of many geological and agricultural studies. An accurate understanding of 
the movement of sand and dust by aeolian processes has widespread practical implications for predicting landform evolution, erosion of agricultural areas, and guiding environmental management of coastal and desert regions. Numerous studies, beginning with Bagnold (1941), have devised empirical relations between wind conditions and resulting sediment motion; this and other transport equations have been developed and tested in wind-tunnel and field settings with the goal of being utilized as predictive models.

Many comparative studies have indicated that the application of commonly cited aeolian transport models to field settings is problematic, however, and that measured sediment flux may vary substantially from that predicted by models (Hunter and others, 1983; Berg, 1983; Sarre, 1988, 1989; Bauer and others, 1990, 1996; Goldsmith and others, 1990; Sherman and Hotta, 1990; Sherman and others, 1998; Craig, 2000). Assessment of discrepancies between predicted and measured aeolian transport rates prompted Chapman (1990) and Bauer and others (1996) to suggest that field-based aeolian sediment-transport investigations suffer from inherent problems of indeterminacy, due to the great number of physical factors affecting such complex systems relative to the number of variables represented in current transport equations. Studies of sand transport on coastal dunes have identified complications of transport prediction such as vegetative cover, soil moisture, topographic slope, variable sediment composition and grain size, presence of salt crystals in sand, and variations in sand-source area due to tidal fluctuations and runnel development.

One approach to field studies in a discipline prone to complications of indeterminacy, as proposed by Bauer and others (1996), is to minimize uncertainty by focusing on systems that have been simplified to the greatest degree possible. By eliminating or minimizing variables that are known to exacerbate uncertainties in such transport investigations, the predictive capability of standard transport equations can be most accurately assessed. Recognizing that it may never be possible to entirely eliminate sources of uncertainty, we 
chose to test eight aeolian transport models in a desert sand-sheet environment where the complications mentioned above are absent or minimal. In doing so, we evaluate whether the models used in this study show sufficient predictive value to be utilized in future assessment of sediment-supply limitation.

\section{Sediment-Supply Limitation:}

Existing transport equations were developed under the assumption that sand transport will be limited by wind conditions (velocity, and therefore bed shear stress necessary to mobilize sediment). Sediment transport and erosion

processes are commonly affected by limitations in sediment supply, however, a factor not incorporated into current models (Leys, 1999). Three implications arise from this: (1) the predictive capability of current aeolian transport models will decrease as a given sediment source diminishes by erosion over time; (2) discrepancies between measured and predicted sediment flux may in some cases be attributable to limited availability of sediment for transport; (3) it may be possible to identify and quantify limitation in the amount of available sediment from such discrepancies. This investigation was motivated by (2) and (3) above. By first evaluating the predictive power of existing transport models in a supplyunlimited desert setting unaffected by variables that can influence transport rates measured elsewhere, we evaluate the potential use of these models for determining the degree to which sediment supply is limited.

\section{Aeolian Transport Models Tested:}

Most commonly used sediment-transport models incorporate a shear velocity parameter, $u_{*}$, which is defined as a function of shear stress $\left(u_{*}^{2}=\tau / \rho\right.$, where $\tau$ is boundary shear stress and $\rho$ the fluid density). Wind-velocity profiles are typically used to calculate shear velocity using the Karman-Prandtl equation, or 'law of the wall': 


$$
u(z)=\frac{u_{*}}{\kappa} \ln \left(\frac{z}{z_{0}}\right)
$$

in which $u(z)$ is the wind velocity at elevation $z, \kappa$ is the von Karman constant (taken to be 0.4 ) and $z_{0}$ is the roughness length of the sand surface. Shear velocity is considered relative to a critical threshold of motion represented by the shear velocity $u_{*}$, given by Bagnold (1941) as:

$$
u_{* t}=A_{t} \sqrt{\frac{\rho_{s}-\rho}{\rho} g d}
$$

in which $A_{t}$ is a dimensionless constant equal to 0.1 for the initiation of saltation (Bagnold's fluid threshold), $\rho_{s}$ and $\rho$ are the densities of quartz sediment and air respectively $\left(2650 \mathrm{~kg} \mathrm{~m}^{-3}\right.$ and $\left.1.2 \mathrm{~kg} \mathrm{~m}^{-3}\right), \mathrm{g}$ is gravitational acceleration $\left(9.8 \mathrm{~m} \mathrm{~s}^{-}\right.$ ${ }^{2}$ ) and $d$ is the sediment grain diameter in meters.

Table 4 lists the eight aeolian transport models evaluated during this study. The empirical models of Bagnold (1941) and Zingg (1953), derived from wind-tunnel studies, are of the same form but differ in the constant and exponent. Kawamura (1951), a model also based on wind-tunnel experiments, first incorporated the threshold shear velocity $u_{* t}$ into an aeolian transport model. The Lettau and Lettau (1977) and White (1979) models, and the Sørensen (1991) equation, the derivation of which incorporated sand-grain trajectories and grainbed collision processes, also use threshold shear-velocity terms. With the exception of Lettau and Lettau (1977), equations of this form do not require a separate term for grain size because $u_{* t}$ is itself a function of particle diameter. Hsu (1971; see also Hsu, 1973) used a modified Froude number (of the form $\left.u /(g d)^{n}\right)$ to express sediment transport rate. Among these eight models, the Williams (1964) model alone describes $q$ (sediment flux) as a linear function of $u *$ 


\begin{tabular}{|c|c|c|}
\hline Reference & Expression for sand transport rate & $\begin{array}{l}\mathrm{u} * \text { range } \\
\left(\mathrm{m} \mathrm{s}^{-1}\right)\end{array}$ \\
\hline Bagnold (1941) & $q=1.8 \sqrt{\frac{d}{D}} \frac{\rho}{g} u_{*}^{3}$ & $0.6-1.8$ \\
\hline Kawamura (1951) & $q=2.78 \frac{\rho}{g}\left(u_{*}-u_{*_{t}}\right)\left(u_{*}+u_{*_{t}}\right)^{2}$ & N/A \\
\hline Zingg (1953) & $q=0.83\left(\frac{d}{D}\right)^{0.75} \frac{\rho}{g} u_{*}^{3}$ & $0.35-1.06$ \\
\hline Williams (1964) & $q=4.066 \frac{\rho}{g} u_{*}$ & $0.4-1.35$ \\
\hline Hsu (1971) & $q=10^{-4} e^{4.79 d-0.47} \frac{u_{*}^{3}}{(g d)^{1.5}}$ & $0.05-0.8$ \\
\hline Lettau and Lettau (1977) & $q=4.2 \sqrt{\frac{d}{D}} \frac{\rho}{g}\left(u_{*}-u_{* t}\right) u_{*}^{2}$ & N/A \\
\hline White (1979) & $q=2.61 u_{*}^{3}\left(1-\frac{u_{* t}}{u_{*}}\right)\left(1+\frac{u_{* t}^{2}}{u_{*}^{2}}\right) \frac{\rho}{g}$ & $0.9-1.7$ \\
\hline Sørensen (1991) & $q=10^{-4} \rho u_{*}\left(u_{*}-u_{*_{t}}\right)\left(u_{*}+7.6 u_{* t}+205\right)$ & $0.2-0.6$ \\
\hline
\end{tabular}

TABLE 4. Aeolian sand-transport models tested in Dumont Dunes (Death Valley, $C A)$ and Malgosa (Grand Canyon); third column lists shear velocities for which the models were developed. In the equations, $d$ is grain diameter in meters, $D$ is a reference grain diameter for $250 \mu$ sand, in meters, $u_{*}$ is shear velocity, $u_{*}$ is threshold shear velocity for motion of the grain size considered, $\rho_{s}$ and $\rho$ are the densities of sediment and air respectively (taken to be $2650 \mathrm{~kg} \mathrm{~m}^{-3}$ and $1.2 \mathrm{~kg} \mathrm{~m}^{-}$ $\left.{ }^{3}\right), g$ is gravitational acceleration $\left(9.8 \mathrm{~m} \mathrm{~s}^{-2}\right)$. In the Williams (1964) formula, the constant is represented as the multiple of two constants obtained for $330 \mu$ sand, slightly coarser than the $306 \mu$ in this study. Sand flux, q, is expressed in all models as a mass of sand passing through unit width in unit time $\left(\mathrm{kg} \mathrm{m}^{-1} \mathrm{~s}^{-1}\right)$. For comparison to field data, $q$ values were adjusted to reflect the $10 \mathrm{~s}$ averaging interval of wind data, and the $0.02 \mathrm{~m}$ width of the BSNE sand traps used. The Bagnold (1941) model was derived from wind-tunnel data and tested in desert dunes. Kawamura (1951), Zingg (1953), Williams (1964), and White (1979) models were derived from wind-tunnel data. The Hsu (1971) and Lettau and Lettau (1977) models are based on field studies on beaches. Sørensen (1991) gives an analytically derived model tested in wind-tunnel experiments. 
Several models exist that do not depend upon shear velocity (for example, Kadib [1965], which uses a normally distributed transport intensity function, and O'Brien and Rindlaub [1936] which does not include a grain-size term but depends solely on the cube of wind velocity measured at $1.52 \mathrm{~m}$ ). We restricted this analysis to those in Table 4 because the Kadib (1965) model has been found less reliable than equations that rely on $u_{*}$, particularly at high wind speeds (Sarre, 1988; Sherman and others, 1998) and because the shear-velocity term represents flow characteristics (shear affecting the bed, which determines sediment motion) independent of the height of measurement.

\section{METHODS}

An experiment was conducted in the Dumont dune field at the southern end of Death Valley in the Mojave Desert, California. The dune field occupies $\sim 20 \mathrm{~km}^{2}$ and contains central star dunes up to $120 \mathrm{~m}$ tall, with lower barchan and linear dunes at its margins (McDonald, 1970; Nielson and Kocurek, 1987). A sand sheet at its northern edge provides an ideal location to collect sandtransport data in an area unaffected by vegetation or other bed-roughness elements (other than wind ripples, footprints, and vehicle tracks all $<10 \mathrm{~cm}$ high). Instruments were located in a relatively flat area to minimize the effect of surface slope on wind velocity. Soil moisture was not detected in the surface sediment and is usually negligible in this arid environment.

A test was conducted at Dumont Dunes in late February-early March 2004 during a 16-hour interval. Wind velocity was measured using three spinning-cup anemometers mounted on an instrument tripod at heights of 2.0, 1.0, and $0.3 \mathrm{~m}$ and connected to a data logger (Fig. 15). Mean wind velocity, maximum gust velocity, and mean wind direction were measured with a $1 \mathrm{~Hz}$ sampling interval and recorded as 10 -second averages. This sampling strategy used the shortest averaging interval over which statistical reliability of shear 


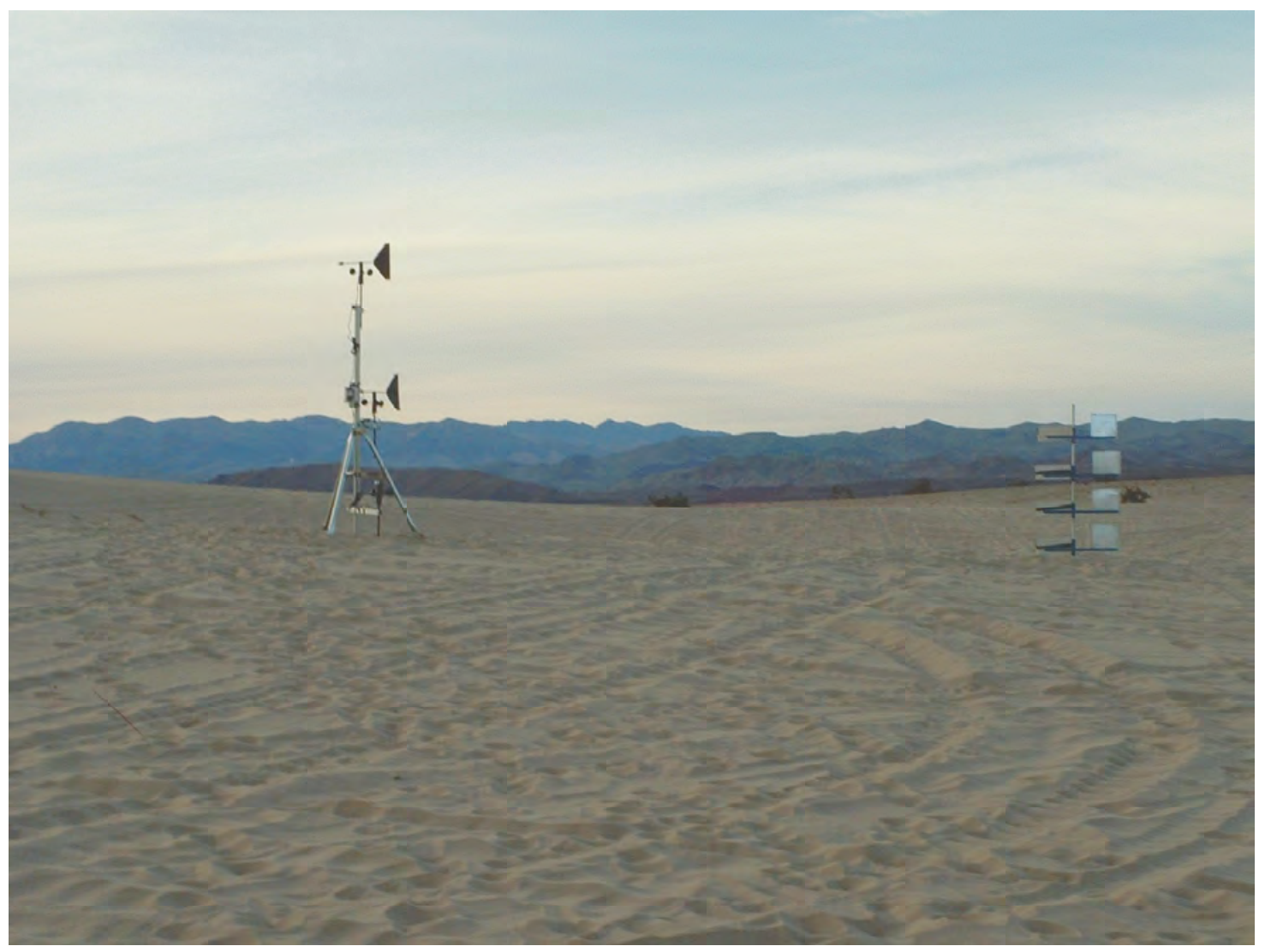

FIGURE 15. Photograph showing the location of the experiment at Dumont Dunes, Death Valley, CA. At left is a tripod on which three anemometers (at heights of $2.0 \mathrm{~m}, 1.0 \mathrm{~m}$, and $0.3 \mathrm{~m}$ ) and a data logger were mounted; on the right are four sand traps at heights $1.0 \mathrm{~m}, 0.7 \mathrm{~m}, 0.4 \mathrm{~m}$, and $0.1 \mathrm{~m}$. The surrounding sand sheet is free of vegetation and nonerodible obstacles such as rocks, and has very little slope for tens of meters in any direction. 
velocity measurements can be retained (Namikas and others, 2003; see also Anderson and others, 1991).

An array of sand traps was set up $\sim 5 \mathrm{~m}$ from the anemometer tripod to collect wind-blown sand (see Zobeck and others, 2003). Four BSNE sand traps (Fryrear, 1986) were mounted on a vertical pole; these traps are equipped with vanes to turn them into the wind. Sand trap heights were set at 1.0, 0.7, 0.4, and $0.1 \mathrm{~m}$ (Fig. 15). Air temperature was measured at 2.0 and $0.3 \mathrm{~m}$ to evaluate local atmospheric instabilities caused by insolation heating, which may affect velocity profiles (Rasmussen and others, 1985; Lancaster and others, 1991; Frank and Kocurek, 1994). The measured temperature gradient was minor as heavy cloud cover limited direct solar heating during the study. Because vertical motion of air due to such instabilities is negligible relative to lateral motion at wind speeds high enough to generate sediment transport (G. Kocurek, pers. comm., 2004; N. Lancaster, pers. comm., 2004) this factor is not considered further here.

The total sand mass collected from each trap during the experiment was weighed. Mass-transport rates were calculated by integration of a curve fit to the mass-vs.-height data. The curve-fitting procedure uses a five-parameter combined power-law and exponential function, as this has been shown to model vertical aeolian mass flux more accurately than either power or exponential fits alone (Sterk and Raats, 1996). Grain size analysis of surface sand at the Dumont Dunes instrument site by Coulter counter yielded a $d_{50}$ value of $305.8 \mu$ (an average of six analyses), which (from Equation 2) gives $u_{* t}$ equal to 0.257 . Sand in the upper part of the Malgosa dune field was similar, yielding a $d_{50}$ value of $312.9 \mu$ (an average of four analyses) and thus $u_{* t}$ is equal to 0.260 . Using these threshold shear velocities, cumulative values of sand flux were predicted from wind measurements using the eight models outlined in Table 4 and were then compared with the measured sand flux.

In May 2004, a similar experiment was conducted during two days of high winds at the Malgosa dune field, river-mile 57.9, Grand Canyon. Equipment at 
one of the weather stations in use at that site (Station Mal U; Draut and Rubin, 2005,2006 ) was refitted to match the configuration used in the Dumont Dunes experiment, with anemometers at heights of 2.0, 1.0, and $0.3 \mathrm{~m}$, BSNE sand traps at $1.0,0.7,0.4$, and $0.1 \mathrm{~m}$, and the data logger recording with a $1 \mathrm{~Hz}$ sampling interval and 10-second averaging interval (as opposed to 4-minute averaging during normal operation of that weather station). Two trials were conducted at Malgosa on May 11 and 12, respectively; sand traps were emptied at the end of each of those tests.

\section{RESULTS}

Table 5 compares predicted and measured sediment flux for each of the eight models evaluated in the trial at Dumont Dunes and both trials at Malgosa. In the 16-hour Dumont Dunes experiment, mean sustained winds recorded at 2.0 $\mathrm{m}$ (averaged over 10-second intervals) were $3.6 \pm 1.6 \mathrm{~m} \mathrm{~s}^{-1}$ with gusts up to 10.8 $\mathrm{m} \mathrm{s}^{-1}$. The actual mass flux is considered to span an efficiency range of $105-115 \%$ for the BSNE traps with the grain size at Dumont Dunes and the wind speeds measured (Goossens and others, 2000). In the first trial at Malgosa, which lasted seven hours, mean sustained winds recorded at $2.0 \mathrm{~m}$ were $5.8 \pm$ $3.2 \mathrm{~m} \mathrm{~s}^{-1}$ with gusts up to $20.8 \mathrm{~m} \mathrm{~s}^{-1}$. In the second trial at Malgosa, which lasted 14.5 hours, mean sustained winds at $2.0 \mathrm{~m}$ were $3.1 \pm 1.9 \mathrm{~m} \mathrm{~s}^{-1}$ with gusts up to $13.7 \mathrm{~m} \mathrm{~s}^{-1}$. Mass flux during both high-resolution experiments at Malgosa was considered to span an efficiency range of $95-115 \%$ for the BSNE traps with the available sand size and the wind speeds measured during the two trials (Goossens and others, 2000) $)^{2}$. Figure 16 shows histograms of $u_{*}$ values calculated for the entire duration of each experiment.

\footnotetext{
${ }^{2}$ Sand traps would ideally be isokinetic (100\% efficiency), meaning that the trap would not disrupt air flow around it and would thus capture $100 \%$ of the sediment locally in transport per unit width. No perfectly isokinetic sand traps have yet been designed. If a trap is found to operate at $<100 \%$ efficiency, air is being diverted around (away from) the trap orifice and the amount of sediment captured by the trap thus under-represents the amount of sediment locally in transport. A trap
} 
The Kawamura (1951) model predicts cumulative sediment flux that most closely approximates the measured transport during the test at Dumont Dunes. Three models were found to overpredict sediment transport in that trial: Bagnold (1941) by a factor of $\sim 1.5$ to 1.7 (given the sand trap efficiency range), the Hsu (1971) model that uses a modified Froude number (by a factor of more than two) and the Williams (1964) model (by more than one order of magnitude). The remaining four models underpredicted the observed sediment flux. Zingg (1953) gives predicted transport that is $\sim 75$ to $82 \%$ of the measured amount. The Lettau and Lettau (1977) and White (1979) equations performed similarly, indicating $43 \%$ to $50 \%$ of the measured transport. The Sørensen (1991) model predicted only 25 to $28 \%$ of the sand flux measured at Dumont Dunes.

In the first trial at Malgosa, in which the absolute sand transport over the experiment duration was two orders of magnitude greater than in the Dumont Dunes trial, sand-flux predictions made by the models performed generally with similar accuracy as in the experiment at Dumont Dunes though with a greater tendency toward over-prediction (Table 5). The model that most closely approximated measured transport in Test 1 at Malgosa was that of Zingg (1953), which yielded $\sim 84-101 \%$ of the measured sand transport, given a sand-trap efficiency of $95-115 \%$. The Kawamura (1951) model, which had best predicted the Dumont Dunes data, over-predicted sand transport in the first Malgosa test by a factor of $2.5-3$. In the second Malgosa trial, during which total sand transport was intermediate between the amounts measured at Dumont Dunes and in the first Malgosa experiment (order $100 \mathrm{~g}$ ), all models greatly overpredicted aeolian sand transport.

operating at $>100 \%$ efficiency is causing diversion of air flow into the trap, thus over-representing the amount of sediment locally in transport per unit width. 
TABLE 5. Comparison of modeled sand flux with sand flux measured using sand traps during high-resolution experiments at Dumont Dunes and Malgosa. Measured sand transported is given for each test as an integrated value for height 0-1 m, along with modeled flux predicted from wind data measured at 10second intervals. Modeled fluxes in $\mathrm{kg} \mathrm{m}^{-1} \mathrm{~s}^{-1}$ have been adjusted to account for the 10-second logging interval and the 0.02-m width of sand trap orifices. Values are indicated for the possible range of measured sand flux given the efficiency range of BSNE sand traps (105-115\% for the grain size and the wind velocity range during the study in Dumont Dunes, and 95-115\% for the Malgosa trials; Goossens and others, 2000).

\begin{tabular}{|l|c|c|c|}
\hline Dumont Dunes & Measured & $\begin{array}{c}\text { 105\% Trap } \\
\text { Efficiency }\end{array}$ & $\begin{array}{c}115 \% \text { Trap } \\
\text { Efficiency }\end{array}$ \\
\hline Measured transported sand (g) & 61.8 & 58.9 & 53.7 \\
\hline $\begin{array}{l}\text { Ratio of Predicted: Measured } \\
\text { Sediment Flux }\end{array}$ & & & \\
\hline Bagnold (1941) & 1.47 & 1.54 & 1.69 \\
\hline Kawamura (1951) & 0.856 & 0.898 & 0.985 \\
\hline Zingg (1953) & 0.712 & 0.747 & 0.819 \\
\hline Williams (1964) & 34.9 & 36.6 & 40.2 \\
\hline Hsu (1971) & 2.29 & 2.41 & 2.64 \\
\hline Lettau and Lettau (1977) & 0.430 & 0.452 & 0.495 \\
\hline White (1979) & 0.406 & 0.426 & 0.467 \\
\hline Sørensen (1991) & 0.241 & 0.253 & 0.277 \\
\hline
\end{tabular}

\begin{tabular}{|l|c|c|c|}
\hline Malgosa, Test 1 & Measured & $\begin{array}{c}95 \% \text { Trap } \\
\text { Efficiency }\end{array}$ & $\begin{array}{c}115 \% \text { Trap } \\
\text { Efficiency }\end{array}$ \\
\hline Measured transported sand (g) & 2770 & 2910 & 2400 \\
\hline $\begin{array}{l}\text { Ratio of Predicted: Measured } \\
\text { Sediment Flux }\end{array}$ & & & \\
\hline Bagnold (1941) & 1.82 & 1.73 & 2.09 \\
\hline Kawamura (1951) & 2.58 & 2.45 & 2.96 \\
\hline Zingg (1953) & 0.880 & 0.840 & 1.01 \\
\hline Williams (1964) & 17.3 & 16.4 & 19.8 \\
\hline Hsu (1971) & 2.85 & 2.70 & 3.27 \\
\hline Lettau and Lettau (1977) & 1.99 & 1.89 & 2.29 \\
\hline White (1979) & 1.38 & 1.31 & 1.59 \\
\hline Sørensen (1991) & 0.620 & 0.590 & 0.710 \\
\hline
\end{tabular}




\begin{tabular}{|l|c|c|c|}
\hline Malgosa, Test 2 & Measured & $\begin{array}{c}\text { 95\% Trap } \\
\text { Efficiency }\end{array}$ & $\begin{array}{c}115 \% \text { Trap } \\
\text { Efficiency }\end{array}$ \\
\hline Measured transported sand (g) & 183 & 193 & 160.0 \\
\hline $\begin{array}{l}\text { Ratio of Predicted: Measured } \\
\text { Sediment Flux }\end{array}$ & & & \\
\hline Bagnold (1941) & 48.6 & 46.2 & 55.9 \\
\hline Kawamura (1951) & 63.0 & 59.8 & 72.4 \\
\hline Zingg (1953) & 23.6 & 22.4 & 87.5 \\
\hline Williams (1964) & 603 & 574 & 694 \\
\hline Hsu (1971) & 76.1 & 72.3 & 87.5 \\
\hline Lettau and Lettau (1977) & 42.6 & 40.5 & 49.0 \\
\hline White (1979) & 32.0 & 30.4 & 36.8 \\
\hline Sørensen (1991) & 16.3 & 15.5 & 18.7 \\
\hline
\end{tabular}




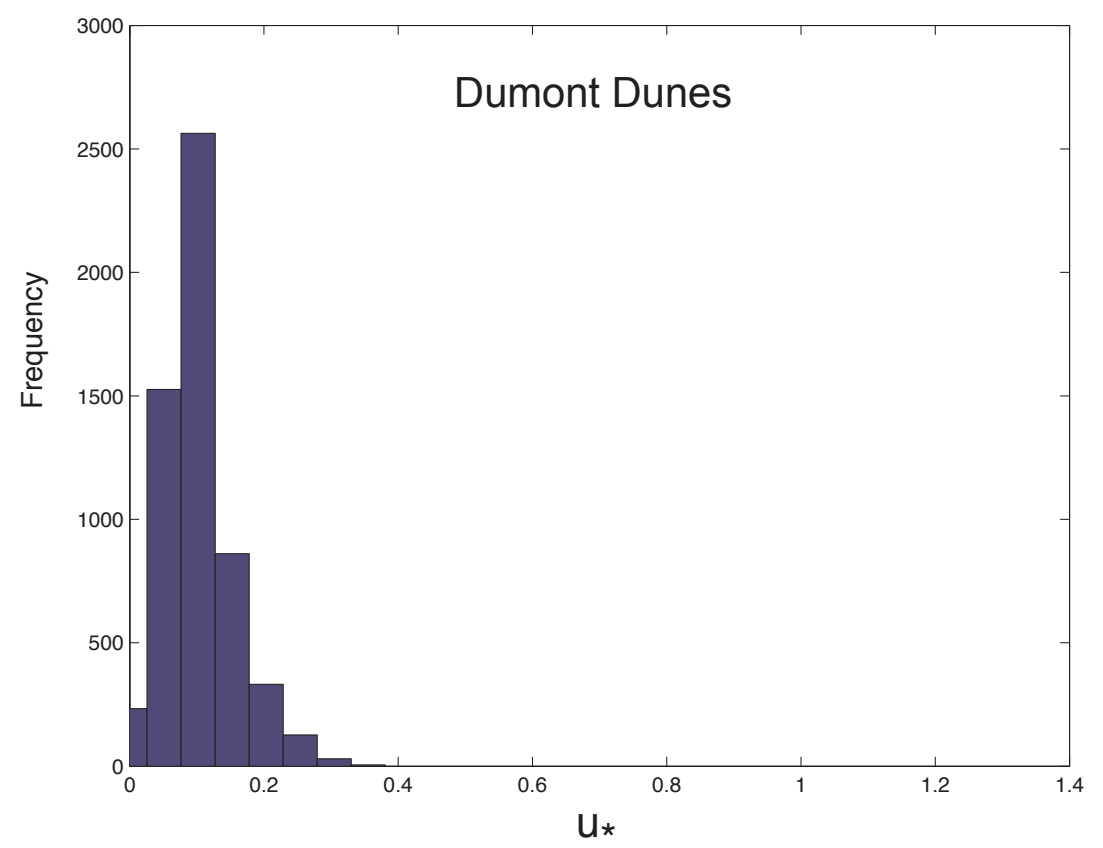

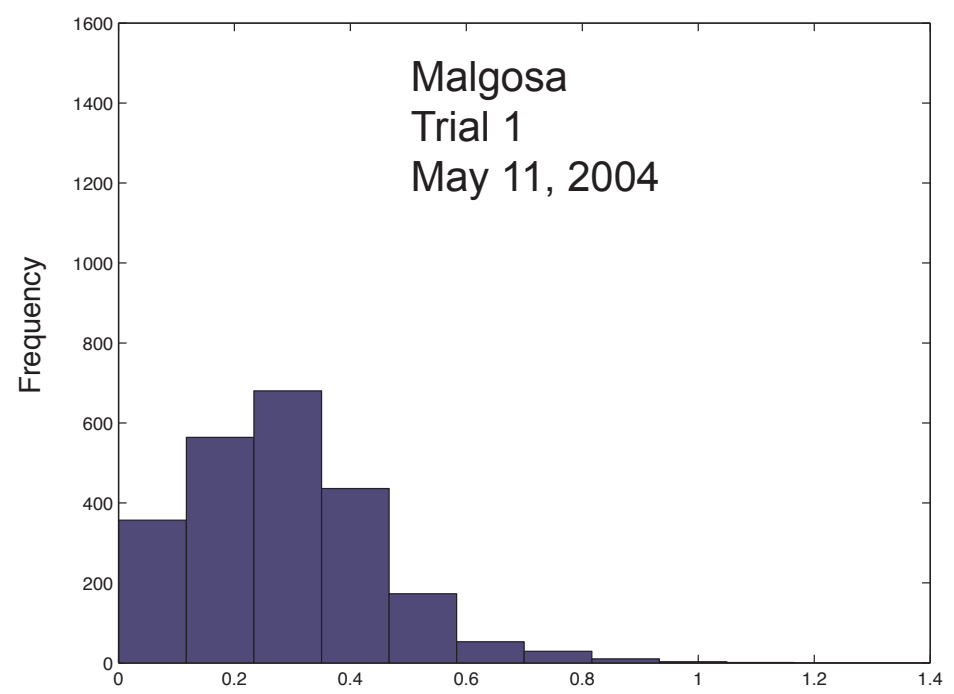

$\mathrm{u}_{*}$

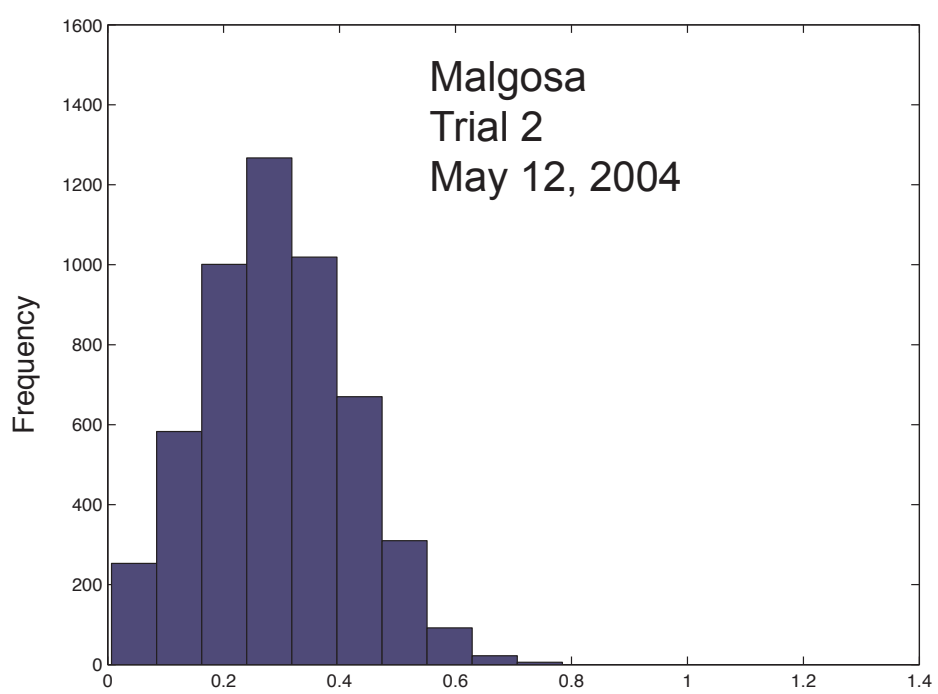

$\mathrm{u}_{*}$

FIGURE 16. Histograms of shear velocity $\left(u^{*}\right)$ measured during high-resolution experiments at Dumont Dunes and Malgosa. A. Shear velocity during the 16-hour Dumont Dunes experiment on February 29 to March 1, 2004, in which mean sustained winds recorded at $2.0 \mathrm{~m}$ (averaged over 10-second measurement intervals) were $3.6 \pm 1.6 \mathrm{~m} \mathrm{~s}^{-1}$ (one standard deviation) with gusts up to $10.8 \mathrm{~m} \mathrm{~s}^{-1}$. Shear velocity was calculated using Equation (1). B. Shear velocity during the first high-resolution experiment at Malgosa, which lasted seven hours on May 11, 2004, with mean sustained winds at $2.0 \mathrm{~m}$ of $5.8 \pm 3.2 \mathrm{~m} \mathrm{~s}^{-1}$ with gusts up to $20.8 \mathrm{~m} \mathrm{~s}^{-1}$. C. Shear velocity during the second high-resolution experiment at Malgosa, which lasted 14.5 hours on May 12, 2004, with mean sustained winds at $2.0 \mathrm{~m}$ of $3.1 \pm 1.9 \mathrm{~m} \mathrm{~s}^{-1}$ (one standard deviation) with gusts up to $13.7 \mathrm{~m} \mathrm{~s}^{-1}$. 


\section{DISCUSSION}

\section{Potential Sources of Error:}

Calibration of sand-trap efficiency plays a clear role in evaluating measured sand transport, and can be a substantial source of error in field studies if not well-established (McEwan and Willets, 1993; Sherman and others, 1998). The BSNE trap design used in this study (Fryrear, 1986; Stout and Fryrear, 1989 ) is one of the most widely used in agricultural and sedimentological studies (Zobeck and others, 2003). Its efficiency has been determined by multiple windtunnel and field studies using a range of grain sizes for sand and dust, and over a wide range of wind velocities (Fryrear, 1986; Shao and others, 1993; Goossens and Offer, 2000; Goossens and others, 2000, 2001). The widespread use of this trap also allows comparison between studies. The BSNE was chosen for the present study because existing calibrations suggests that the efficiency range of $95-115 \%$ for the grain size and velocities in this experiment can be reasonably assumed.

Accuracy of shear-velocity estimates is affected by the number of anemometers used to generate wind profiles. In the case of this experiment, $u_{*}$ values for each 10-second data point were generated from three measurements of wind velocity. Although the use of more anemometers would decrease the uncertainty associated with calculations of $u_{*}$, the accuracy of the results would not necessarily increase (Namikas and others, 2003; see comparison of four- vs. eight-anemometer $u_{*}$ estimates by Namikas, 1999).

Bed-roughness elements are not believed to have affected data collection significantly during the Dumont Dunes experiment. Location of the instrument tripod at Dumont Dunes was selected based on the absence of vegetation, large bedforms, or pebbles on the sand surface. Values of roughness length, $z_{0}$, obtained from wind velocity profiles tend to be within an order of magnitude of twice the Nikuradse roughness for the grain size at the instrument site $\left(2 d_{50} / 30\right)$, 
and their departure from this value is attributed to the influence of saltation and/or ripple development. The low apparent roughness values obtained in Dumont Dunes indicate that form drag on the bed was negligible during this test. With unobstructed sand on an approximately flat surface for distances of at least $20 \mathrm{~m}$ surrounding the instrument tripod and sand traps in all directions, we are reasonably confident that aeolian sand transport measured at Dumont Dunes reached equilibrium conditions (Anderson and Haff, 1988; Anderson and others, 1991; Raupach and others, 1993; King and others, 2005; R.S. Anderson, written comm., 2006).

In contrast, bed-roughness elements in the Malgosa dune field are problematic. Even though this site has among the sparsest vegetation of any known Grand Canyon aeolian deposit, vegetation and possibly also a nearby talus slope generated measurably more roughness than in Dumont Dunes; the Malgosa wind data yielded $z_{0}$ values five to six orders of magnitude above Nikuradse roughness. Sand transport measured at Malgosa was probably also affected by variations in wind velocity caused by the $\sim 20$-degree slope of the stoss side of the dune on which the weather station was located (cf. Lancaster, 1985; Mulligan, 1988). Previous studies have shown that wind-velocity profiles on the stoss sides of dunes are not log-linear as they are on flat surfaces such as the sand sheet in our Dumont dunes test, complicating the use of the KarmanPrandtl equation (1) to obtain shear velocity (Frank and Kocurek, 1996; Lancaster and others, 1996). The height of the lowermost anemometer used in our study $(0.3 \mathrm{~m})$ was also likely not low enough to measure velocity in the part of the boundary layer where much of the sediment transport occurred (Lancaster and others, 1996).

Using spinning-cup anemometers in conditions of abundant wind-blown sand introduces an additional source of error as sand can clog the instruments and interfere with the movement of the cups. Lower-elevation anemometers in a vertical array are preferentially affected by this problem, causing the wind speeds 
recorded by the lower anemometers to be erroneously low. If the lower anemometers are preferentially slowed by wind-blown sand, velocity profiles appear artificially steep and the $u *$ values calculated from them will then lead to artificially high modeled sand flux $q$. We believe that this is a potential source of significant error in experiments of this type where anemometers are used for an extended time, and was probably the reason why all models greatly overpredicted sediment transport in the second test at Malgosa (Table 5), which was conducted after anemometers had been subjected to sustained high winds and abundant sand transport for several days. Although anemometers were cleaned between the two high-resolution tests at Malgosa (and during every maintenance visit throughout the two-year Grand Canyon study) wind-blown sand continued to slow the function of the lower-elevation anemometer there (and also at the Forster study site, where the lower anemometer was eventually removed). It is likely that this same problem affected the first high-resolution trial at Malgosa especially toward the end of the seven-hour test, which may explain why the transport models showed a greater tendency toward over-prediction in the first Malgosa test compared to the experiment at Dumont Dunes (Table 5). The anemometers used at Dumont Dunes had never been deployed in the field before, suggesting that sand clogging was only a minimal factor there, whereas those at Malgosa had been in use (with regular cleaning and maintenance) for the six months before the May 2004 high-resolution tests.

\section{Performance of Tested Models:}

Figure 17 shows modeled aeolian sand flux plotted against a range of shear velocity $(u *)$ values up to $5 \mathrm{~m} \mathrm{~s}^{-1}$. Differences in the behavior of the eight models become much more apparent at higher shear velocity (higher wind speed) than was measured in any of the three experiments conducted at Dumont Dunes or Malgosa. Values of $u *$ represented in our data sets (Fig. 16) were $<0.5$ 

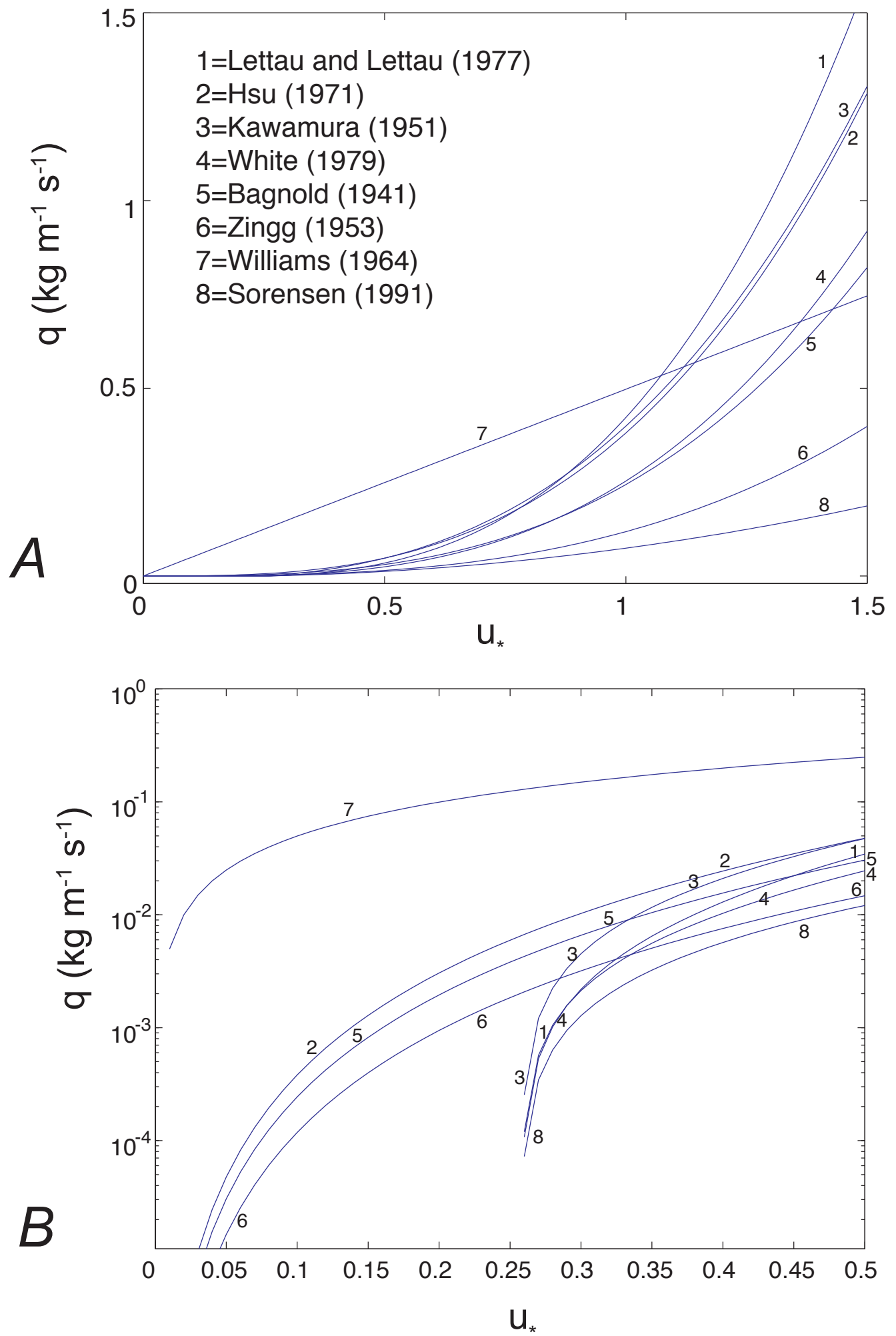

FIGURE 17. Sediment flux $(q)$ predicted for various shear velocities $\left(u_{*}\right)$ by eight aeolian sediment-transport models. $A$ and $B$ show identical curves plotted at different scales to highlight different behavior of the models at higher $(A)$ and lower $(B)$ shear velocities. The greatest divergence in modeled sediment flux occurs when $u_{*}>1.0$, such that shear velocities are substantially greater than were calculated from wind data measured during the three experiments in this study. 
$\mathrm{m} \mathrm{s}^{-1}$ at Dumont Dunes (clustering around $0.1 \mathrm{~m} \mathrm{~s}^{-1}$ ) and $<1 \mathrm{~m} \mathrm{~s}^{-1}$ at Malgosa (clustering around $0.3 \mathrm{~m} \mathrm{~s}^{-1}$ ). Available wind velocities measured during these experiments were therefore low enough that the models tested would not necessarily show significant differences in the amount of sand transport that they predict, with the exception of the linear Williams (1964) model, because most of the divergence in their predicted fluxes occurs at $u *$ greater than $1 \mathrm{~m} \mathrm{~s}^{-1}$ (Fig. 17).

Several of the models tested in this study showed somewhat greater predictive capability in the very simplified desert setting of Dumont Dunes than indicated by previous studies conducted in coastal dune environments. In coastal settings, aeolian transport rates are often over-predicted and in other cases under-predicted. Bauer and others (1996) found that predicted rates exceeded measured rates by factors of 1.9 to 5.6 on a sparsely vegetated foredune zone beach site, using the Lettau and Lettau (1977) model. Hunter and others (1983) found that the Bagnold (1941) model over-predicted transport rates measured from bedform migration of coastal dunes by a factor of 3.6. Over-prediction factors of five and $~ 50$ were obtained by Goldsmith and others (1990) and Bauer and others (1990), respectively, applying the Bagnold (1941) equation to wind and sand transport data on coastal beach areas. Sherman and others (1998) found overprediction of sand transport on a beach by factors of two and greater using the Bagnold (1941), Kawamura (1951), and Lettau and Lettau (1977) models, while Zingg (1953) underpredicted transport. Coastal studies of Sarre (1988) showed that the predictive power of most tested equations can vary with shear velocity, with Bagnold (1941) overpredicting transport at shear velocities comparable to those in this study $\left(u_{*}<0.5 \mathrm{~m} \mathrm{~s}^{-1}\right)$. Sarre (1989) found that the White (1979) model substantially overpredicted sand transport on foredunes studied in an intertidal zone.

The improved predictive value of transport equations in a highly simplified field setting such as Dumont Dunes would be expected (for example, Sherman and Hotta, 1990). Aeolian transport in coastal or other more complex sand 
systems can be influenced by multiple factors that did not affect the Dumont site: vegetation (Olson, 1958; Bressolier and Thomas, 1977; Ash and Wasson, 1983; Wasson and Nanninga, 1986; Buckley, 1987; Bauer and others, 1996; King and others, 2005) soil moisture (e.g., Svasek and Terwindt, 1974; Sarre, 1988, 1989; McKenna Neuman and Nickling, 1989; Namikas and Sherman, 1995; Selah and Fryrear, 1995; Wiggs and others, 2004), salt encrustation on sediment (Nickling, 1984; Sarre, 1989), fetch limitation due to nearby dune crests (Bauer and others, 1990) and tidal fluctuations (Sarre, 1988; Nordstrom and Jackson, 1992), trapping of sand by runnels and tidal channels (Bauer and others, 1996), nonerodible surface objects such as rocks (Gillette and Stockton, 1989; Raupach and others, 1993; King and others, 2005), cryptogamic soil crusts (Leys and Eldridge, 1998; Belnap, 2003; Goossens, 2004) and perturbation of the wind velocity profile by waves breaking near shore (Bauer and others, 1996). The absence of factors that could effectively inhibit sediment transport (such as vegetation, runnels, moisture, cryptogamic soil crust, or salt deposits) allows evaluation of the performance of these transport formulae in a field setting that can be considered, for practical purposes, unlimited with respect to sediment supply.

The Kawamura (1951) equation, one of the four in Table 4 that incorporates threshold shear velocity into its expression for transport rate, most closely represented the measured sand flux at Dumont Dunes. Although the actual transport was slightly under-predicted, the range of values indicates that the Kawamura (1951) model may have predicted up to $98.5 \%$ of the actual transport if the BSNE traps performed at the upper limit of their known efficiency range for this grain size. The efficiency range for which Kawamura (1951) most closely approximates the measured sand flux occurs for BSNE traps collecting medium-sized sand at wind velocities below $\sim 7 \mathrm{~m} / \mathrm{s}$ (Goossens and others, 2000). The Kawamura (1951) model over-predicted sand flux in the first Malgosa trial by a factor of 2.5-3; however, the performance of models at Dumont Dunes 
is considered a more accurate reflection of their predictive capability given that the second test at Malgosa and possibly also the first were apparently affected by sand-clogged lower anemometers, leading to erroneously high shear-velocity estimates.

The other three tested models that use a threshold velocity term resulted in less accurate predictions of sand transport at Dumont Dunes. The Lettau and Lettau (1977) and White (1979) equations produced similar results, while Sørensen (1991) predicted just over one quarter of the actual transport. In a study of aeolian transport predictions conducted on coastal dunes in an intertidal zone, Sarre (1988) also found close agreement between measured transport and that predicted by Kawamura (1951), though the agreement improved with a constant of 2.4 used in place of the standard 2.78. Sarre (1988) found that, in general, equations using the cube of $u_{*}$ and a $u_{*}$ term provided the closest approximation of measured transport, with White (1979) performing the best. Svasek and Terwindt (1974) determined that the Bagnold (1941) and Kawamura (1951) models both performed poorly compared when tested on a beach, which was attributed to capillary forces associated with moisture in the beach sand. Sherman and others, (1998), in a study of transport equations on coastal dunes in Ireland, found that the Kawamura (1951) model overpredicted actual transport rates by a factor of two to three (after correction for soil moisture and surface slope). Lettau and Lettau (1977) yielded ratios of predicted to measured transport that ranged from 1.0 to 1.2 after such corrections when applied to one coastal system (Sherman and others, 1998) and ratios of 1.9 to nearly 6 in another coastal area (Bauer and others, 1996). Hsu (1971), a method based on the cube of $u_{*}$ that is essentially a modified Froude number, overpredicted transport in this study by a factor greater than two. This behavior is similar to that found by Sarre (1988), in which Hsu (1971) overpredicted transport at low to moderate $u_{*}$ in a similar manner to Bagnold (1941). 
Arguably the most commonly used aeolian transport equation, that of Bagnold (1941) that depends on the cube of $u_{*}$, overpredicted transport rates in this study by a factor of at least 1.5. This is comparable to the result of Sarre (1988) that showed over-predictive behavior of Bagnold (1941) for shear velocities in the range measured during this study $(<0.5 \mathrm{~m} / \mathrm{s}$, and usually $<0.4$ $\mathrm{m} / \mathrm{s}$ ). This model yields a close fit to our data when the constant in this equation is lowered from 1.8 to 1.2. Zingg (1953), whose model is of the same form as that of Bagnold but differs in its constant and exponent, predicted $\sim 75$ to $82 \%$ of the measured sand transport at Dumont Dunes. This is similar to the upper end of this model's predictive power determined by Sherman and others (1998) after corrections were applied to remove effects of soil moisture and slope. Sarre (1988) also found that the Zingg (1953) equation was a reasonable predictor of transport in the range of shear velocities considered here, though at higher $u_{*}$ this model under-predicted actual sand flux at Dumont Dunes

Williams (1964), the only model in this study that considers sediment transport rate to be a linear function of shear velocity, performed poorly in this assessment. Transport in the Dumont Dunes trial was over-predicted by more than an order of magnitude using this method; Willams (1964) also overpredicted sand flux in both Malgosa trials to a much greater degree than did the other models (Table 5). It is not possible to draw a direct comparison between this study and the wind-tunnel work that led to the Williams (1964) model, however, as the constant terms in that equation apply to a specific grain size (330 $\mu$, coarser than that collected at the Dumont dune field). However, using

sediment with a similar grain size to that required by Williams (1964), Sarre (1988) obtained transport results that differed substantially from those predicted by this model.

\section{Relevance for Investigation of Supply-Limited Systems:}


Testing of these eight transport models in the Dumont Dunes setting, where sediment supply is essentially unlimited, indicates that the Kawamura (1951) model appears most feasible as one that could potentially be used to discern the effect of supply limitation, bearing in mind the limited range of wind velocities available in that Dumont Dunes experiment and the more variable behavior of the models at higher shear velocity (Fig. 17). In order to be useful in the context of determining the degree of sediment-supply limitation, a transport model would need to accurately predict sediment transport rates to within $5 \%$ (a reasonable confidence interval) in a supply-unlimited setting. The Kawamura (1951) model predictions are within this boundary for the upper end of the sandtrap efficiency range. Given that BSNE sand-trap efficiency decreases with increasing wind speed, this suggests that this model is most applicable at lower wind speeds where transport rates are low. This implication is consistent with the result of Sarre (1988), in which Kawamura (1951) predicted transport most closely at the lowest shear velocities considered $\left(<0.35 \mathrm{~m} \mathrm{~s}^{-1}\right.$; the Sarre [1988] field data also agreed well with the Lettau and Lettau [1977] and White [1979] models). The wide variation in model applicability among different field areas and at different shear velocities indicates that the use of this or any other model to assess the effects of sediment-supply limitation warrants caution; for this reason, we did not pursue similar modeling applications extensively as a means of identifying sediment-supply limitation in Grand Canyon dune fields, which are much more complex environments than our highly simplified Dumont Dunes test site. More extensive testing is warranted to determine the reliability of this model in supply-unlimited areas with, for instance, different grain size, sorting, and in higher wind velocities than those represented here.

Although developing a new transport model specifically for supply-limited systems is beyond the scope of this work, the practical applications of such a model would be extensive (Leys, 1999). Quantification of, for instance, agricultural erosion processes would benefit from modeling capabilities that 
include adjustment for diminished sediment supply as erosion proceeds. Environmental management problems that concern sediment availability could be more fully addressed if it were possible to determine the degree to which a system undergoing aeolian sediment transport is supply-limited. Examples include sediment mobilization on subaerial sand bars in dam-controlled river systems such as Grand Canyon, and the condition of beaches used for recreation on eroding coastlines. The development of models that can be used for such purposes is recommended as a future research direction.

\section{CONCLUSIONS}

Evaluation of eight aeolian sediment transport models in a desert setting considered to have unlimited sediment supply indicates that the Kawamura (1951) model most closely predicted the cumulative sand flux measured during the 16-hour study at Dumont Dunes, Death Valley, CA. This model appears the most potentially viable as a method by which sediment-supply limitation might be discerned, although we recognize that at higher wind velocities than were measured during this study the predictive capability of the tested models could vary substantially. Additional testing of this and other models in supply-unlimited settings is advisable as a future direction of research, as is development of an aeolian transport model that could quantify expected reduction in sediment transport as sediment supply becomes progressively more limited. The ability to quantify the influence of supply limitation on aeolian erosion, transport, and deposition would be advantageous to many environmental management initiatives. 


\section{APPENDIX 2: Estimation of historical changes in aeolian sand sources using a GIS database developed at Utah State University}

This appendix catalogs an effort to evaluate changes in the availability of sand involved in aeolian transport systems within the Colorado River corridor over decadal scales. To do this, we used a Geographic Information System (GIS) database developed by the Fluvial Geomorphology Laboratory, Department of Aquatic, Watershed, and Earth Resources, Utah State University that is based on aerial photographs taken from 1935-1996 between Glen Canyon Dam and the Unkar area (river-mile 73). The aerial photographs and GIS resources discussed below were part of the data set used by Schmidt and others (2004) to document decreased fine sediment in the river corridor between the dam and Bright Angel Creek (river-mile 88). For the purposes of our evaluation, although site-by-site changes are apparent, widespread decadal-scale trends in aeolian deposits and sediment-source areas were not readily apparent. We believe that this is due in part to great differences in river discharge in the early photographs compared to those taken in the 1990s, when all aerial photography missions were flown during steady $226 \mathrm{~m}^{3} \mathrm{~s}^{-1}\left(8,000 \mathrm{ft}^{3} \mathrm{~s}^{-1}\right)$ flows. Lack of regional decadal trends is likely also due to difficulties of interpreting sedimentary features on the land surface using only aerial photographs without the benefit of supplemental information such as oblique photographs and field ground-truthing.

\section{Aerial Photographs Incorporated Into GIS at Utah State University:}

Aerial photographs of five reaches of the Colorado River corridor between Glen Canyon Dam and approximately river-mile 73 were studied by members of the Fluvial Geomorphology Laboratory led by Dr. J. C. Schmidt, Department of Aquatic, Watershed, and Earth Resources, at Utah State University (USU). 
Scientists from the USU research group interpreted geomorphology in multiple sets of photographs taken between 1935 and 1996, identified geomorphic units and mapped their boundaries as polygons, and stored the layers of polygons as shape files in an GIS database.

Using the polygons in those shape files that represent previously interpreted geomorphic units, the total area of sediment deposits considered relevant to aeolian sand-transport systems were summed for each reach of the river in each set of available photographs. Geomorphic assignments (for example, of debris fans, channel-margin sand deposits, aeolian deposits, and eddy sandbars) made by USU scientists were not re-interpreted during this exercise, but representative areas were checked by independently studying the original photographs from which the features had been mapped. Reaches of the river for which USU scientists compiled shape files of geomorphic features, and ages of available aerial photographs used for each, are listed in Table 6. Table 7 lists dates of aerial photographs included in the USU GIS database, and the available mapped reaches in each.

\begin{tabular}{|l|l|}
\hline Name of reach & River miles \\
\hline Glen Canyon (GL) & $-15.2($ dam)-0 \\
\hline Lees Ferry (LF) & $-0.4-8.3$ \\
\hline Redwall Gorge (RW) & $29.2-35.3$ \\
\hline Point Hansbrough (PH) & $42.3-48.9$ \\
\hline Little Colorado River (LCR) & $60.0-72.8$ \\
\hline
\end{tabular}

TABLE 6. Reaches of the Colorado River, and corresponding river miles, analyzed using a geomorphology GIS database developed by Utah State University. River miles are those given by the Grand Canyon Monitoring and Research Center (GCMRC) at http://www.gcmrc.gov/products/ims/ims.htm and are measured downstream from Lees Ferry (Fig. 1), with negative miles indicating distance upstream from Lees Ferry. These were the same reaches used for aerial photographic analyses by Leschin and Schmidt (1995) and Schmidt and others (2004). 


\begin{tabular}{|l|l|l|}
\hline Date & Discharge & Reaches \\
\hline mid-1930s & $\begin{array}{l}\text { Unknown; appears 142-226 } \mathrm{m}^{3} \mathrm{~s}^{-1} \\
\left(5,000-8,000 \mathrm{ft}^{3} \mathrm{~s}^{-1}\right)\end{array}$ & LF, RW, PH, LCR (partial) \\
\hline 1951 & Unknown & LF \\
\hline 1952 & $\begin{array}{l}252-380 \mathrm{~m}^{3} \mathrm{~s}^{-1}\left(8,800-13,400 \mathrm{ft}^{3} \mathrm{~s}^{-1}\right) \\
\text { on Sep. } 24-25, \sim 175 \mathrm{~m}^{3} \mathrm{~s}^{-1}\left(6,200 \mathrm{ft}^{3}\right. \\
\left.\mathrm{s}^{-1}\right) \text { on Oct. } 8 .\end{array}$ & $\begin{array}{l}\text { GL (Sep.), LF (Sep. and } \\
\text { Oct. } \mathrm{RW} \text { (Sep.), PH (Sep.) }\end{array}$ \\
\hline 1954 & $119-156 \mathrm{~m}^{3} \mathrm{~s}^{-1}\left(4,200-5,500 \mathrm{ft}^{3} \mathrm{~s}^{-1}\right)$ & LCR \\
\hline 1958 & $186-201 \mathrm{~m}^{3} \mathrm{~s}^{-1}\left(6,600-7,100 \mathrm{ft}^{3} \mathrm{~s}^{-1}\right)$ & LCR \\
\hline 1965 & $680-792 \mathrm{~m}^{3} \mathrm{~s}^{-1}\left(24,000-28,000 \mathrm{ft}^{3} \mathrm{~s}^{-1}\right)$ & $\mathrm{LF}, \mathrm{RW}, \mathrm{PH}, \mathrm{LCR}$ \\
\hline 1973 & $76-396 \mathrm{~m}^{3} \mathrm{~s}^{-1}\left(2,700-14,000 \mathrm{ft}^{3} \mathrm{~s}^{-1}\right)$ & $\mathrm{LF}, \mathrm{RW}, \mathrm{PH}, \mathrm{LCR}$ \\
\hline 1984 & $144-226 \mathrm{~m}^{3} \mathrm{~s}^{-1}\left(5,100-8,000 \mathrm{ft}^{3} \mathrm{~s}^{-1}\right)$ & GL, LF, RW, PH, LCR \\
\hline 1990 & $142 \mathrm{~m}^{3} \mathrm{~s}^{-1}\left(5,000 \mathrm{ft}^{3} \mathrm{~s}^{-1}\right)$ & GL, LF, RW, PH, LCR \\
\hline 1992 & $226 \mathrm{~m}^{3} \mathrm{~s}^{-1}\left(8,000 \mathrm{ft}^{3} \mathrm{~s}^{-1}\right)$ & GL, PH, LCR \\
\hline 1996 (March) & $226 \mathrm{~m}^{3} \mathrm{~s}^{-1}\left(8,000 \mathrm{ft}^{3} \mathrm{~s}^{-1}\right)$ & GL, LF, RW, PH, LCR \\
\hline 1996 (April) & $\sim 226 \mathrm{~m}^{3} \mathrm{~s}^{-1}\left(8,000 \mathrm{ft}^{3} \mathrm{~s}^{-1}\right)$ & GL, LF, RW, PH, LCR \\
\hline 1996 (Sept.) & $226 \mathrm{~m}^{3} \mathrm{~s}^{-1}\left(8,000 \mathrm{ft}^{3} \mathrm{~s}^{-1}\right)$ & LF, RW \\
\hline 1997 (August) & $226 \mathrm{~m}^{3} \mathrm{~s}^{-1}\left(8,000 \mathrm{ft}^{3} \mathrm{~s}^{-1}\right)$ & RW \\
\hline
\end{tabular}

TABLE 7. Dates and river discharges of aerial photographs included in the USU GIS database, and the available mapped reaches in each. Abbreviations of reach names are given in Table 6 above. The March and April 1996 sets of photographs were flown before and after the first controlled-flood experiment (Webb and others, 1999b; Schmidt and others, 2001), respectively. Discharge is based on instantaneous discharge from the Lees Ferry gage at the time of overflight photography (Topping and others, 2003). 
Categories of geomorphic features that together indicate aeolian deposits were grouped together and their areas summed for each river reach and set of photographs. Polygons designated as aeolian sand in the GIS database were those that the USU group determined to be "fine-grained sand deposits, often with dune-like features visible, commonly found on high terrace deposits and large, high-relief gravel bars. Reworking of a deposit between times of photography was considered to be good evidence of aeolian sand if the deposit was topographically higher than any level reached by river flows during the intervening years" (description excerpted from USU laboratory procedure notes). In the case of numerous polygons the exact geomorphic category was not identified exclusively but was listed under a combined heading, such as "aeolian sand / channel margin" deposit, or "aeolian sand / gravel". Pre-dam sediment deposits formed above the $2,700 \mathrm{~m}^{3} \mathrm{~s}^{-1}\left(97,000 \mathrm{ft}^{3} \mathrm{~s}^{-1}\right)$ stage (a level reached by the post-dam flood of 1983) were assigned categories of 'upper terrace' or 'high terrace' deposits. Also summed for this exercise were areas of polygons representing fluvial sand deposits in eddies: separation bars, reattachment bars, and, when the distinction between separation and reattachment bars could not be made, simply eddy bars (Rubin and others, 1990; Schmidt, 1990).

\section{Results and Interpretation:}

Figures 18-22 show bar graphs of the summed area of different types of sediment deposits, by year, for each of the five reaches listed in Table 6. The total mapped areas occupied by various types of sand deposits varies substantially between sets of photographs for each reach. This is believed to be largely an artifact of the variable river flows represented in each set of photographs until it became customary, in the 1990s, to conduct overflight photography only during steady $226 \mathrm{~m}^{3} \mathrm{~s}^{-1}\left(8,000 \mathrm{ft}^{3} \mathrm{~s}^{-1}\right)$ discharge. Differences in flow between set of photographs should not have affected the mapped area of 'upper' or 'high terrace' sand, however, as those deposits lie above the above the $2,700 \mathrm{~m}^{3} \mathrm{~s}^{-1}\left(97,000 \mathrm{ft}^{3} \mathrm{~s}^{-1}\right)$ stage. 
Schmidt and others (2004) used changes in the eddy sandbars visible in these aerial photographs, combined with oblique photography and site-specific field study, to estimate that the area of sand in the pre-dam and post-dam flood zone was 1-20 percent less in the 1990s than in pre-dam time. The Schmidt and others (2004) analysis did not distinguish between sand deposits that were strictly fluvial and those that had undergone (or were available for) wind reworking. It is apparent from the aerial photographs, particularly in the upstream ( $G L$ and LF) reaches, that eddy sandbar area decreased as a result of the 1996 controlled flood. This is consistent with the more widely documented pattern of accretion and growth of sandbars farther downstream in Grand Canyon at the expense of sandbars that had been eroded from Marble Canyon, and was a primary why the 2004 controlled flood was designed to follow recent substantial input of sediment from the Paria River (Topping and others, 2006; note that because the Paria River joins the Colorado at Lees Ferry, sandbars in the Glen Canyon reach would still have been sediment-starved and eroded during the 2004 flood).

Lack of apparent regional decadal trends in aeolian sand is partly due to difficulties of interpreting sedimentary features on the land surface using only aerial photographs without the benefit of supplemental information such as oblique photographs and field ground-truthing (using sedimentary structures, for instance, to determine more accurately the depositional history of sediment by examining it in three dimensions). In particularly the earlier sets of photographs, poor quality (commonly overexposure), shadows, and large scale also complicate detailed interpretation. Error is also introduced into the geomorphic mapping methods by inherent subjective decisions that must be made by the interpreter-whether, in one set of photographs, a deposit should be considered to contain aeolian sand while in another set of photographs, the same sediment deposit may look ambiguous or may appear to have no features suggesting wind reworking of sediment. These complications would obviously be amplified substantially the more people are responsible for interpretation and polygon naming, but this source of error was reduced in the USU laboratory by having the 
same personnel interpret most or all of the photograph sets and was determined to be minimal when the accuracy of interpretations made by different scientists were compared (Schmidt and others, 2004). 
Sum of components containing aeolian sand

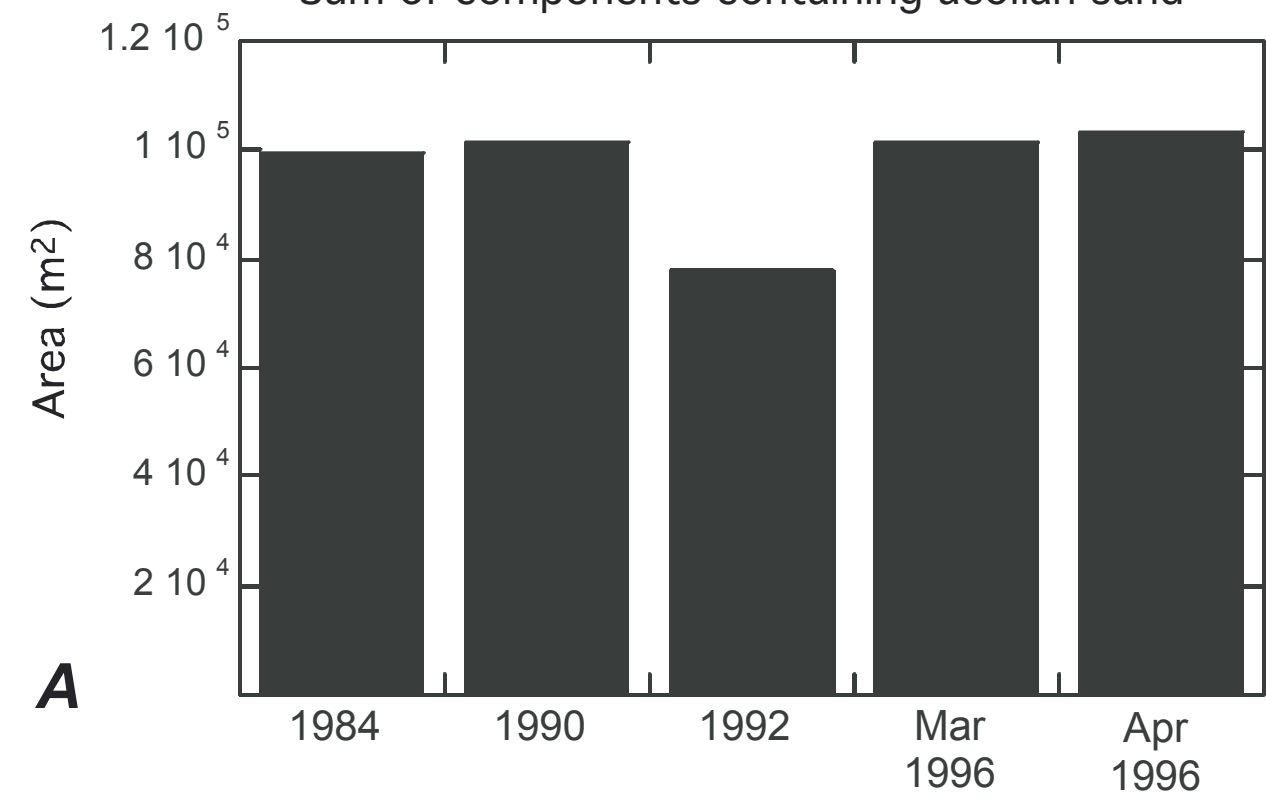

FIGURE 18. Total areas of various types of sediment deposits mapped from aerial photographs in the Glen Canyon (GL) reach. A. Total area of polygons mapped by USU scientists as containing aeolian sand, whether alone or in combination with another geomorphic category. $B$. Total area of polygons containing sediment mapped as 'upper' or 'high terrace' deposits (pre-dam deposits formed above the 2,700 $\mathrm{m}^{3} \mathrm{~s}^{-1}$ [97,000 $\left.\mathrm{ft}^{3} \mathrm{~s}^{-1}\right]$ stage). While not deposited by wind, those categories indicate sediment available for remobilization by wind. C. Total area of polygons containing fluvial sand deposits in eddies, including 'separation bars', 'reattachment bars', and, when separation and reattachment bars were not distinguished as separate categories, 'eddy bars'. Fluvial deposits in eddies, when exposed subaerially, indicate source areas from which sand could be reworked and transported by wind. The March and April 1996 sets of aerial photographs were taken just before and just after the first controlled flood release from Glen Canyon Dam (Schmidt and others, 2001), respectively. Note the decreased area of eddy sandbars in the Glen Canyon reach (between the dam and Lees Ferry) over the time of the 1996 flood; sandbars downstream in Grand Canyon that accreted during the 1996 flood were built by sand eroded from eddy sand deposits upstream in the Glen Canyon and adjacent reaches.
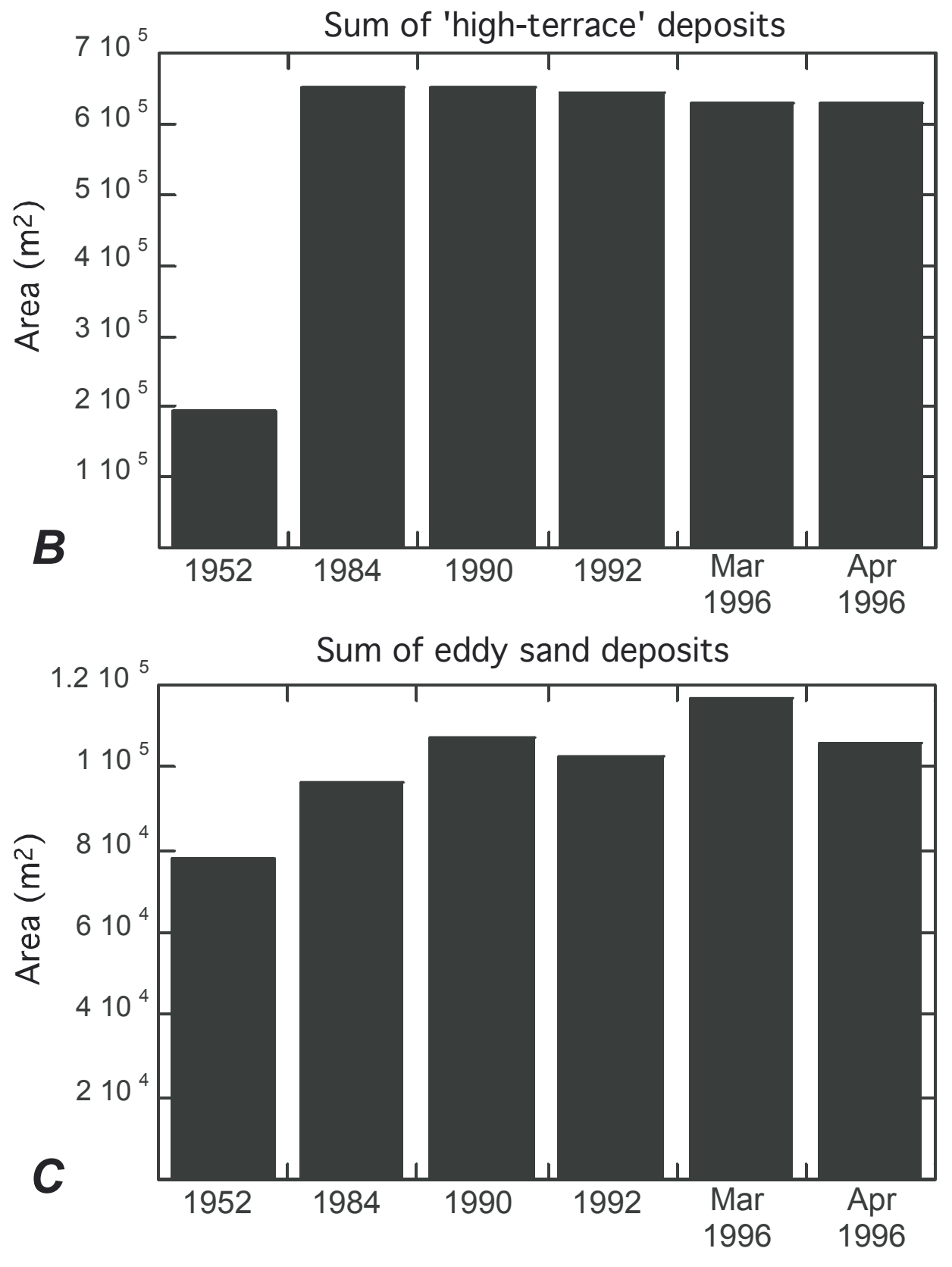
Sum of components containing aeolian sand

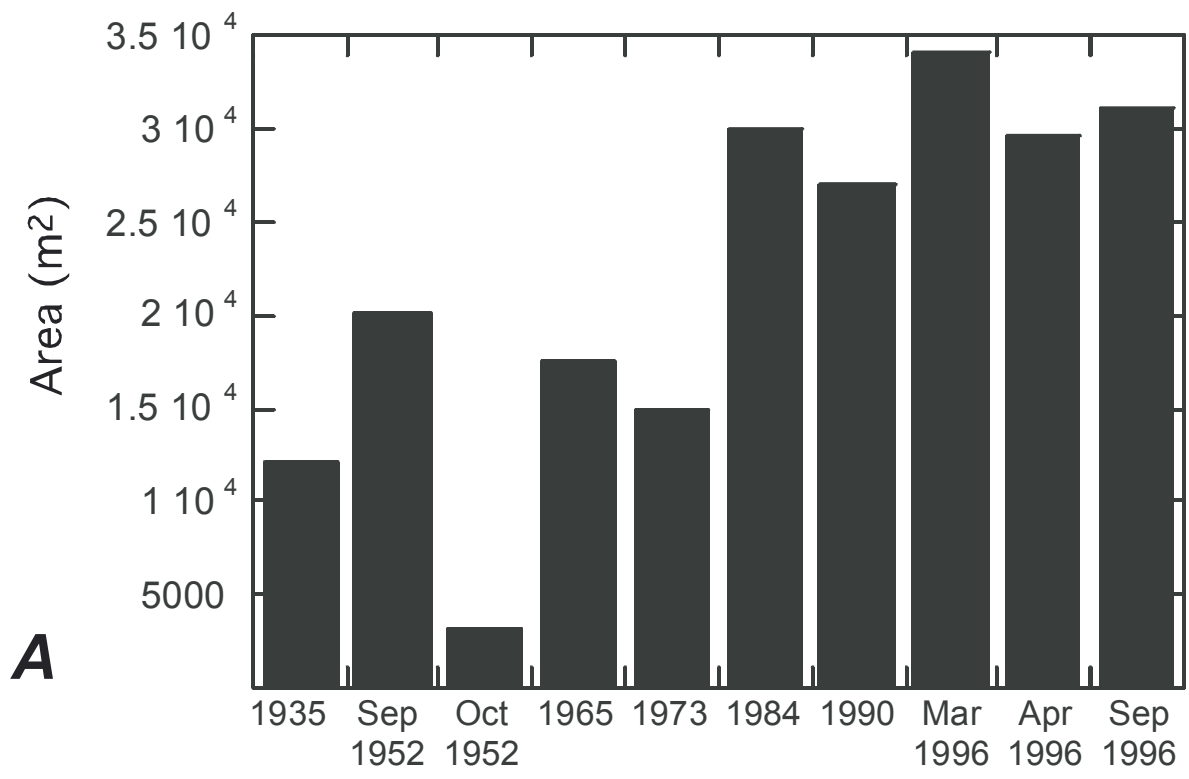

FIGURE 19. Total areas of various types of sediment deposits mapped from aerial photographs in the Lees Ferry (LF) reach. A. Total area of polygons mapped by USU scientists as containing aeolian sand, whether alone or in combination with another geomorphic category. B. Total area of polygons containing sediment mapped as 'upper' or 'high terrace' deposits (pre-dam deposits formed above the 2,700 $\mathrm{m}^{3} \mathrm{~s}^{-1}$ $\left.\left[97,000 \mathrm{ft}^{3} \mathrm{~s}^{-1}\right] \mathrm{stage}\right)$. Those categories indicate sediment available for remobilization by wind. C. Total area of polygons containing fluvial sand deposits in eddies, including 'separation bars', 'reattachment bars', and, when those were not distinguished as separate categories, 'eddy bars'. Fluvial deposits in eddies, when exposed subaerially, indicate source areas from which sand could be transported by wind. The March and April 1996 photographs were taken just before and just after the first controlled flood, respectively. As in the Glen Canyon reach, eddy sand deposits in the Lees Ferry reach appear to have decreased slightly in area between March and April 1996 as a result of the flood, and to have decreased further between April and September 1996. It is possible that the decreased area from March to April 1996 of deposits containing aeolian sand was related to the loss of subaerial sandbars in eddies; it is not known why, if that were the case, deposits containing aeolian sand apparently increased between April and September 1996 while eddy sandbar area declined.
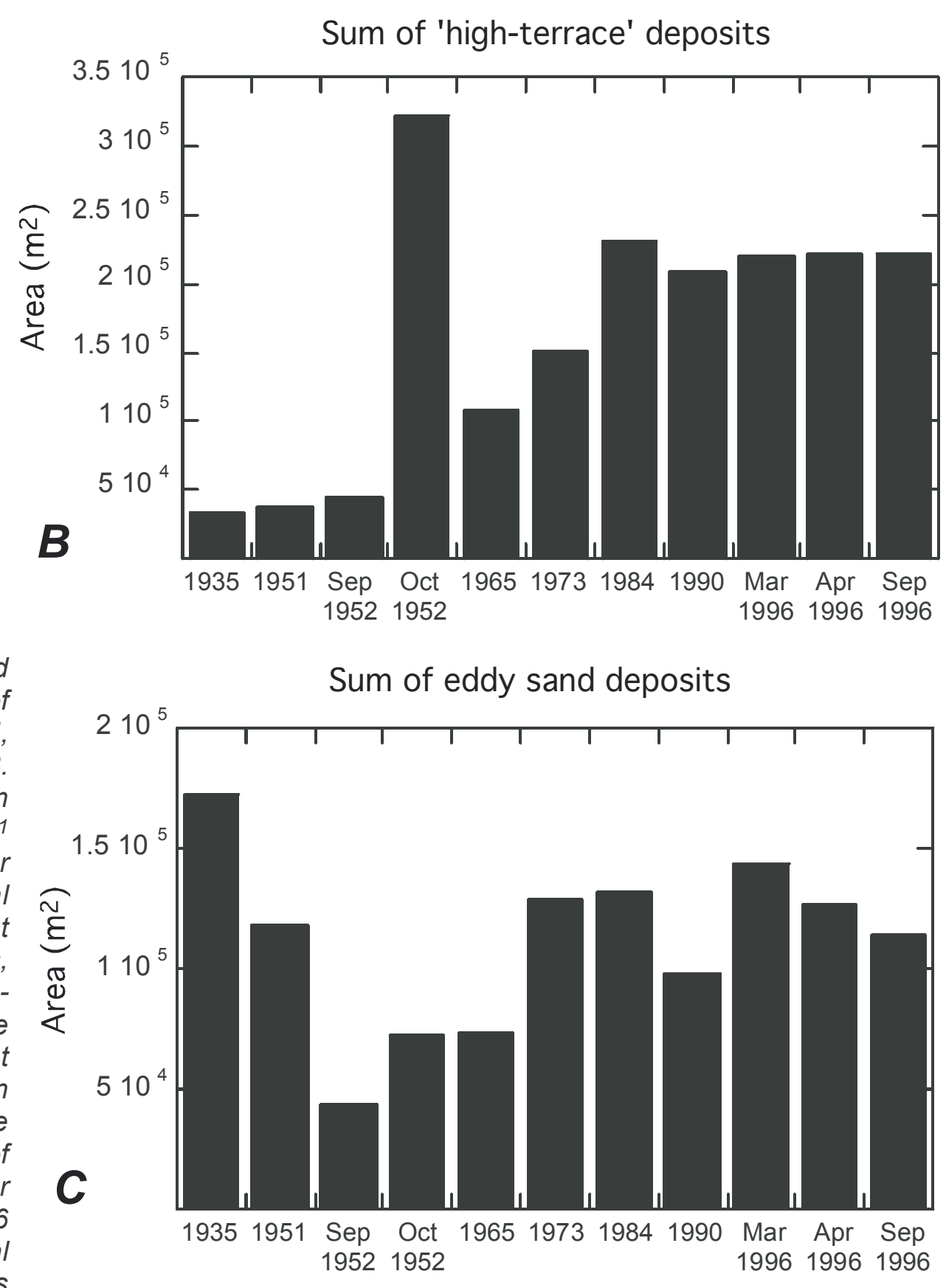

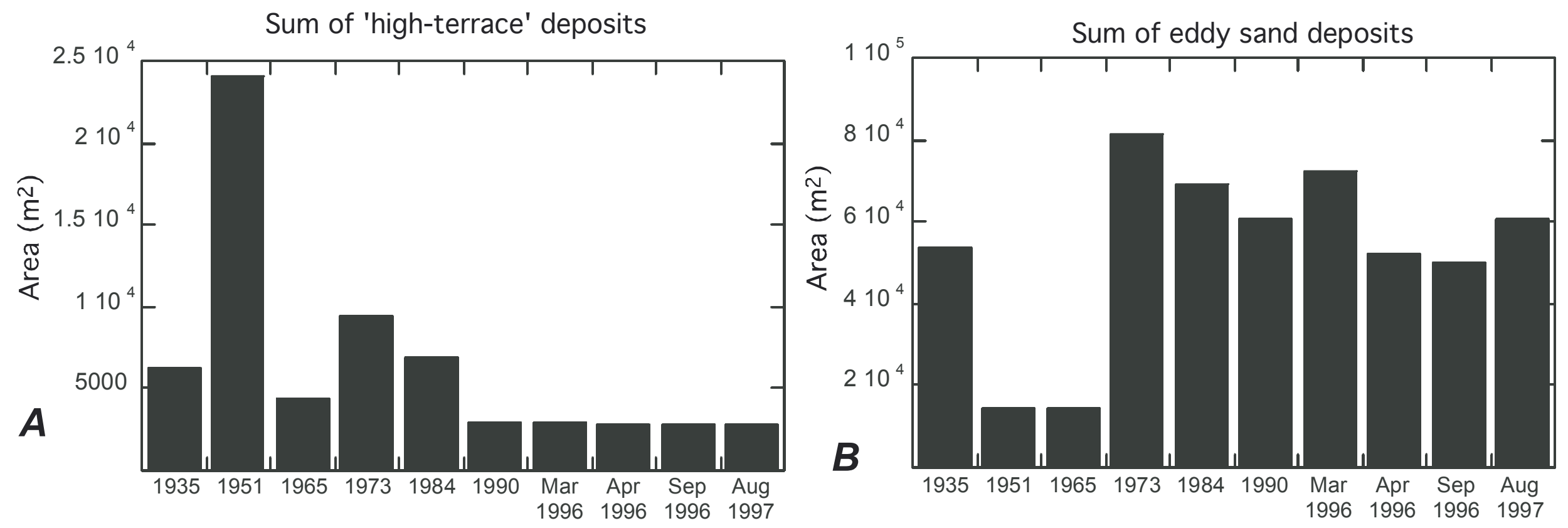

FIGURE 20. Total areas of various types of sediment deposits mapped from aerial photographs in the Redwall Gorge (RW) reach. A. Total area of polygons mapped by USU scientists as containing 'upper' or 'high terrace' sediment deposits (pre-dam deposits formed above the 2,700 $\mathrm{m}^{3} \mathrm{~s}^{-1}\left[97,000 \mathrm{ft}^{3} \mathrm{~s}^{-1}\right]$ stage). While not deposited by wind, those categories indicate sediment available for remobilization by wind. B. Total area of polygons containing fluvial sand deposits in eddies, including 'separation bars', 'reattachment bars', and, when separation and reattachment bars were not distinguished as separate categories, 'eddy bars'. Fluvial deposits in eddies, when exposed subaerially, indicate source areas from which sand could be reworked and transported by wind. Aeolian sediment was not mapped as a separate category for the Redwall Gorge reach; aeolian deposits in this reach are now rare and those that do occur are small relative to those in other reaches. 
Sum of components containing aeolian sand

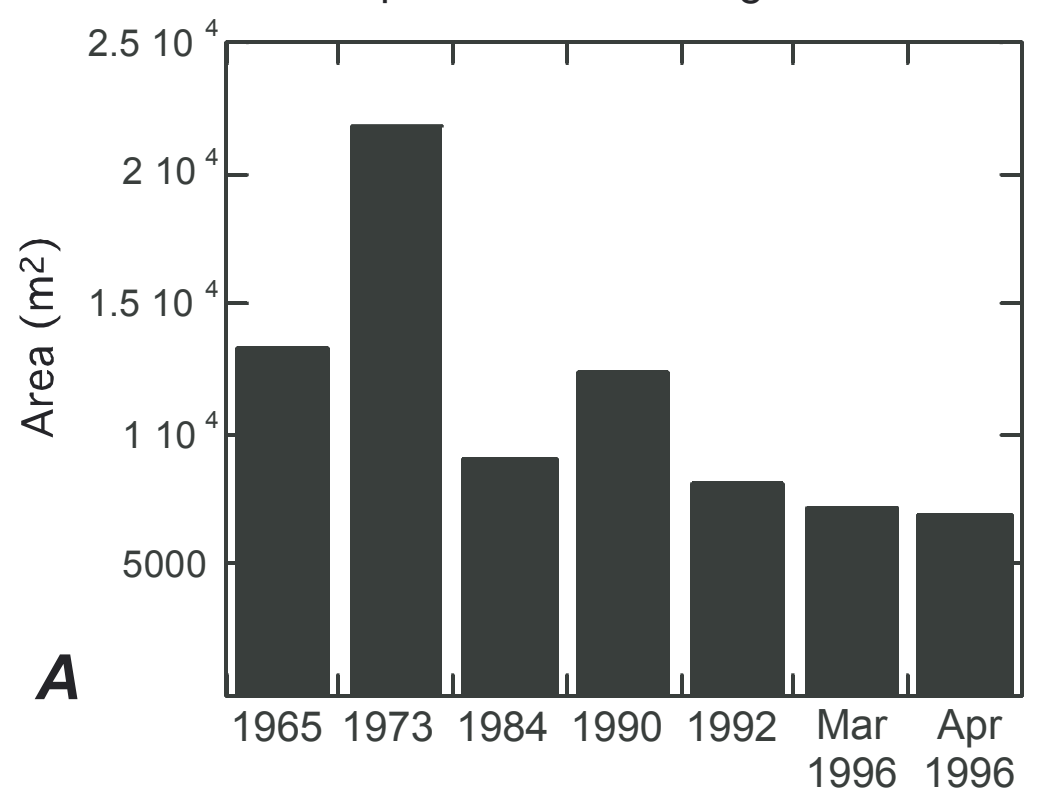

FIGURE 21. Total areas of various types of sediment deposits mapped from aerial photographs in the Point Hansbrough (PH) reach. A. Total area of polygons mapped by USU scientists as containing aeolian sand, whether alone or in combination with another geomorphic category. Aeolian deposits were not mapped as separate categories on the 1935 or 1952 sets of photographs for the $\mathrm{PH}$ reach. $\mathrm{B}$. Total area of polygons containing sediment mapped as 'upper' or 'high terrace' deposits (pre-dam deposits formed above the 2,700 $\mathrm{m}^{3} \mathrm{~s}^{-1}\left[97,000 \mathrm{ft}^{3} \mathrm{~s}^{-1}\right]$ stage). While not deposited by wind, those categories indicate sediment available for remobilization by wind. C. Total area of polygons containing fluvial sand deposits in eddies, including 'separation bars', 'reattachment bars', and, when separation and reattachment bars were not distinguished as separate categories, 'eddy bars'. Fluvial deposits in eddies, when exposed subaerially, indicate source areas from which sand could be reworked and transported by wind. The March and April 1996 sets of aerial photographs were taken just before and just after the first controlled flood release from Glen Canyon Dam (Schmidt and others, 2001), respectively. Note the decreased area of eddy sandbars as a result of the 1996 flood.
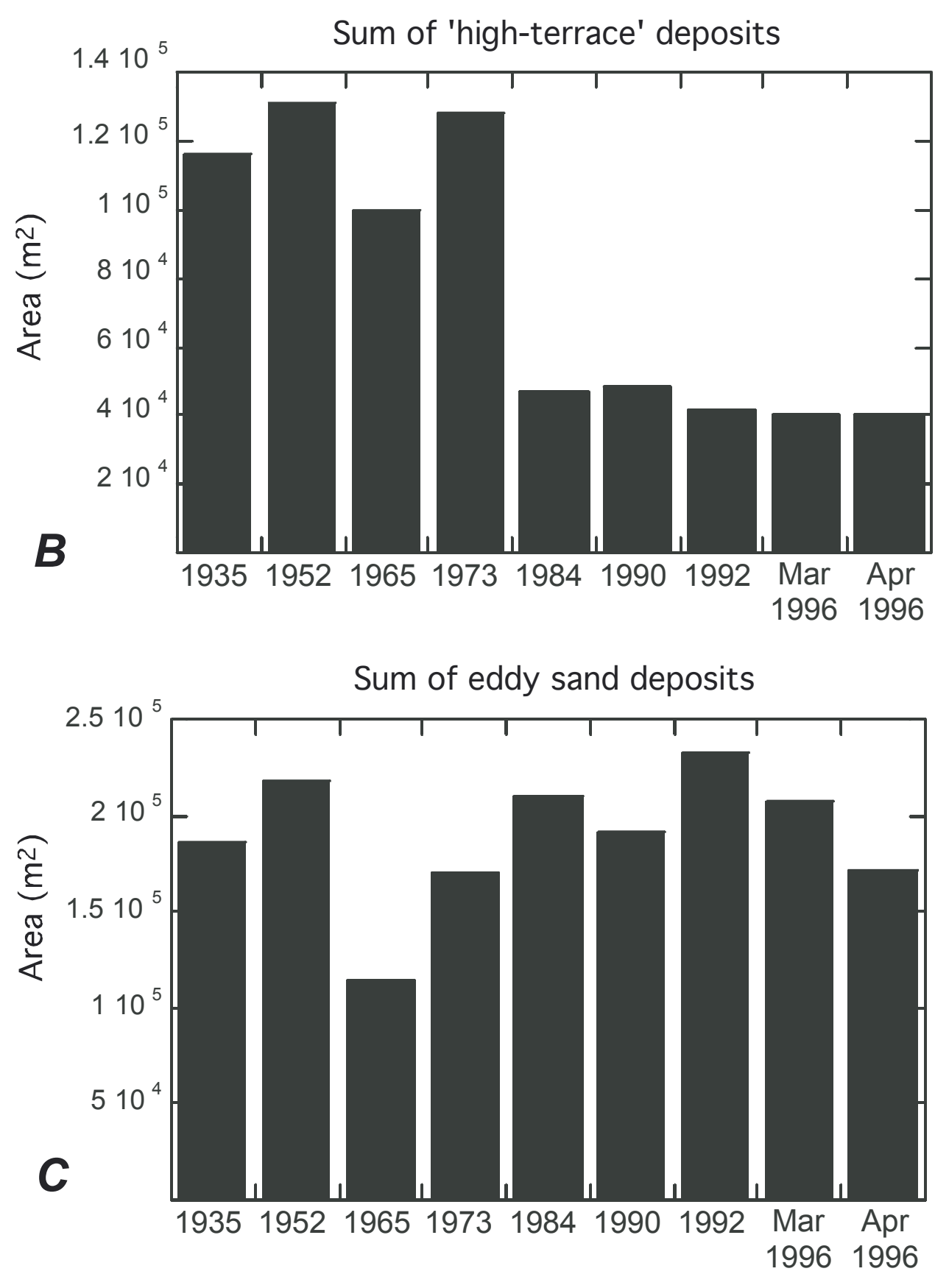

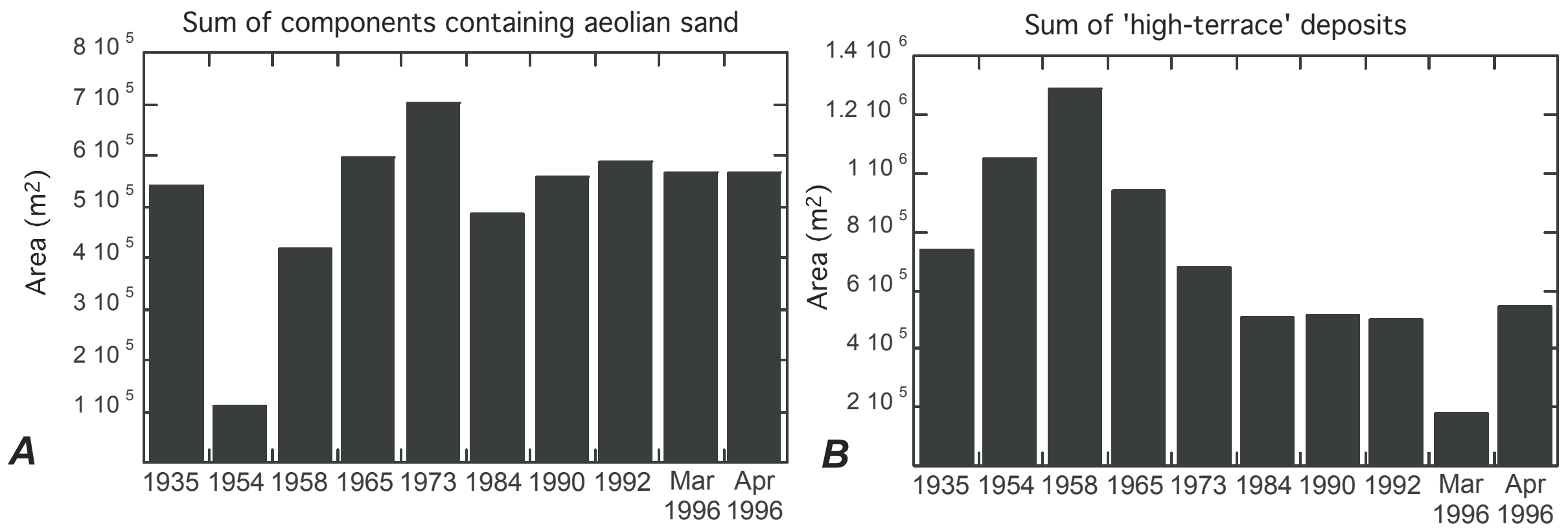

FIGURE 22. Total areas of various types of sediment deposits mapped from aerial photographs in the Little Colorado River (LCR) reach. A. Total area of polygons mapped by USU scientists as containing aeolian sand, whether alone or in combination with another geomorphic category. B. Total area of polygons containing sediment mapped as 'upper' or 'high terrace' deposits (pre-dam deposits formed above the 2,700 $\mathrm{m}^{3} \mathrm{~s}^{-1}$ [97,000 $\left.\mathrm{ft}^{3} \mathrm{~s}^{-1}\right]$ stage). While not deposited by wind, those categories indicate sediment available for remobilization by wind. C. Total area of polygons containing fluvial sand deposits in eddies, including 'separation bars', 'reattachment bars', and, when separation and reattachment bars were not distinguished as separate categories, 'eddy bars'. Fluvial deposits in eddies, when exposed subaerially, indicate source areas from which sand could be reworked and transported by wind. The March and April 1996 sets of aerial photographs were taken just before and just after the first controlled flood release from Glen Canyon Dam (Schmidt and others, 2001), respectively.

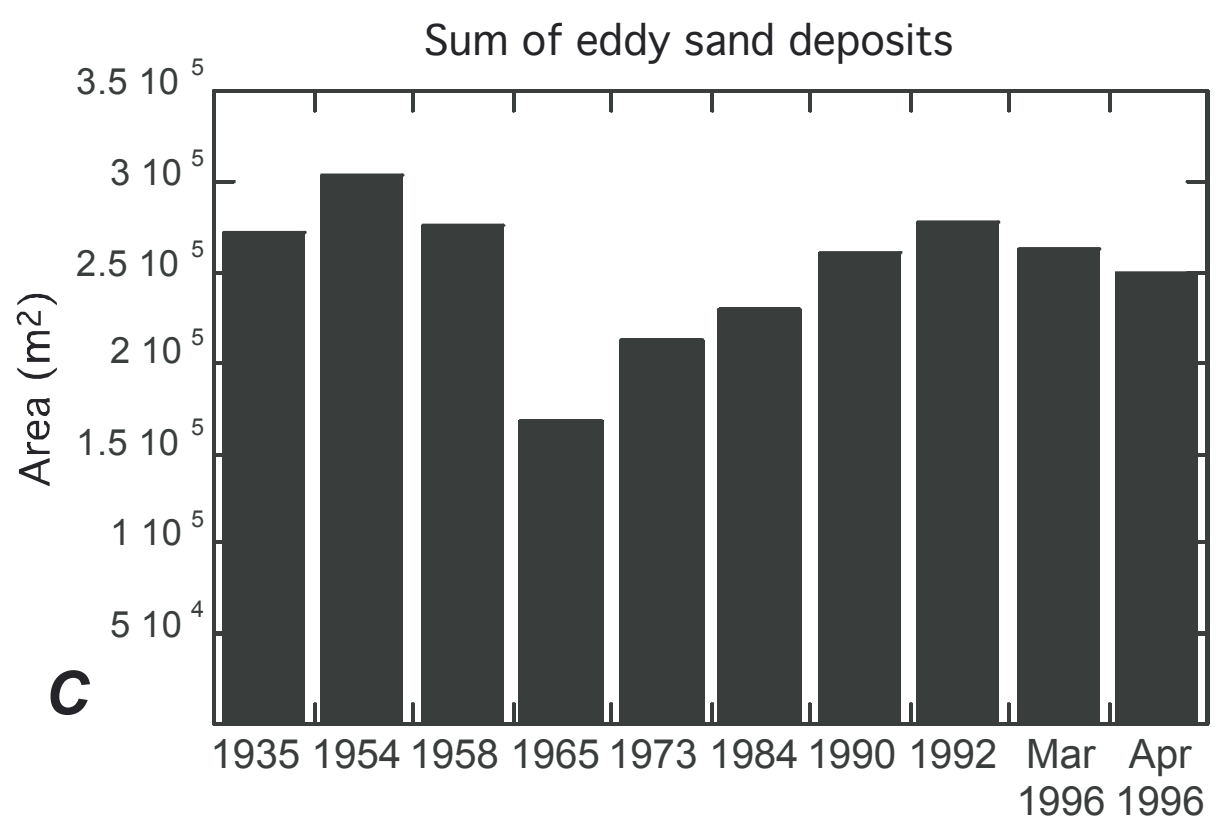




\section{REFERENCES}

Ahlbrandt, T.S., 1979, Textural parameters of eolian deposits, in McKee, E.D., (ed.), A study of global sand seas: U.S. Geological Survey Professional Paper 1052, p. 21-58.

Anderson, R.S., and Haff, P.K., 1988, Simulation of eolian saltation: Science, v. 241, p. 820-823.

Anderson, R.S., Sørensen, M., and Willetts, B.B., 1991, A review of recent progress in our understanding of aeolian sediment transport: Acta Mechanica Supplementum 1, p. 1-19.

Andrews, E.D., 1986, The Colorado River-a perspective from Lees Ferry, Arizona, in Wolman, M.G., and Riggs, H.C. (eds.), Surface water hydrology:

Geological Society of America, Decade of North American Geology, v. O-1, p. 304-310.

Ash, J.E., and Wasson, R.J., 1983, Vegetation and sand mobility in the Australian desert dunefield: Zeitschrift für Geomorphologie Suppl.-Bd. 45, p. 7-25.

Bagnold, R.A., 1941, The physics of blown sand and desert dunes: London, Chapman and Hall (4 ${ }^{\text {th }}$ edition, 1973), 265 pages.

Balsom, J.R., Ellis, J.G., Horn, A. and Leap, L.M., 2005, Using cultural resources as part of the plan-Grand Canyon management and implications for resource preservation, in van Riper, C., III, and Mattson, D.J., (eds.), The Colorado Plateau II: biophysical, socioeconomic, and cultural research: University of Arizona Press, p. 367-377.

Bauer, B.O., Sherman, D.J., Nordstrom, K.F., and Gares, P.A., 1990, Aeolian transport measurement and prediction across a beach and dune at Castroville, California, in Nordstrom, K.F., Psuty, N.P., and Carter, R.W.G., (eds.), Coastal Dunes-Form and Process: New York, John Wiley and Sons, 39-55. 
Bauer, B.O., Davidson-Arnott, R.G.D., Nordstrom, K.F, Ollerhead, J., and Jackson, N.L., 1996, Indeterminacy in aeolian sediment transport across beaches: Journal of Coastal Research, v. 12, p. 641-653.

Belnap, J., 2003, Biological soil crusts and wind erosion, in Belnap, J., and Lange, O.L., (eds.), Biological soil crusts-structure, function, and management: Berlin, Springer-Verlag, Ecological Studies Series 150, p. 339-347.

Belnap, J., and D. Eldridge, 2003, Disturbance and recovery of biological soil crusts, in Belnap, J., and Lange, O.L., (eds.), Biological soil crusts-structure, function, and management: Berlin, Springer-Verlag, Ecological Studies Series 150, p. 363-383.

Berg, N.H., 1983, Field evaluation of some sand transport models: Earth Surface Processes and Landforms, v. 8, p. 101-114.

Beus, S.S., Carothers, S.W., and Avery, C.C., 1985, Topographic changes in fluvial terrace deposits used as campsite beaches along the Colorado River in Grand Canyon: Journal of the Arizona-Nevada Academy of Science, v. 20, p. 111-120.

Boyd, R.T. (ed.), 1999, Indians, fire, and the land: Corvallis, Oregon, Oregon State University Press.

Bressolier, C. and Thomas, Y.-F., 1977, Studies on wind and plant interactions on French Atlantic coastal dunes: Journal of Sedimentary Petrology, v. 47, p. 331-338.

Buckley, R., 1987, The effect of sparse vegetation on the transport of dune sand by wind: Nature v. 325, p. 426-428.

Burke, K.J., Fairley, H.C., Hereford, R., and Thompson, K.S., 2003, Holocene terraces, sand dunes, and debris fans along the Colorado River in Grand Canyon, in Beus, S.S., and Morales, M., (eds.), Grand Canyon Geology: New York, Oxford University Press, p. 352-370.

Chapman, D.M., 1990, Aeolian sand transport-an optimized model: Earth Surface Processes and Landforms, v. 15, p. 751-760. 
Craig, M.S., 2000, Aeolian sand transport at the Lanphere dunes, northern California: Earth Surface Processes and Landforms, v. 25, p. 239-253.

Dierker, J.L., and Downum, C.E., 2004, Excavations at four sites on and near the Palisades delta, Grand Canyon National Park: Northern Arizona University, Archaeological Report 1216b, 80 pages.

Draut, A.E., Rubin, D.M., Dierker, J.L., Fairley, H.C., Griffiths, R.E., Hazel, J.E. Jr., Hunter, R.E., Kohl, K., Leap, L.M., Nials, F.L., Topping, D.J., and Yeatts, M., 2005, Sedimentology and stratigraphy of the Palisades, Lower Comanche, and Arroyo Grande areas of the Colorado River corridor, Grand Canyon, Arizona: U.S. Geological Survey Scientific Investigations Report 2005-5072, 68 pages, http://pubs.usgs.gov/sir/2005/5072/

Draut, A.E., and Rubin, D.M., 2005, Measurements of wind, aeolian sand transport, and precipitation in the Colorado River corridor, Grand Canyon, Arizona-November 2003 to December 2004: U.S. Geological Survey Open-File Report 2005-1309, 70 pages: http://pubs.usgs.gov/of/2005/1309/

Draut, A.E., and Rubin, D.M., 2006, Measurements of wind, aeolian sand transport, and precipitation in the Colorado River corridor, Grand Canyon, Arizona-January 2005 to January 2006: U.S. Geological Survey Open-File Report 2006-1188, 88 pages: http://pubs.usgs.gov/of/2006/1188/

Draut, A.E., and Rubin, D.M., The role of aeolian sediment in the preservation of archaeological sites, Colorado River corridor, Grand Canyon, Arizona, in Van Riper, C., and Sogge, M., (eds.), Integrating science and management on the Colorado Plateau: University of Arizona Press, in review.

Draut, A.E., Rubin, D.M., Dierker, J.L., Fairley, H.C., Griffiths, R.E., Hazel, J.E. Jr., Hunter, R.E., Kohl, K., Leap, L.M., Nials, F.L., Topping, D.J. and Yeatts, M., Application of sedimentary-structure interpretation to geoarchaeological studies in the Colorado River corridor, Grand Canyon, Arizona, USA: Geomorphology, in press.

Fairley, H.C., Bungart, P.W., Coder, C.M., Huffman, J., Samples, T.L., and Balsom, J.R., 1994, The Grand Canyon river corridor survey project-archaeological survey along the Colorado River between Glen 
Canyon Dam and Separation Canyon: Cooperative agreement No. 9AA-4007920, Grand Canyon National Park, prepared in cooperation with the Bureau of Reclamation, Glen Canyon Environmental Studies, Flagstaff, Ariz., 276 pages.

Fairley, H.C., 2003, Changing river; time, culture, and the transformation of landscape in the Grand Canyon-a regional research design for the study of cultural resources along the Colorado River in lower Glen Canyon and Grand Canyon National Park, Arizona: Statistical Research, Inc., prepared for the U.S. Geological Survey, Grand Canyon Monitoring and Research Center, Flagstaff, Ariz., Technical Series 79, 179 pages.

Fairley, H.C., 2005, Cultural resources in the Colorado River corridor, in Gloss, S.P., Lovich, J.E., and Melis, T.S., eds., The state of the Colorado River ecosystem in Grand Canyon: U.S. Geological Survey Circular 1282, p. 177-192.

Frank, A., and Kocurek, G., 1994, Effects of atmospheric conditions on wind profiles and aeolian sand transport with an example from White Sands National Monument: Earth Surface Processes and Landforms, v. 19, p. 735-745.

Frank, A.J., and Kocurek, G., 1996, Airflow up the stoss slope of sand dunes-limitations of current understanding: Geomorphology, v. 17, p. $47-54$.

Fryrear, D.W., 1986, A field dust sampler: Journal of Soil and Water Conservation, v. 41, p. 117-119.

Gillette, D.A., and Stockton, P.H., 1989, The effect of nonerodible particles on wind erosion of erodible surfaces: Journal of Geophysical Research, v. 94, D10, p. 12,885-12,893.

Gillies, J.A., Lancaster, N., Nickling, W.G., and Crawley, D.M., 2000, Field determination of drag forces and shear stress partitioning effects for a desert shrub (Sarcobatus vermiculatus, greasewood): Journal of Geophysical Research, v. 105, D20, p. 24,871-24,880. 
Gladfelter, B.G., 1985, On the interpretation of archaeological sites in alluvial settings, in Stein, J.K., and Farrand, W.R., (eds.), Archaeological sediments in context: University of Maine, Peopling of the Americas edited volume series, v. 1, p. 41-52.

Goldsmith, V., Rosen, P., and Gertner, Y., 1990, Eolian transport measurements, winds, and comparison with theoretical transport in Israeli coastal dunes, in Nordstrom, K.F., Psuty, N.P. and Carter, R.W.G., (eds.), Coastal Dunes-Form and Process: New York, John Wiley and Sons, p. 79-104.

Goossens, D., and Offer, Z.Y., 2000, Wind tunnel and field calibration of six aeolian dust samplers: Atmospheric Environment, v. 34, p. 1043-1057.

Goossens, D., Offer, Z., and London, G., 2000, Wind tunnel and field calibration of five aeolian sand traps: Geomorphology, v. 35, p. 233-252.

Goossens, D., 2001, Calibration of aeolian sediment catchers: WEELS (Wind Erosion on European Light Soils) Final Report, section 4.2: http://www.geog.ucl.ac.uk/weels/final_report/section_4.2.pdf

Goossens, D., 2004, Effect of soil crusting on the emission and transport of winderoded sediment: field measurements on loamy sandy soil: Geomorphology, v. 58, p. $145-160$.

Grams, P.E., and Schmidt, J.C., 1999, Integration of photographic and topographic data to develop temporally and spatially rich records of sand bar change in the Point Hansbrough and Little Colorado River confluence study reaches: Report submitted to Grand Canyon Monitoring and Research Center, Flagstaff, Ariz., 84 pages.

Hazel, J.E. Jr., Kaplinski, M., Parnell, R., Manone, M., and Dale, A., 1999, Topographic and bathymetric changes at thirty-three long-term study sites, in Webb, R.H., Schmidt, J.C., Marzolf, G.R., and Valdez, R.A., (eds.), The controlled flood in Grand Canyon: Washington, D. C., American Geophysical Union: Geophysical Monograph 110, p. 161-183.

Hazel, J.E., Kaplinski, M., Manone, M., and Parnell, R., 2000, Monitoring arroyo erosion of pre-dam river terraces in the Colorado River ecosystem, 1996-1999, Grand Canyon National Park, Arizona: Northern Arizona 
University, Department of Geology, Draft final report to the Grand Canyon Monitoring and Research Center, cooperative agreement CA 1425-98-FC40-22630, 29 pages.

Hazel, J.E. Jr., Kaplinski, M., Parnell, R., Schmidt, J.C., and Topping, D.J., 2005, A tale of two floods: comparing sandbar responses to the 1996 and 2004 high-volume experimental flows on the Colorado River in Grand Canyon: Colorado River ecosystem science symposium, Tempe, Arizona, October 2005.

Hazel, J.E. Jr., Topping, D.J., Schmidt, J.C., and Kaplinski, M., 2006a, Influence of a dam on fine-sediment storage in a canyon river: Journal of Geophysical Research 111, F01025.

Hazel, J.E. Jr., Kaplinski, M., Parnell, R., Kohl, K., and Topping, D.J., 2006b, Stage-discharge relations for the Colorado River in Glen, Marble, and Grand Canyons, Arizona, 1990-2005: U.S. Geological Survey Open-File Report 2006-1243, 18 p.

Hereford, R., Fairley, H.C., Thompson, K.S., and Balsom, J.R., 1993, Surficial geology, geomorphology, and erosion of archeological sites along the Colorado River, eastern Grand Canyon, Grand Canyon National Park, Arizona: U.S. Geological Survey Open-File Report 93-517.

Hereford, R., 1993, Map showing surficial geology and geomorphology of the Palisades Creek archaeological area, Grand Canyon National Park, Arizona: U.S. Geological Survey Open-File Report 93-553, scale 1:4,600.

Hereford, R., 1996, Surficial geology and geomorphology of the Palisades Creek area, Grand Canyon National Park, Arizona: U.S. Geological Survey Miscellaneous Investigations Series Map I-2449, scale 1:2000 (with discussion).

Hereford, R., Thompson, K.S., Burke, K.J. and Fairley, H.C., 1996, Tributary debris fans and the late Holocene alluvial chronology of the Colorado River, eastern Grand Canyon, Arizona: Geological Society of America Bulletin, v. 108, p. 3-19. 
Hereford, R., Burke, K.J., and Thompson, K.S., 2000, Quaternary geology and geomorphology of the Granite Park area, Grand Canyon, Arizona: US Geological Survey Geologic Investigations Series I-2662, scale 1:2,000.

Hsu, S.A., 1971, Measurement of shear stress and roughness length on a beach: Journal of Geophysical Research, v. 76, p. 2880-2885.

Hsu, S.A., 1973, Computing eolian sand transport from shear velocity measurements: Journal of Geology, v. 81, p. 739-743.

Hunter, R.E., 1977, Basic types of stratification in small eolian dunes: Sedimentology, v. 24, p. 361-387.

Hunter, R.E., Richmond, B.M., and Alpha, T.R., 1983, Storm-controlled oblique dunes of the Oregon coast: Geological Society of America Bulletin, v. 94, p. 1450-1465.

Johnson, R.R., and Carothers, S.W., 1987, External threats-the dilemma of resource management on the Colorado River in Grand Canyon National Park, USA: Environmental Management, v. 11, p. 99-107.

Kadib, A.A., 1965, A function for sand movement by wind: Berkeley, University of California Hydraulics Engineering Laboratory Report HEL 2-8.

Kawamura, R., 1951, Study of sand movement by wind: Report of the Institute of Science and Technology, University of Tokyo, v. 5 (3-4), p. 95-112 (in Japanese).

Kearsley, L.H., Schmidt, J.C., and Warren, K.D., 1994, Effects of Glen Canyon Dam on Colorado River sand deposits used as campsites in Grand Canyon National Park, USA: Regulated Rivers: Research and Management, v. 9, p. 137-149.

Kelly, I.T., and Fowler, C.S., 1986, Southern Paiute, in d'Azevedo, W.L., (ed.), Handbook of North American Indians, Vol 11-Great Basin: Washington, D.C., Smithsonian Institution, p. 368-397.

King, J., Nickling, W.G., and Gillies, J.A., 2005, Representation of vegetation and other nonerodible elements in aeolian shear stress partitioning models for predicting transport threshold: Journal of Geophysical Research, v. 110, F04015. 
Lancaster, N., 1985, Variations in wind velocity and sand transport on the windward flanks of desert sand dunes: Sedimentology, v. 32, p. 581-593.

Lancaster, N., Greeley, R., and Rasmussen, K.B., 1991, Interaction between unvegetated desert surfaces and the atmospheric boundary layer-a preliminary assessment: Acta Mechanica Supplementum 2, p. 80-102.

Lancaster, N., Nickling, W.G., McKenna Neuman, C.K., and Wyatt, V.E., 1996, Sediment flux and airflow on the stoss slope of a barchan dune: Geomorphology, v. 17, p. 55-62.

Leap, L.M., and Coder, C.M., 1995, Erosion control project at Palisades delta along the Colorado River corridor, Grand Canyon National Park: River Corridor Monitoring Project Report prepared for the Bureau of Reclamation, Salt Lake City, Utah, Grand Canyon National Park, River Corridor Monitoring Project, Report \#29.

Leap, L.M., Kunde, J.L., Hubbard, D.C., Andrews, N.B., Downum, C.E., Miller, A.R., and Balsom, J., 2000, Grand Canyon Monitoring Project 1992-1999: synthesis and annual report FY99: Report prepared by Grand Canyon National Park and Northern Arizona University, submitted to the Bureau of Reclamation, Upper Colorado Region, Salt Lake City, Utah, Grand Canyon National Park, River Corridor Monitoring Project, Report \#66.

Leschin, M.F., and Schmidt, J.C., 1995, Description of map units to accompany maps showing surficial geology and geomorphology of the Point Hansbrough and Little Colorado River confluence reaches of the Colorado River, Grand Canyon National Park, Arizona: Flagstaff, U.S. Bureau of Reclamation, Glen Canyon Environmental Studies report, 6 pages and plates.

Lettau, H., 1969, Note on aerodynamic roughness-parameter estimation on the basis of roughness-element description: Journal of Applied Meteorology, v. 8, p. 828-832.

Lettau, K., and Lettau, H.H., 1977, Experimental and micro-meteorological field studies of dune migration, in Lettau, H.H., and Lettau, K., (eds.), Exploring 
the world's driest climates: Madison, Wisconsin, University of Wisconsin, Institute of Environmental Science Report 101, p. 110-147.

Leys, J.F., 1990, Soil crusts-their effect on wind erosion: Soil conservation service of New South Wales, Australia, Research Note 1/90.

Leys, J.F., and Eldridge, D.J., 1998, Influence of cryptogamic crust disturbance to wind erosion on sand and loam rangeland soils: Earth Surface Processes and Landforms, v. 23, p. 963-974.

Leys, J., 1999, Wind erosion on agricultural land, in: Goudie, A.S., Livingstone, I., and Stokes, S., (eds.), Aeolian environments, sediments, and landforms: Chichester, John Wiley and Sons, p. 143-166.

Marshall, J.K., 1971, Drag measurements in roughness arrays of varying density and distribution: Agricultural Meteorology, v. 8, p. 269-292.

McDonald, A.A., 1970, The northern Mojave Desert's little Sahara: California Division of Mines and Geology Mineral Information Service, v. 23 (1), p. 3-6.

McEwan, I.K., and Willets, B.B., 1993, Sand transport by wind-a review of the current conceptual model, in Pye, K., (ed.), The dynamics and environmental context of aeolian sedimentary systems: Geological Society Special Publication 72, p. 7-16.

McKenna Neuman, C., and Nickling, W.G., 1989, A theoretical and wind-tunnel investigation of the effect of capillary water on the entrainment of sediment by wind: Canadian Journal of Soil Science, v. 69, p. 79-96.

Mulligan, K.R., 1988, Velocity profiles measured on the windward slope of a transverse dune: Earth Surface Processes and Landforms, v. 13, p. 573-582.

Namikas, S.L., and Sherman, D.J., 1995, A review of the effects of surface moisture content on aeolian sand transport, in Tchakerian, V. (ed.), Desert aeolian processes: London, Chapman and Hall, p. 269-293.

Namikas, S.L., 1999, Field investigation of aeolian transport: mechanics of saltation. Ph.D. dissertation, University of Southern California, Los Angeles, 460 pages. 
Namikas, S.L., Bauer, B.O., and Sherman, D.J., 2003, Influence of averaging interval on shear velocity estimates for aeolian transport modeling: Geomorphology, v. 53, p. 235-246.

National Park Service, 2004, U.S. Department of the Interior, National Park Service, Intermountain Antiquities computer system archaeological site database, Grand Canyon National Park.

Neal, L.A., Gilpin, D., Jonas, L., and Ballagh, J.H., 2000, Cultural resources data synthesis within the Colorado River corridor, Grand Canyon National Park and Glen Canyon National Recreation Area, Arizona: SWCA, Inc. Cultural Resources Report 98-85 submitted to Grand Canyon Monitoring and Research Center.

Nickling, W.G., 1984, The stabilising role of bonding agents on the entrainment of sediment by wind: Sedimentology, v. 31, p. 111-117.

Nielson, J., and Kocurek, G., 1987, Surface processes, deposits, and development of star dunes-Dumont dune field, California: Geological Society of America Bulletin, v. 99, p. 177-186.

Nordstrom, K.F., and Jackson, N.L., 1992, Effect of source width and tidal elevation changes on aeolian transport on an estuarine beach: Sedimentology, v. 39, p. 769-778.

O'Brien, M.P., and Rindlaub, B.D., 1936, the transport of sand by wind: Civil Engineering, v. 6, p. 325-327.

Olson, J.S., 1958, Lake Michigan dune development 1; wind-velocity profiles: Journal of Geology, v. 66, p. 254-263.

Patten, D.T., Harpman, D.A., Voita, M.I., and Randle, T.J., 2001, A managed flood on the Colorado River-background, objectives, design, and implementation: Ecological Applications, v. 11, p. 635-643.

Patton, P.C., and Schumm, S.A., 1981, Ephemeral-stream processes-implications for studies of Quaternary valley fills: Quaternary Research, v. 15, p. 24-43.

Powell, J.W., 1878, Report on the lands of the arid region of the United States, with a more detailed account of the lands of Utah: Washington, D.C., U.S. 
Government Printing Office, reprinted in 1962 (Wallace Stegner, ed.) by The Belknap Press of Harvard University, Cambridge, MA.

Rasmussen, K.R., Sorensen, M., and Willetts, B.B., 1985, Measurement of saltation and wind strength on beaches, in Barnhoff-Nielson, O.S., Muller, J.T., Rasmussen, K.R., and Willetts, B.B., (eds.), Proceedings of the International Workshop on the Physics of Windblown Sand: University of Aarhus Memoirs (Institute of Mathematics, Department of Theoretical Statistics), v. 8, p. 301-325.

Raupach, M.R., Gillette, D.A., and Leys, J.F., 1993, The effect of roughness elements on wind erosion threshold: Journal of Geophysical Research, v. 98, D2, p. 3023-3029.

Rubin, D.M., and Hunter, R.E., 1982, Bedform climbing in theory and nature: Sedimentology, v. 29, p. 121-138.

Rubin, D.M., 1987, Cross-bedding, bedforms, and paleocurrents: SEPM Concepts in sedimentology and paleontology, v. 1, 187 p.

Rubin, D.M., and Hunter, R.E., 1987, Field guide to sedimentary structures in the Navajo and Entrada Sandstones in southern Utah and northern Arizona: Bureau of Geology and Mineral Technology, Special Paper 5, p. 126-139.

Rubin, D.M., Schmidt, J.C., and Moore, J.N., 1990, Origin, structure, and evolution of a reattachment bar, Colorado River, Grand Canyon, Arizona: Journal of Sedimentary Petrology, v. 60, p. 982-991.

Rubin, D.M., Nelson, J.M., and Topping, D.J., 1998, Relation of inversely graded deposits to suspended-sediment grain-size evolution during the 1996 flood experiment in Grand Canyon: Geology, v. 26, p. 99-102.

Rubin, D.M., Topping, D.J., Schmidt, J.C., Hazel, J., Kaplinski, M., and Melis, T.S., 2002, Recent sediment studies refute Glen Canyon Dam hypothesis: EOS, Transactions of the American Geophysical Union, v. 83, p. 277-278.

Rubin, D.M., Chezar, H., Harney, J.N., Topping, D.J., Melis, T.S., and Sherwood, C.R., 2006, Underwater microscope for measuring spatial and temporal changes in bed-sediment grain size: U.S. Geological Survey Open-File Report 2006-1360. 
Sarre, R.D., 1988, Evaluation of aeolian sand transport equations using intertidal zone measurements, Saunton Sands, England: Sedimentology, v. 35, p. 671-679.

Sarre, R.D., 1989, Aeolian sand drift from the intertidal zone on a temperate beach: potential and actual rates: Earth Surface Processes and Landforms, v. 14, p. $247-258$.

Schmidt, J.C., and Graf, J.B., 1987, Aggradation and degradation of alluvial sand deposits, 1965 to 1986, Colorado River, Grand Canyon National Park, Arizona: U.S. Geological Survey Open-File Report 87-555, 120 pages.

Schmidt, J.C., 1990, Recirculating flow and sedimentation in the Colorado River in Grand Canyon, Arizona: Journal of Geology, v. 98, p. 709-724.

Schmidt, J.C., Parnell, R.A., Grams, P.E., Hazel, J.E., Kaplinski, M.A., Stevens, L.E., and Hoffnagle, T.L., 2001, The 1996 controlled flood in Grand Canyon-flow, sediment transport, and geomorphic change: Ecological Applications, v. 11, p. 657-671.

Schmidt, J.C., Topping, D.J., Grams, P.E., and Hazel, J.E., 2004, System-wide changes in the distribution of fine sediment in the Colorado River corridor between Glen Canyon Dam and Bright Angel Creek, Arizona: Final report submitted to Grand Canyon Monitoring and Research Center by the Department of Aquatic, Watershed, and Earth Resources, Utah State University, 107 pages.

Selah, A., and Fryrear, D.W., 1995, Threshold wind velocities of wet soils as affected by wind blown sand: Soil Science, v. 160, p. 304-309.

Shao, Y., McTainsh, G.H., Leys, J.F., and Raupach, M.R., 1993, Efficiencies of sediment samplers for wind erosion measurements: Australian Journal of Soil Research, v. 31, p. 519-532.

Sherman, D.J., and Hotta, S., 1990, Aeolian sediment transport: theory and measurement, in Nordstrom, K.F., Psuty, N.P., and Carter, R.W.G., (eds.), Coastal dunes-form and process: New York, John Wiley and Sons, p. 17-37. 
Sherman, D.J., Jackson, D.W.T., Namikas, S.L., and Wang, J., 1998, Windblown sand on beaches-an evaluation of models: Geomorphology, v. 22, p. 113-133.

Sørensen, M., 1991, An analytical model of wind-blown sand transport: Acta Mechanica Supplementum 1, p. 135-144.

Southard, J.B., and Boguchwal, L.A., 1990, Bed configurations in steady unidirectional water flows, part 2, synthesis of flume data: Journal of Sedimentary Petrology, v. 60, p. 658-679.

Sterk, G., and Raats, P.A.C., 1996, Comparison of models describing the vertical distribution of wind-eroded sediment: Soil Science Society of America Journal, v. 60, p. 1914-1919.

Stout, J.E., and Fryrear, D.W., 1989, Performance of a windblown-particle sampler: Transactions of the American Society of Agricultural Engineers, v. 32, p. 2041-2045.

Svasek, J.N., and Terwindt, J.H.J., 1974, Measurements of sand transport by wind on a natural beach: Sedimentology, v. 21, p. 311-322.

Thompson, K.S., and Potochnik, A.R., 2000, Development of a geomorphic model to predict erosion of pre-dam Colorado River terraces containing archaeological resources: SWCA, Inc. Cultural Resources Report 99-257, submitted to the Grand Canyon Monitoring and Research Center.

Topping, D.J., Rubin, D.M., and Vierra, L.E. Jr., 2000a, Colorado River sediment transport 1. Natural sediment supply limitation and the influence of Glen Canyon Dam: Water Resources Research, v. 36, p. 515-542.

Topping, D.J., Rubin, D.M., Nelson, J.M., Kinzel III, P.J., and Corson, I.C., 2000b, Colorado River sediment transport 2. Systematic bed-elevation and grain-size effects of sand supply limitation: Water Resources Research, v. 36 , p. 543-570.

Topping, D.J., Schmidt, J.C., and Vierra, L.E. Jr., 2003, Computation and analysis of the instantaneous-discharge record for the Colorado River at Lees Ferry, Arizona-May 8, 1921 through September 30, 2000: U.S. Geological Survey Professional Paper 1677, 118 pages. 
Topping, D.J., Rubin, D.M., Schmidt, J.C., Hazel, J.E. Jr., Melis, T.S., Wright, S.A., Kaplinski, M., Draut, A.E., and Breedlove, M.J., 2006, Comparison of sediment-transport and bar-response results from the 1996 and 2004 controlled-flood experiments on the Colorado River in Grand Canyon: Proceedings of the $8^{\text {th }}$ Federal Interagency Sedimentation Conference, Reno, Nevada, April 2006.

Tucker, R.W., and Vacher, H.L., 1980, Effectiveness of discriminating beach, dune, and river sands by moments and the cumulative weight percentages: Journal of Sedimentary Petrology v. 50, p. 165-172.

Turner, R.M., and Karpiscak, M.M., 1980, Recent vegetation changes along the Colorado River between Glen Canyon Dam and Lake Mead, Arizona: U.S. Geological Survey Professional Paper 1132, 125 pages.

Walker, R.G., 1963, Distinctive types of ripple-drift cross-lamination: Sedimentology, v. 2, p. 173-188.

Wasson, R.J., and Nanninga, P.M., 1986, Estimating wind transport of sand on vegetated surfaces: Earth Surface Processes and Landforms, v. 11, p. 505-514.

Waters, M.R., and Haynes, C.V., 2001, Late Quaternary arroyo formation and climate change in the American southwest: Geology, v. 29, p. 399-402.

Webb, R.H., Wegner, D.L., Andrews, E.D., Valdez, R.A., and Patten, D.T., 1999a, Downstream effects of Glen Canyon Dam on the Colorado River in Grand Canyon-a review, in Webb, R.H., Schmidt, J.C., Marzolf, G.R., and Valdez, R.A., (eds.), The controlled flood in Grand Canyon: Washington, D.C., American Geophysical Union, Geophysical Monograph 110, p. 1-21.

Webb, R.H., Schmidt, J.C., Marzolf, G.R., and Valdez, R.A., (eds.), 1999b, The controlled flood in Grand Canyon: Washington, D.C., American Geophysical Union, Geophysical Monograph 110.

Webb, R.H., and Hereford, R., 2001, Floods and geomorphic change in the southwestern United States-a historical perspective: Proceedings of the $7^{\text {th }}$ Interagency Sedimentation Conference, Reno, Nevada, March 2001. 
White, B.R., 1979, Soil transport by winds on Mars: Journal of Geophysical Research, v. 84, p. 4643-4651.

Wiele, S.M., Graf, J.B., and Smith, J.D., 1996, Sand deposition in the Colorado River in the Grand Canyon from flooding of the Little Colorado River: Water Resources Research, v. 32, p. 3579-3596.

Wiggs, G.F.S., Baird, A.J., and Atherton, R.J., 2004, The dynamic effects of moisture on the entrainment and transport of sand by wind: Geomorphology, v. 59, p. 13-30.

Williams, G., 1964, Some aspects of the eolian saltation load: Sedimentology, v. 3, p. 257-287.

Wright, S.A., Melis, T.S., Topping, D.J., and Rubin, D.M., 2005, Influence of Glen Canyon Dam operations on downstream sand resources of the Colorado River in Grand Canyon, in Gloss, S.P., Lovich, J.E., and Melis, T.S., eds., The state of the Colorado River ecosystem in Grand Canyon: U.S. Geological Survey Circular 1282, p. 17-31.

Wright, S.A., 2006, 2005-2006 Fine sediment experiment update: Presentation to the Adaptive Management Working Group of the Glen Canyon Dam Adaptive Management Program, Phoenix, Arizona, March 8, 2006.

Yeatts, M., 1996, High elevation sand deposition and retention from the 1996 spike flow-an assessment for cultural resources stabilization, in Balsom, J.R., and Larralde, S. (eds.), Mitigation and monitoring of cultural resources in response to the experimental habitat building flow in Glen and Grand Canyons, Spring 1996: Report submitted to the Bureau of Reclamation (Grand Canyon Monitoring and Research Center), Flagstaff, Ariz., December 1996, p. 124-158.

Yeatts, M., 1997, High elevation sand retention following the 1996 spike flow: Report to the Grand Canyon Monitoring and Research Center, Flagstaff, Ariz., 15 pages.

Yeatts, M., 1998, 1997 data recovery at five sites in the Grand Canyon-Final report. Report submitted to Grand Canyon National Park, River Corridor Monitoring Project, Report \#60. 
Zingg, A.W., 1953, Wind tunnel studies of the movement of sedimentary material: lowa City, lowa State University, Proceedings of the $5^{\text {th }}$ Hydraulic Conference Bulletin, Studies in Engineering, v. 34, p. 111-135.

Zobeck, T.M., Sterk, G., Funk, R., Rajot, J.L., Stout, J.E., and Van Pelt, R.S., 2003, Measurement and data analysis methods for field-scale wind erosion studies and model validation: Earth Surface Processes and Landforms, v. 28, p. 1163-1188. 